\title{
Energy Assurance: Essential Energy Technologies for Climate Protection and Energy Security
}

December 2009

Prepared by David L. Greene 


\section{DOCUMENT AVAILABILITY}

Reports produced after January 1, 1996, are generally available free via the U.S. Department of Energy (DOE) Information Bridge.

Web site http://www.osti.gov/bridge

Reports produced before January 1, 1996, may be purchased by members of the public from the following source.

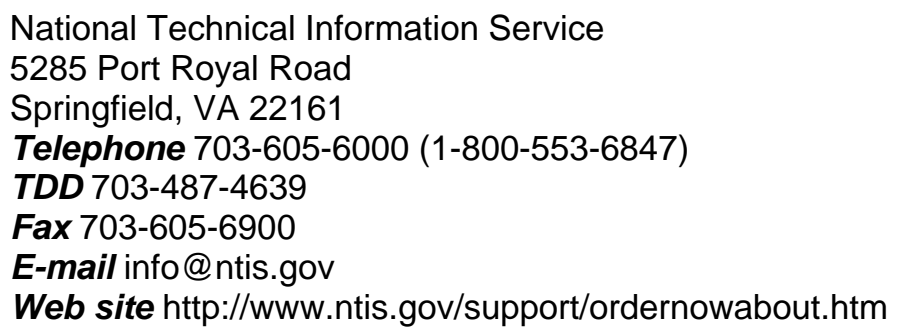

Reports are available to DOE employees, DOE contractors, Energy Technology Data Exchange (ETDE) representatives, and International Nuclear Information System (INIS) representatives from the following source.

Office of Scientific and Technical Information

P.O. Box 62

Oak Ridge, TN 37831

Telephone 865-576-8401

Fax 865-576-5728

E-mail reports@osti.gov

Web site http://www.osti.gov/contact.html

This report was prepared as an account of work sponsored by an
agency of the United States Government. Neither the United States
Government nor any agency thereof, nor any of their employees,
makes any warranty, express or implied, or assumes any legal
liability or responsibility for the accuracy, completeness, or
usefulness of any information, apparatus, product, or process
disclosed, or represents that its use would not infringe privately
owned rights. Reference herein to any specific commercial product,
process, or service by trade name, trademark, manufacturer, or
otherwise, does not necessarily constitute or imply its endorsement,
recommendation, or favoring by the United States Government or
any agency thereof. The views and opinions of authors expressed
herein do not necessarily state or reflect those of the United States
Government or any agency thereof.




\title{
ENERGY ASSURANCE: ESSENTIAL ENERGY TECHNOLOGIES FOR CLIMATE PROTECTION AND ENERGY SECURITY
}

\author{
David L. Greene \\ Philip R. Boudreaux \\ David J. Dean \\ William Fulkerson \\ Abigail L. Gaddis \\ Robin Lambert Graham \\ Ronald L. Graves \\ Janet L. Hopson \\ Patrick Hughes \\ Melissa Voss Lapsa \\ Thomas E. Mason \\ Robert F. Standaert \\ Thomas J. Wilbanks \\ Alexander Zucker
}

December 2009

\author{
Prepared by \\ OAK RIDGE NATIONAL LABORATORY \\ Oak Ridge, Tennessee 37831-6283 \\ managed by \\ UT-BATTELLE, LLC \\ for the \\ U.S. DEPARTMENT OF ENERGY \\ under contract DE-AC05-00OR22725
}





\section{CONTENTS}

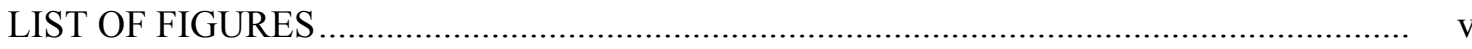

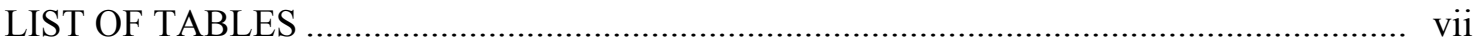

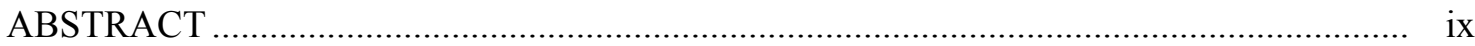

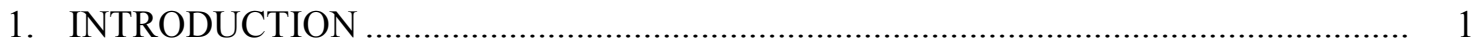

2. U.S. ENERGY GOALS: GREENHOUSE GAS MITIGATION

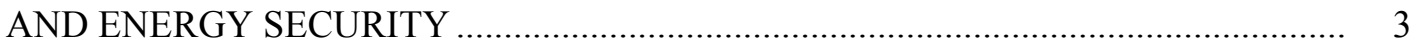

3. REFERENCE SCENARIO: THE FUTURE WITHOUT ADVANCED TECHNOLOGIES .......................................................................... 5

4. UNCERTAINTY OF TECHNOLOGICAL BREAKTHROUGHS ................................. 7

5. ESSENTIAL ENERGY TECHNOLOGIES.............................................................. 9

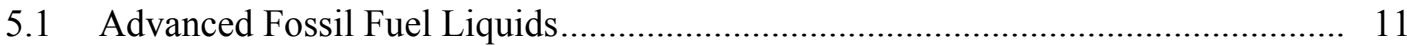

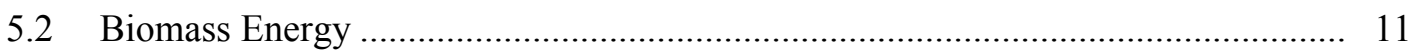

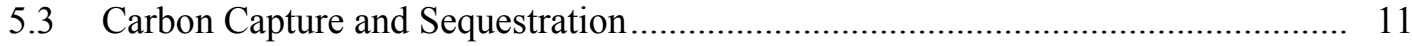

5.4 Efficient Electricity Generation and Distribution ........................................... 11

5.5 Electric Drive Vehicles ................................................................................ 12

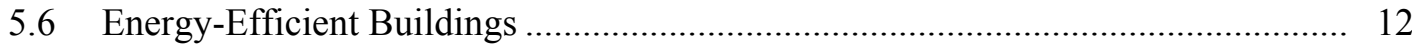

5.7 Energy-Efficient Industrial Practices .............................................................. 12

5.8 Energy-Efficient Transportation ................................................................... 12

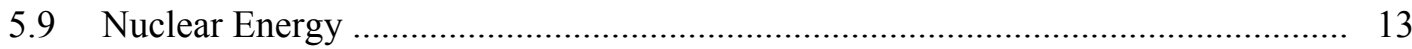

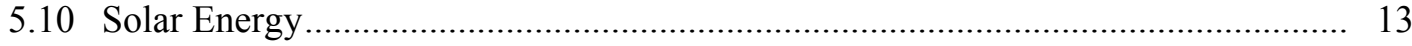

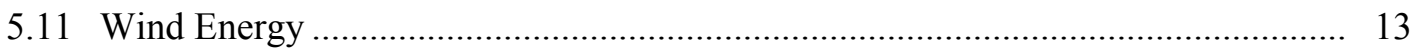

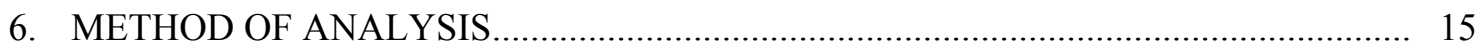

6.1 Calculating Impacts on Carbon Emissions and Oil Dependence ............................ 15

6.2 Inferring the Necessary Probabilities of Success for Essential Energy Technologies.................................................................. 17

6.3 Uncertainty and Sensitivity Analysis ........................................................... 18

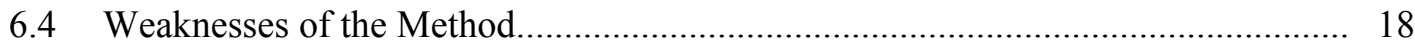

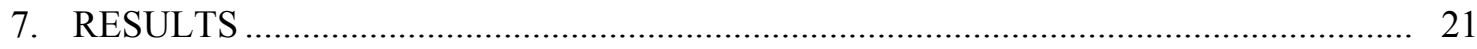

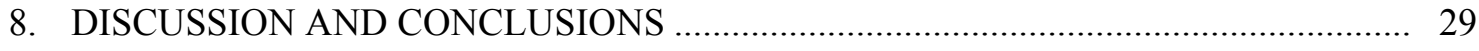

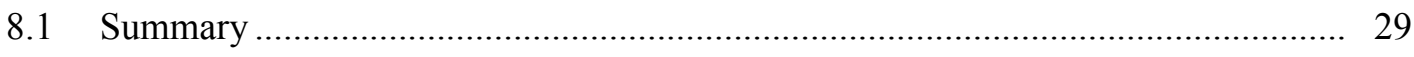

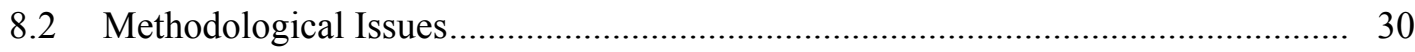

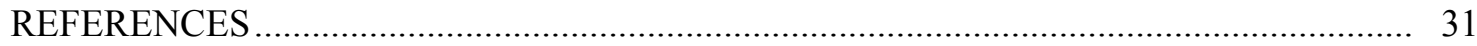

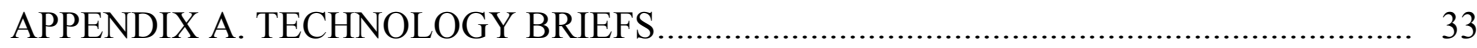

A.1 Advanced Fossil Fuel Liquids ...................................................................... 35

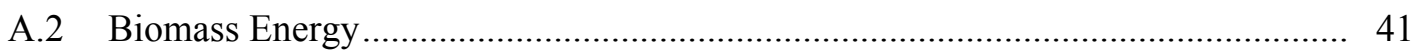

A.3 Carbon Capture and Sequestration .............................................................. 45

A.4 Efficient Electricity Generation and Distribution............................................. 53 


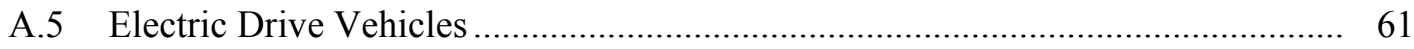

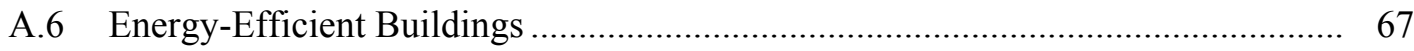

A.7 Energy-Efficient Industrial Practices ............................................................ 71

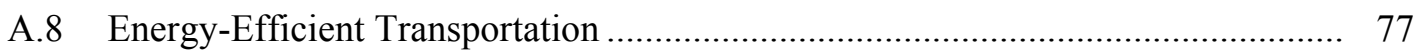

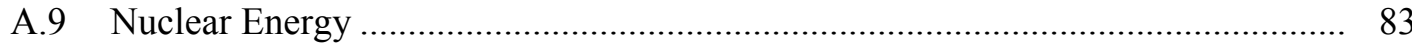

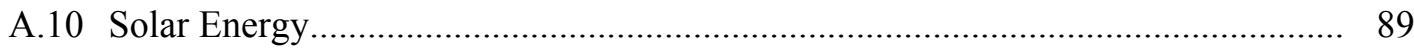

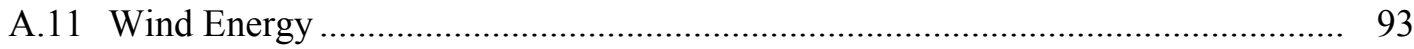

APPENDIX B. TECHNOLOGY IMPACT MATRICES ................................................. 99

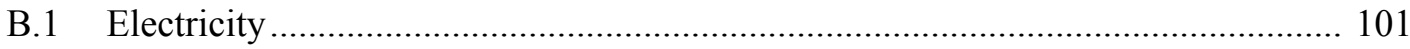

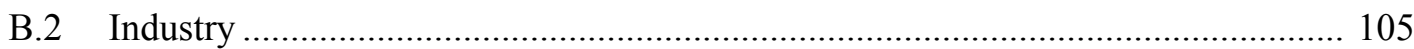

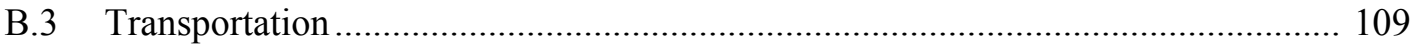

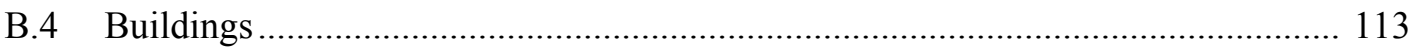




\section{LIST OF FIGURES}

Figure

1 U.S. carbon dioxide emissions scenarios to 2050

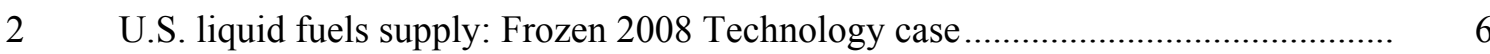

$3 \quad$ Number of technologies included in successful sets........................................... 21

$4 \quad$ Frequency with which technologies appear in the 40 successful sets of technologies (i.e., those that meet both energy goals)............................................ 22

$5 \quad$ Probability that both energy goals can be met if a given technology is not successful

6 Number of technologies in sets meeting a relaxed GHG emission goal (50\% reduction in $\mathrm{CO}_{2}$ emissions by 2050) and the baseline oil independence goal.

$7 \quad$ Probability that both energy goals can be met if a given technology is not successful (-50\% CO2 mitigation, $11 \mathrm{mmbd}$ change in oil S-D balance).

8 Probability that relaxed goals $\left(50 \%\right.$ reduction in $\mathrm{CO}_{2}$ emissions by 2050 , 7 mmbd improvement in oil supply/demand balance by 2030) can be met if a given technology is not successful

9 Probability of individual technology success required for $95 \%$ assurance that reference case goals $\left(60 \% \mathrm{CO}_{2}\right.$ reduction, $11 \mathrm{mmbd}$ change in petroleum balance) will be met.

A.4.1 Total U.S. electric generation in 2007 broken up by source ..................................... 53

A.7.1 Industrial delivered energy consumption, 1980־2030 (quadrillion Btu) .................... 74

A.8.1 Transportation energy use (in quadrillion Btu) in 2030 in the Frozen 2008 Technology scenario

A.11.1 Total U.S. wind capacity

A.11.2 U.S. wind resource map, showing annual average wind power estimates at a height of $50 \mathrm{~m}$ 


\section{LIST OF TABLES}

Table

1 Essential energy technologies and their impacts on $\mathrm{CO}_{2}$ emissions and U.S. petroleum supply and demand................................................................ 10

A.1.1 Estimated increase in unconventional petroleum supply ....................................... 38

A.1.2 Energy supply and WTW carbon intensity of unconventional fossil fuels ................ 38

A.2.1 Biomass technologies.................................................................................... 42

A.3.1 Large ( $\geq 100 \mathrm{Gg}$ /year), stationary sources of $\mathrm{CO}_{2}$ in the United States...................... 45

A.5.1 Potential reductions in U.S. $\mathrm{CO}_{2}$ emissions resulting from deployment of fuel cell vehicles

A.5.2 Potential reductions in U.S. petroleum use resulting from deployment of fuel cell vehicles .................................................................................................. 64

A.5.3 Estimated impacts of light-duty PHEVs on petroleum and electricity use ................ 65

A.7.1 Potential reductions in $\mathrm{CO}_{2}$ emissions from the U.S. industrial sector by $2050 \ldots \ldots \ldots . .73$

A.7.2 Breakdown of energy use and $\mathrm{CO}_{2}$ emissions by fuel type for the U.S. industrial sector ............................................................................... 74

A.8.1 Potential to increase transportation energy and energy savings................................ 80

A.9.1 Emissions reduction obtainable by increasing nuclear-based energy generation from $19 \%$ to $25 \%$ of total electricity generation $(6,918 \mathrm{kWh})$ in $2050 \ldots \ldots \ldots \ldots \ldots \ldots \ldots . . . . . . . . . \quad 86$

B.1.1 Electricity sector: 2050 reference projections ................................................... 101

B.1.2 Technology impacts on $\mathrm{CO}_{2}$ emissions in the electricity sector ............................ 102

B.1.3 Technology impacts on petroleum in the electricity sector...................................... 103

B.2.1 Industry sector: 2050 reference projections …...................................................... 105

B.2.2 Technology impacts on $\mathrm{CO}_{2}$ emissions in the industry sector ................................ 106

B.2.3 Technology impacts on petroleum in the industry sector....................................... 107

B.3.1 Transportation sector: 2050 reference projections ............................................... 109

B.3.2 Technology impacts on $\mathrm{CO}_{2}$ emissions in the transportation sector ........................ 110

B.3.3 Technology impacts on petroleum in the transportation sector .............................. 111

B.4.1 Buildings sector: 2050 reference projections .................................................... 113

B.4.2 Technology impacts on $\mathrm{CO}_{2}$ emissions in the buildings sector .............................. 114

B.4.3 Technology impacts on petroleum in the buildings sector..................................... 115 



\begin{abstract}
We present and apply a new method for analyzing the significance of advanced technology for achieving two important national energy goals: climate protection and energy security. Quantitative metrics for U.S. greenhouse gas emissions in 2050 and oil independence in 2030 are specified, and the impacts of 11 sets of energy technologies are analyzed using a model that employs the Kaya identity and incorporates the uncertainty of technological breakthroughs. The goals examined are a $50 \%$ to $80 \%$ reduction in $\mathrm{CO}_{2}$ emissions from energy use by 2050 and increased domestic hydrocarbon fuels supply and decreased demand that sum to $11 \mathrm{mmbd}$ by 2030 . The latter is intended to insure that the economic costs of oil dependence are not more than $1 \%$ of U.S. GDP with $95 \%$ probability by 2030 . Perhaps the most important implication of the analysis is that meeting both energy goals requires a high probability of success (much greater than even odds) for all 11 technologies. Two technologies appear to be indispensable for accomplishment of both goals: carbon capture and storage, and advanced fossil liquid fuels. For reducing $\mathrm{CO}_{2}$ by more than $50 \%$ by 2050 , biomass energy and electric drive (fuel cell or battery powered) vehicles also appear to be necessary. Every one of the 11 technologies has a powerful influence on the probability of achieving national energy goals. From the perspective of technology policy, conflict between the $\mathrm{CO}_{2}$ mitigation and energy security is negligible. These general results appear to be robust to a wide range of technology impact estimates; they are substantially unchanged by a Monte Carlo simulation that allows the impacts of technologies to vary by $\pm 20 \%$.
\end{abstract}




\section{INTRODUCTION}

The United States will not be able to achieve energy security, do its share to protect the global climate, and ensure continued economic growth without major advances in energy technology. ${ }^{1-3}$ Stabilizing atmospheric concentrations of greenhouse gases (GHGs) at levels that avoid dangerous climate change is likely to require developed economies such as the United States to reduce emissions of carbon dioxide $\left(\mathrm{CO}_{2}\right)$ by $50-85 \%$ below 2005 levels by 2050 (Refs. 4 and 5). Although there remains some uncertainty about the benefits to the global climate of achieving such goals, the range is supported by rigorous quantitative analyses that have demonstrated the importance of advanced technology for meeting these climate goals (see, e.g., Ref. 6).

Quantitative analysis of the importance of energy technologies to achieving energy security, on the other hand, has been hampered by the absence of a rigorously measurable objective. Energy security is a broad concept with many different facets. Here we focus on just one of those facets: the problem of oil dependence. We adopt the quantitative definition of oil independence proposed by Greene and Leiby ${ }^{7}$ : ensuring that the economic costs of U.S. oil dependence are less than $1 \%$ of gross domestic product (GDP) with $95 \%$ probability by 2030 . Achieving this oil security goal will require reductions in U.S. petroleum use and/or increases in domestic liquid fuels supply, vs levels projected for 2030, whose absolute values sum to approximately 11 million barrels of oil per day. ${ }^{8}$

There appears to be a consensus among energy analysts that these two energy goals - stabilization of $\mathrm{CO}_{2}$ emissions and oil security — cannot be achieved simultaneously at a cost that enables sustained economic prosperity without major advances in key technologies. ${ }^{6,9}$ But technological progress of the kind and magnitude necessary is by no means a sure thing. We analyze the importance of advanced technologies to achieving our nation's two key energy goals and (by extension) a globally sustainable energy future. The key contribution of the analysis is to explicitly incorporate the uncertainty of technological breakthroughs.

Several important analyses have measured the benefits of advanced technology for mitigating GHG emissions (see, e.g., Refs. 4, 6, 10, and 11). All are based on sets of assumptions, or scenarios, describing the future performance and costs of energy technologies; none has explicitly addressed the fundamental uncertainties about the key technological advances that will be required. Given our inability to predict technological success, the need to carry out research and development (R\&D) on a portfolio of technologies has been duly noted (e.g., in Refs. 2 and 12). Yet the possibility that not all of the desired technologies will succeed has important implications for our energy technology strategy that remain poorly understood.

This study identifies 11 energy technologies, each with significant potential to mitigate $\mathrm{CO}_{2}$ emissions, reduce petroleum dependence, or both. Every one faces important barriers to full implementation that could be overcome by $R \& D$, demonstration, and deployment. But because technological advances are uncertain, we cannot be sure which of these technologies will succeed and which will fall short. This study develops a new perspective by enumerating all possible subsets of these 11 technologies and using the Kaya identity ${ }^{13}$ to determine which combinations enable the United States to achieve both energy goals. The successful sets are then analyzed to derive insights about the dependence of our energy goals on the success of the portfolio of 11 essential energy technologies.

Clearly, we will need both policies and advanced technologies to achieve energy security and global climate protection at a reasonable cost. Without advanced technologies, $\mathrm{CO}_{2}$ emissions from energy use will almost certainly increase through 2050 (see, e.g., Ref. 2). Without supporting policies and appropriate market signals, the transformation necessary to achieve a sustainable energy future is highly unlikely. However, this study focuses on technology. The potential effects of behavioral change, changes in the demand for energy services, and economic substitution effects (beyond what is included in the reference scenario) are not considered. A key premise of this study is that while those 
factors are important and can make a meaningful contribution beyond what can be accomplished by technological change alone, technology and supporting policies must carry most of the load in achieving our climate protection and energy security goals. 


\section{U.S. ENERGY GOALS: GREENHOUSE GAS MITIGATION AND ENERGY SECURITY}

A consensus is emerging that in order to avoid "dangerous" climate change, the rise in average global temperatures should be limited to $+2^{\circ} \mathrm{C}$. A doubling of atmospheric GHGs over preindustrial levels $(280 \mathrm{ppm})$ would lead to concentrations in the vicinity of $550 \mathrm{ppm}$ of $\mathrm{CO}_{2}$ equivalent. Climate models predict a wide range of increase in average temperatures $\left(+1.5^{\circ} \mathrm{C}\right.$ to $\left.+4.5^{\circ} \mathrm{C}\right)$ at $550 \mathrm{ppm} .{ }^{4}$ Whether stabilization at $550 \mathrm{ppm}$ is sufficient is therefore a subject of intense research and analysis. The difficulty of establishing a target for the United States is further complicated by uncertainty about how responsibility for reducing GHG emissions will be allocated among the nations of the world. Stern ${ }^{5}$ proposed that the wealthier economies reduce their emissions by $60-80 \%$, and his proposal has gained a substantial degree of acceptance. While recognizing the importance of other GHGs and other anthropogenic sources, this study focuses exclusively on reducing $\mathrm{CO}_{2}$ emissions from energy use.

For the United States, achieving oil independence has proven an elusive goal. In part, this is because oil independence has been incorrectly understood to imply importing no oil or even using no oil. Leiby and Greene ${ }^{7}$ propose a measurable goal for U.S. oil independence that is firmly grounded in economic theory: "taking into consideration oil market uncertainties, ensure (with 95\% probability) that the annual costs of oil dependence will not exceed 1\% of U.S. Gross Domestic Product by the year 2030."

Using a model developed for the U.S. Department of Energy (DOE),${ }^{14}$ Greene ${ }^{8}$ calculated that reducing U.S. oil use by somewhat more than one-third and increasing the domestic supply of liquid fuels by an equal proportion would achieve oil independence. The sum of the absolute values of the changes in supply and demand (i.e., the change in the U.S. petroleum balance) is $\sim 11$ million barrels per day (mmbd). This compares with projected petroleum consumption of $22.7 \mathrm{mmbd}$ and production of $8.5 \mathrm{mmbd}$ in 2030 in the reference projection used in this study. 


\section{REFERENCE SCENARIO: THE FUTURE WITHOUT ADVANCED TECHNOLOGIES}

A continuation of "business as usual" will result in substantially increased GHG emissions in 2050. The U.S. Energy Information Administration (EIA) 2008 reference projection ${ }^{15}$ forecasts U.S. emissions of $\mathrm{CO}_{2}$ increasing from $6 \mathrm{Pg}$ in 2005 to $7 \mathrm{Pg}$ by 2030; a simple extrapolation would lead to nearly 8 Pg by 2050 (red line in Fig. 1). This projection assumes continued deployment of today's best technology, structural changes in the U.S. economy toward less carbon-intensive activities, and a normal rate of technological progress, but no major breakthroughs.

With no reduction in the carbon intensity of the economy below 2005 levels, $\mathrm{CO}_{2}$ emissions would increase to $>16 \mathrm{Pg}$ annually by 2050 (black line in Fig. 1). This "frozen carbon intensity" projection is extremely unlikely but does give a sense of the magnitude of the carbon mitigation that must be achieved by all means. ${ }^{16}$ Without new technology but assuming continued deployment of the best technologies currently available ("frozen" 2008 technology) and continued structural shifts toward less carbon-intensive activities, U.S. $\mathrm{CO}_{2}$ emissions would exceed 9 Pg by 2050 (brown line in Fig. 1). This scenario is similar to the "technology as usual" scenario of Richels and Blanford ${ }^{17}$ and is used as the reference projection for this analysis.

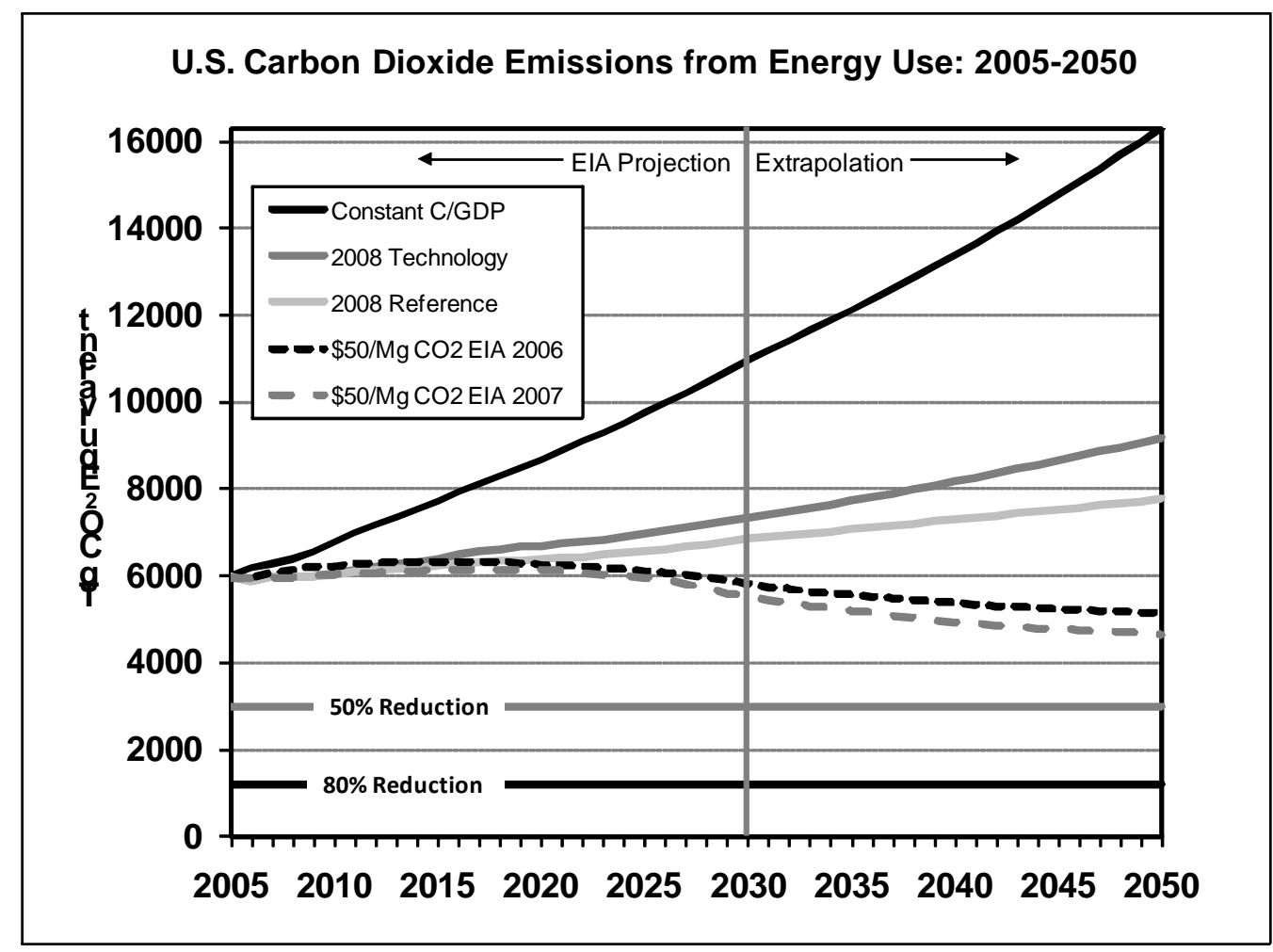

Fig. 1. U.S. carbon dioxide emissions scenarios to 2050. All projections are based on EIA National Energy Systems Model (NEMS) runs to 2030. The constant C/GDP case freezes carbon intensity at the 2005 level, uses the EIA's GDP projection to 2030, and reduces the rate of GDP growth from EIA's 2025-2030 rate of 2.4\%/year to 2.0\%/year through 2050. The other cases use EIA projections of carbon emissions from energy use through 2030 and extrapolate to 2050 based on each sector's rate of change in $\mathrm{CO}_{2}$ emissions from 2025 to 2030. The 2008 Technology case assumes deployment of existing technologies but no new technology development. The 2008 Reference case represents business as usual, with no new policies but continued normal technological progress. The $\$ 50 / \mathrm{Mg} \mathrm{CO}_{2}$ cases represent EIA analyses conducted to estimate the impacts of carbon cap-and-trade systems reaching a carbon price of $\$ 50 / \mathrm{Mg} \mathrm{CO}_{2}$ by 2030 ; both assume increased used of nuclear power and carbon sequestration for coal-fired plants in electricity 
Even with significant new policies to curb carbon emissions, reductions of 50-80\% could not be accomplished by 2050 according to EIA analyses. Also shown in Fig. 1 are results for EIA assessments that assume carbon policies equivalent to a carbon tax of $\$ 50 / \mathrm{Mg} \mathrm{CO}_{2}$ by 2030 and continued normal technological progress, including overcoming barriers to carbon capture and storage (CCS) and nuclear energy ( 2 of the 11 essential energy technologies). Even with these key technologies and a price on carbon that is roughly consistent with plausible estimates of the external costs of $\mathrm{CO}_{2}$ emissions, it appears unlikely that the United States could come close to the goal of a $50-80 \%$ reduction in annual $\mathrm{CO}_{2}$ emissions.

Likewise, under business as usual U.S. petroleum dependence will continue (Fig. 2). Even with a seven-fold increase in biofuel use by $2030,>90 \%$ of U.S. liquid fuels supply would be petroleum, almost $60 \%$ of which would be imported. With the oil prices of the Frozen 2008 Technology case in the vicinity of $\$ 60 / \mathrm{bbl}$ through 2030 , U.S. crude oil and natural gas liquids (NGL) production rises slightly through 2019 but then declines to current levels by 2030. As a consequence, total imports of liquid fuels are estimated to be slightly above today's levels in 2030.

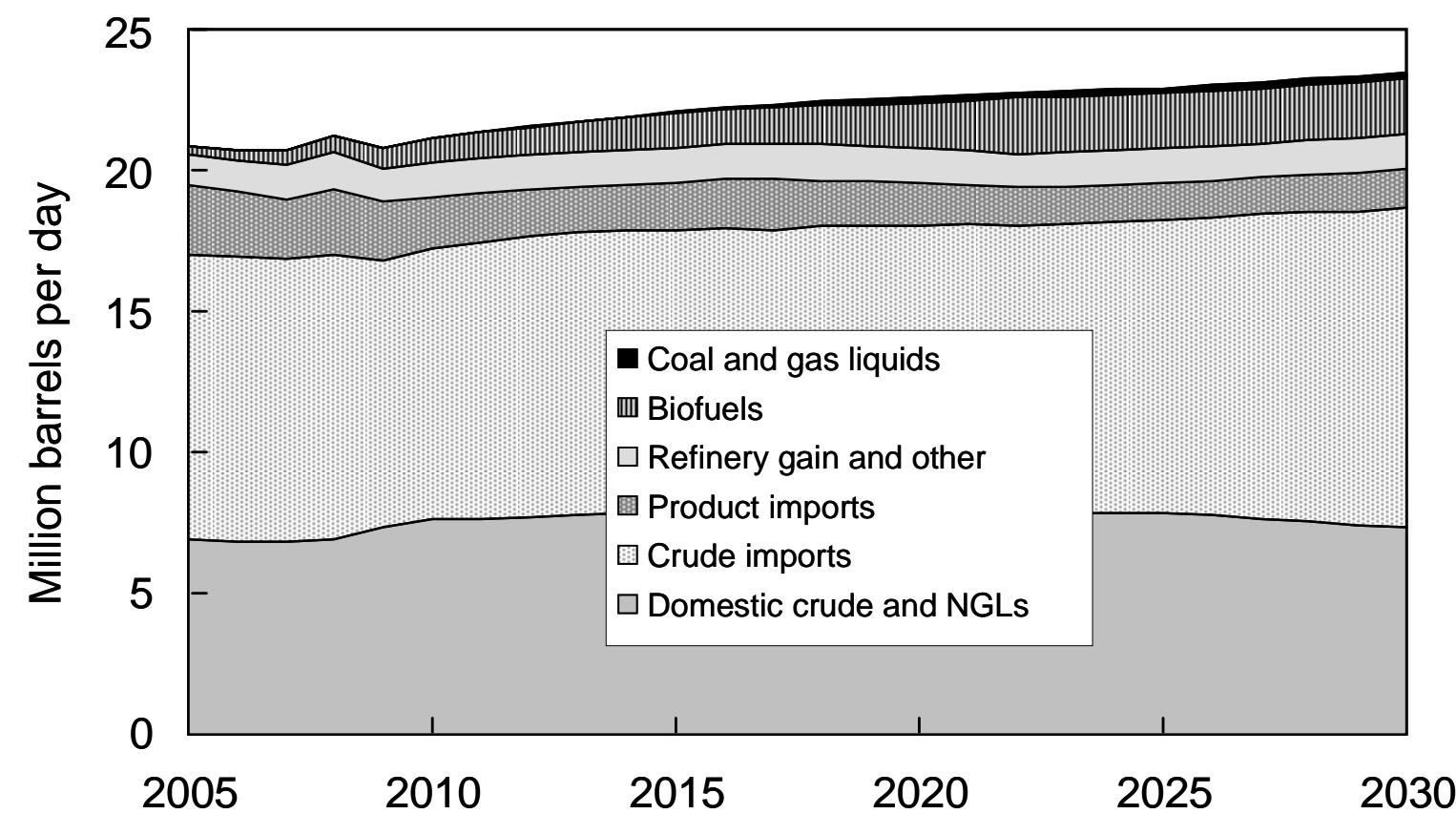

Fig. 2. U.S. liquid fuels supply: Frozen 2008 Technology case.

Under business as usual, the average annual cost of oil dependence to the U.S. economy, including both GDP losses and transfer of wealth due to monopoly pricing, is likely to rise to half a trillion dollars by 2030 , with a $5 \%$ chance of exceeding $\$ 800$ billion in any given year. ${ }^{8}$ Reducing oil dependence costs to $<1 \%$ of GDP with $95 \%$ probability by the year 2030 will require some combination of increased domestic supply and reduced demand. Supply options range from increasing conventional petroleum production from environmentally sensitive areas to synthesizing conventional hydrocarbon fuels from coal. At best, such options will not contribute to mitigating GHG emissions; at worst they may produce twice the $\mathrm{CO}_{2}$ emissions per unit of useful energy. ${ }^{18,19}$ This is the one area of potentially serious conflict between U.S. climate protection and energy security goals. 


\section{THE UNCERTAINTY OF TECHNICAL BREAKTHROUGHS}

The idea that major advances in energy technology in many areas are essential to simultaneously protecting the global climate, achieving energy security, and enabling continued economic growth is not new. ${ }^{9}$ Society's energy requirements are large and diverse and the energy challenges vast and complex. A combination of several technological advances, each of which is uncertain, appears to be necessary. Fortunately, there are many promising technologies to pursue. Unfortunately, there are no guarantees that all or any of them will succeed. This leads to the crucial question for energy R\&D policy: How much effort should be invested in which areas of energy R\&D?

Answering this question requires knowledge of (1) the value of protecting the global climate and achieving energy security, (2) the impact of each technology if successful, and (3) the relationship between investment in R\&D and the probability of success. The second and third items depend on three areas of uncertainty that appear to be irresolvable at present (see p. 10 of Ref. 20):

- uncertainty about the technological outcome of R\&D,

- uncertainty about the market acceptance of a new technology, and

- uncertainty about the future state of the world.

The second and third areas imply that what it will take to make a technology successful is itself uncertain. In that sense, technology R\&D success must be defined as "whatever it takes" to make the technology accepted by the market given uncertain future market conditions. To this we add the assumption of appropriate public policy. In economic terms, this could be a price of $\$ 50$ to $\$ 100$ per $\mathrm{Mg}$ of $\mathrm{CO}_{2}$ and $\$ 10$ to $\$ 50$ per barrel of oil (e.g., estimated costs of approximately $\$ 85$ per $\mathrm{Mg} \mathrm{CO}_{2}$ in Ref. 5; estimated marginal social costs of $\$ 14$ to $\$ 42$ per barrel of oil, not including military or foreign policy costs, in Ref. 21). Additional policies are also likely to be required to overcome technological "lock-in" (Ref. 4, pp. 139-140). A premise of this study is that if a technology is successfully developed, appropriate socially cost-effective policies will be implemented to bring about its adoption in the market.

Of the three factors that determine the value of investing in energy technology $R \& D$, the first (probability of technology success) is the most uncertain and the most difficult to analyze. The premise of this analysis is that valuable insights can be gained by asking the question in reverse: What must the probabilities of success for each technology be in order to be reasonably certain that society's energy goals will be achieved? Posing the question in this way turns the goals into constraints rather than objectives.

The methodological premise of this study is that we do not know which technologies, if any, will succeed. The fact that several breakthroughs will be needed requires consideration of the joint probability of sets of breakthroughs. Unfortunately, not only are the joint probabilities of success for sets of technologies unknown; the probabilities of success of individual technologies cannot be satisfactorily estimated either. Instead of assuming that some or all will succeed and working out the implications, we enumerate all possible combinations (sets) of technologies and identify those sets capable of achieving both energy goals. Having done that, we analyze the successful sets to produce insights about the roles of individual technologies, linkages among technologies, and the dependence of overall success in achieving our energy goals on the likelihood of success of individual technologies.

To find all sets of technologies that accomplish both goals, we enumerate all possible combinations of technologies and then test each combination to determine whether it achieves both goals. The tests are made using the Kaya equation, a methodology similar to wedges ${ }^{22}$ but capable of incorporating first-order interactions among the technologies. However, since the success of each technology is uncertain, there is only a probability that each set will be realized. Here the direction of the analysis is reversed. If society would like to achieve its energy goals with a level of confidence of, 
say $95 \%$, how certain must we be of the success of each individual technology? For any collection of sets, there is likely to be an infinite number of answers. However, the case of equal probabilities for all technologies is particularly interesting because it represents maximum uncertainty, i.e., minimum information about the probabilities of success. If this probability is very high, it implies that we must be quite sure of success for the technologies, in general, if we are to achieve the energy goals. All else being equal, this would imply a greater level of R\&D effort than if the minimum information probability were low. Assuming the maximum uncertainty probability for each technology, we can then ask how the failure of any one technology would affect the overall probability of achieving the goals. A large decrease in overall probability of success (say from $95 \%$ to $10 \%$ ) indicates that the technology in question is of great importance (i.e., achieving the goals without that technology is highly unlikely).

The analysis presented here does not consider uncertainty about future states of the world; a single projection is used for all cases. However, the method can (in principle relatively easily) be extended to include many alternative futures by means of Monte Carlo simulation.

This analysis is focused on the impacts of advanced technology. Of course, it will always be possible to meet any particular climate protection or energy security goal at a sufficiently high cost, as studies of the economic value of advanced technologies have demonstrated; for example, Richels and Blanford note that "in the absence of viable, low-cost substitutes for freely emitting fossil-based technologies, achieving aggressive decarbonization targets is possible but expensive, requiring forced substitution away from high-value energy services" (Ref. 17, p. 22).

The benefit of advanced technology is that it enables achievement of our energy goals while maintaining or enhancing human welfare. Without advanced technology, society might well decline to pay the cost of achieving the energy goals. 


\section{ESSENTIAL ENERGY TECHNOLOGIES}

It is a cliché but nonetheless true: there is no silver bullet for our energy problems. Technological advances will be needed in many areas. Energy technologies can be defined in many ways and at various levels of detail. Since all possible combinations of technologies will be enumerated, a smaller number makes the analysis more manageable. Technology categories must also be broad enough to have a major impact on GHG emissions or oil use, or both. This requires a fairly high level of generalization. At the same time, the set of technologies must be comprehensive enough to include all major sources of $\mathrm{CO}_{2}$ emissions from energy use, all major uses of petroleum, and all major sources of liquid fuels supply. After considerable discussion and debate, a team of scientists and engineers at Oak Ridge National Laboratory (ORNL) with expertise spanning a wide range of energy science and technology decided on a list of 11 energy technology categories for mitigating GHG emissions and reducing oil dependence. Each category includes several different technologies with different technological hurdles to overcome. Appendix A provides detailed descriptions of each technology, of the technological barriers to its full-scale deployment, and of its potential impacts on $\mathrm{CO}_{2}$ emissions and the U.S. petroleum balance. An overview of their impacts on $\mathrm{CO}_{2}$ emissions and the U.S. petroleum balance is given in Table 1. Brief descriptions are provided in Sects. 5.1-5.11.

A number of other studies have identified key energy technologies for mitigating GHG emissions. The Global Energy Technology Strategy Program, for example, identifies six advanced energy technology systems (ten if sublistings are counted) as having the potential for profound impacts on carbon emissions. ${ }^{2}$ The International Energy Agency (IEA) has identified a set of 24 technology options that could reduce global energy-related $\mathrm{CO}_{2}$ emissions in 2050 by more than $75 \%$ (48 $\mathrm{Pg}$ /year from a projected level of $62 \mathrm{Pg} /$ year); several of these (e.g., switching from coal to natural gas in power generation, greater use of heat pumps in buildings) do not require significant technological advances and might therefore be omitted from a list of advanced technologies. Others, such as CCS in power generation and in industry, though different to a degree, might be reasonably combined into one category. A similar list of 17 technology pathways for addressing climate change was assembled by Taylor. ${ }^{23}$ Both lists are based on the IEA's Energy Technology Perspectives 2008 study, ${ }^{6}$ which is also a major source of information for this analysis.

If no impediments existed to adopting a technology, there would be no need for R\&D or demonstration. Indeed, technologies with no significant barriers to adoption are already included in the Frozen 2008 Technology projection. A major premise of this study is that any impediment to the adoption of an advanced technology should be taken as evidence of a need to improve the technology. This includes such arguable issues as societal concerns about the risks posed by nuclear proliferation or radioactive waste disposal. The burden to change is assumed to be borne by technology rather than society.

This is not to say that advanced technology will be sufficient. Both energy security and global climate protection involve "public good" externalities, precisely the kinds of problems that markets are not motivated to solve of their own accord. Thus, meaningful public policies will be needed to induce markets to recognize the value of protecting the climate and achieving oil independence. In addition to the assumptions of the reference (Frozen 2008 Technology) scenario, societal values of approximately $\$ 50-100 / \mathrm{Mg}$ of $\mathrm{CO}_{2}$ for GHG mitigation and $\$ 25$ to $\$ 50$ per barrel for oil dependence are assumed to be implemented in some form of public policy. Any remaining barriers are assumed to be a challenge for improving technology. 
Table 1. Essential energy technologies and their impacts on $\mathrm{CO}_{2}$ emissions and U.S. petroleum supply and demand

\begin{tabular}{|c|c|c|}
\hline Technology set & $\begin{array}{c}\text { Impact on } \\
\mathrm{CO}_{2} \text { emissions (2050) }\end{array}$ & $\begin{array}{c}\text { Impact on U.S. petroleum demand } \\
\text { and supply (2030) }\end{array}$ \\
\hline $\begin{array}{l}\text { Advanced fossil fuel } \\
\text { liquids (AFL) }\end{array}$ & $\begin{array}{l}\text { - Without CCS, increase average carbon } \\
\text { intensity of liquid hydrocarbon fuels } \\
\text { use by } 15 \%\end{array}$ & $\begin{array}{l}\text { Provide additional } 10.1 \text { quads } \\
\text { ( } 4.7 \mathrm{mmbd} \text { ) of domestic supply of } \\
\text { liquid fuels from unconventional } \\
\text { sources of petroleum, advanced oil } \\
\text { recovery, and environmentally benign } \\
\text { oil development in sensitive areas }\end{array}$ \\
\hline Biomass energy & $\begin{array}{l}\text { In addition to reference scenario: } \\
\text { - } 3.7 \text { quads of primary energy for } \\
\text { electricity generation } \\
\text { - } 6.7 \text { quads of biofuels for transportation } \\
\text { - } \quad \text { Net reduction in well-to-wheel GHG } \\
\text { emissions of } 70 \% \text { vs petroleum fuels } \\
\text { - } 0.3 \text { quads displacement of petroleum } \\
\text { in industrial sector }\end{array}$ & $\begin{array}{l}\text { - Transportation sector: Displace an } \\
\text { additional } 6.7 \text { quads of petroleum } \\
\text { - Industrial sector: Displace } 0.2 \text { quads of } \\
\text { petroleum }\end{array}$ \\
\hline $\begin{array}{l}\text { Carbon capture } \\
\text { and sequestration } \\
(\mathrm{CCS})\end{array}$ & $\begin{array}{l}\text { - Reduce } \mathrm{CO}_{2} \text { emissions from electricity } \\
\text { generation with coal and natural gas } \\
\text { by } 90 \% \text { (increases energy intensity } \\
\text { by } 10 \% \text { ) } \\
\text { - Reduce industrial } \mathrm{CO}_{2} \text { emissions from } \\
\text { coal and natural gas by } 50 \% \text { (increases } \\
\text { energy intensity by } 5 \% \text { ) }\end{array}$ & - No direct impact \\
\hline $\begin{array}{l}\text { Efficient electricity } \\
\text { generation and } \\
\text { distribution (EEGD) }\end{array}$ & $\begin{array}{l}\text { - Reduce system-wide energy intensity } \\
\text { by } 30 \% \text { by } 2050\end{array}$ & $\begin{array}{l}\text { - Eliminate petroleum use in electricity } \\
\text { generation: }-0.9 \text { quads }\end{array}$ \\
\hline $\begin{array}{l}\text { Electric drive } \\
\text { vehicles }(\mathrm{EV})\end{array}$ & $\begin{array}{l}\text { - Reduce petroleum use by } 13.2 \text { quads } \\
\text { - Increase electricity demand } \\
\text { by } 6.6 \text { quads }\end{array}$ & $\begin{array}{l}\text { - Transportation sector: Displace } \\
2.5 \text { quads of petroleum } \\
\text { - Industrial sector: Displace } 0.2 \text { quads }\end{array}$ \\
\hline $\begin{array}{l}\text { Energy-efficient } \\
\text { buildings (BLDG) }\end{array}$ & $\begin{array}{l}\text { - Reduce energy intensity of buildings } \\
\text { energy use by } 50 \%\end{array}$ & $\begin{array}{l}\text { - Eliminate petroleum use in buildings: } \\
-2.0 \text { quads }\end{array}$ \\
\hline $\begin{array}{l}\text { Energy-efficient } \\
\text { industrial processes } \\
\text { (IND) }\end{array}$ & $\begin{array}{l}\text { - Reduce energy intensity of industrial } \\
\text { processes by } 25 \%\end{array}$ & $\begin{array}{l}\text { - Reduce energy intensity by an } \\
\text { additional } 10 \%\end{array}$ \\
\hline $\begin{array}{l}\text { Energy-efficient } \\
\text { transportation } \\
\text { (TRAN) }\end{array}$ & $\begin{array}{l}\text { - Reduce transportation energy intensity } \\
\text { by } 35 \% \text { beyond the reference scenario }\end{array}$ & $\begin{array}{l}\text { - Reduce energy intensity of transporta- } \\
\text { tion sector by an additional } 16 \%\end{array}$ \\
\hline Nuclear energy (NE) & $\begin{array}{l}\text { - Increase nuclear share of primary } \\
\text { energy use for electricity generation } \\
\text { from reference scenario level of } 12 \% \\
\text { to } 32 \%\end{array}$ & - No direct impact \\
\hline Solar energy (SE) & $\begin{array}{l}\text { - Replace } 15 \% \text { of reference scenario } \\
\text { primary energy use } \\
\text { for electricity generation } \\
\text { - All solar energy use in buildings either } \\
\text { increases energy efficiency or } \\
\text { displaces grid electricity }\end{array}$ & - No direct impact \\
\hline Wind energy (WE) & $\begin{array}{l}\text { - Replace } 18 \% \text { of coal-fired and } 50 \% \text { of } \\
\text { natural gas-fired electricity generation }\end{array}$ & - No direct impact \\
\hline
\end{tabular}




\subsection{Advanced Fossil Fuel Liquids}

The advanced fossil fuel liquids (AFL) technology set includes both unconventional sources of petroleum (e.g., oil shale, heavy oil, gas- or coal-to-liquids) and conventional petroleum available only with enhanced oil recovery techniques or in environmentally sensitive and extreme environments. Technological barriers include reducing costs and limiting environmental impacts. GHG impacts can range from modest reductions to major increases. Enhanced oil recovery by $\mathrm{CO}_{2}$ injection would decrease net GHG emissions in comparison to conventional petroleum, while coal-to-liquids production without carbon sequestration could increase lifecycle GHG emissions by a factor of 2-2.5. Advanced in situ shale oil production could have $\mathrm{CO}_{2}$ emissions equivalent to those for conventional petroleum. The total potential increase in liquid fuels supply over the base projection by 2030 is estimated at $4.7 \mathrm{mmbd}$.

\subsection{Biomass Energy}

Biomass energy sources range from dedicated lignocellulosic crops to algae to agricultural residues and municipal solid waste, with applications extending from heat and electricity generation to feedstocks for chemicals or transportation fuels. GHG mitigation benefits strongly depend on crop selection, land use, conversion processes, and application. Net GHG emissions may either increase or decrease (for example, if biomass is used to produce hydrogen via gasification and the $\mathrm{CO}_{2}$ emissions are captured and stored). Technological barriers include the need for new, specialized, energy crops; improved logistics for collecting and transporting biomass; strategies for minimizing induced land use impacts; and lower cost processes for converting lignocellulosic feedstocks to liquid fuels. If the United States can produce 1 billion tons of biomass feedstock by 2030, it could replace 5\% of the primary energy for electricity generation, $20 \%$ of transportation fuels, and $30 \%$ of fossil feedstocks for chemicals.

\subsection{Carbon Capture and Sequestration}

Capture and permanent sequestration of anthropogenic $\mathrm{CO}_{2}$ could allow continued use of fossil fuels with drastically reduced climate impacts. The United States has some 1,500 large stationary sources $(>0.1 \mathrm{Tg} /$ year $)$ that collectively emit $2.8 \mathrm{Pg} /$ year of $\mathrm{CO}_{2}$, of which $85-90 \%$ could potentially be captured and stored. The nation also has enormous potential for storage in deep saline aquifers and (to a much lesser degree) depleted oil wells. The chief barrier to implementation is the lack of certainty about the safety and permanence of sequestration. Large-scale demonstrations are needed, together with rigorous monitoring and development of highly reliable predictive models.

\subsection{Efficient Electricity Generation and Distribution}

The average efficiency of conversion of primary energy to electricity in the United States was $33.5 \%$ in 2005 and is projected to increase to $34.5 \%$ in the Frozen 2008 Technology case. ${ }^{15}$ These efficiencies are typical of pulverized coal plants, which account for $97 \%$ of the world's current coalfired capacity. Conversion efficiencies can be increased for nearly every method of electricity generation (Ref. 6, Chap. 7). Supercritical steam-cycle plants could attain efficiencies exceeding 45\%, and future integrated gasification combined cycle (IGCC) coal plants could surpass $50 \%$ efficiency by 2050. The efficiency of natural combined cycle plants could exceed $60 \%$. Broader use of combined heat and power (CHP) could increase energy conversion efficiencies by $20 \%$ or more, with advanced technology. Approximately 7\% of the produced electricity is lost in transmission and distribution, and this too can be reduced. Technology barriers include developing high-temperature, low-cost superconductors and delivering materials improvements to increase the thermodynamic efficiencies of power generation and to reduce capital costs. 


\subsection{Electric Drive Vehicles}

Vehicles can be powered by electrical energy taken from the grid and stored on board in batteries, or by electricity generated on board by hydrogen fuel cells. Both options face significant technological barriers: chiefly cost and performance for batteries; cost and durability of fuel cell stacks and onboard fuel storage for hydrogen fuel cell vehicles. Given successful technology development and supporting policies, electric drive vehicles (EVs) could reduce GHG emissions by $1.0-1.3 \mathrm{Pg}$ of $\mathrm{CO}_{2}$ by 2050 , if the electricity or hydrogen is produced with minimal carbon emissions. Otherwise, GHG emissions will be comparable to those of efficient conventional vehicles. By 2030, EVs could reduce petroleum use by approximately $1.2 \mathrm{mmbd}$.

\subsection{Energy-Efficient Buildings}

Technologies to increase the efficiency of energy use in buildings include designing the shell and materials to passively use solar energy and highly insulating and tightening the building envelope; employing more efficient heating, ventilating, and air conditioning (HVAC) equipment and advanced low-energy lighting; employing advanced building and appliance controls; reducing plug loads; and more. Advanced technologies integrated into whole building designs could reduce energy use by 70 $80 \%$. With solar photovoltaic (PV) added, "zero net energy" buildings become possible. Achieving such levels of performance will require advances in many areas, especially construction techniques that can reliably implement extremely energy efficient designs and technologies, greater automation, and improved controls in the construction process. With such technological advances and supporting policies, the energy intensity of buildings could be cut in half by 2050 , and use of petroleum in home heating could be eliminated by 2030 .

\subsection{Energy-Efficient Industrial Practices}

The industrial sector is diverse and complex, yet approximately $80 \%$ of sectoral energy use occurs in five subsectors: chemical and petrochemical; iron and steel; nonmetallic minerals; paper, pulp, and print; and food and tobacco production. Improvements in energy efficiency can be achieved by increases in recycling, use of CCS technology, increased use of co-generation and biomass for energy, and greater heat and energy recovery from flue gases and other by-products. Such advances could reduce industrial $\mathrm{CO}_{2}$ emissions by $20-30 \%$ by 2050 . Efficiency improvements could reduce petroleum use by $0.1 \mathrm{mmbd}$, while substitution of biomass for petrochemical feedstocks could contribute another $0.2 \mathrm{mmbd}$ reduction.

\subsection{Energy-Efficient Transportation}

Transportation is the key energy end-use target for reducing petroleum dependence by 2030 . A 40\% improvement in fuel economy for new light-duty vehicles by 2020 is required by law and included in the base case. A total improvement of $80 \%$ or more could be possible by 2030 with technologies such as advanced lightweight materials and increased hybridization. Heavy-duty vehicle fuel economy could be improved $40 \%$ by 2030 with advances such as improved aerodynamics, reduced tare weight, and increased engine efficiency for over-the-road vehicles and hybridization of vehicles that operate locally. Similar gains are possible for aircraft with advanced technology. Key technological barriers include low-cost lightweight materials and mass production manufacturing techniques; low-cost, long-life batteries with high energy and high power density; and lower cost control of emissions from lean-burn engines. An overall energy efficiency improvement of $60 \%$ could be possible by 2050 , reducing GHG emissions by approximately $1 \mathrm{Pg}$ of $\mathrm{CO}_{2}$ vs the base case. By 2030 , petroleum use could be reduced by $2 \mathrm{mmbd}$ from the reference case. 


\subsection{Nuclear Energy}

Nuclear power is a proven technology that today generates $20 \%$ of U.S. electricity supply. Nuclear power could supply a far greater share of U.S. electricity, but its expansion has been constrained by concerns about the disposal of long-lived radioactive waste, potential contributions to nuclear weapons proliferation, and, to a lesser extent, the cost of plant construction. While social and institutional issues are important components of these problems, technological advances could significantly reduce their importance. Transmutation of the minor actinides produced by reactors to radioactive wastes with half-lives of hundreds rather than thousands or tens of thousands of years would reduce concerns about the permanency of waste disposal. Other technical challenges include recycling spent fuel, improving materials, and developing safer, modular reactors. If nuclear's share of U.S. electricity generation in 2050 could be increased to $35 \%$ from the present level of $20 \%$, GHG emissions could be reduced by approximately $1 \mathrm{Pg}$ of $\mathrm{CO}_{2}$.

\subsection{Solar Energy}

Each year the sun delivers to the surface of the Earth approximately 10,000 times the amount of energy used by all human activities. Use of this energy to produce electricity is limited by conversion efficiencies in the vicinity of $15 \%$, the intermittency of supply, and the high cost of energy storage. The high cost of solar electricity generation in comparison to coal or natural gas is another barrier. If technology goals for performance and cost are fully achieved, PV and concentrating solar power (CSP) could replace approximately 1,000 TWh of electricity by 2050 .

\subsection{Wind Energy}

Wind turbines of up to $5 \mathrm{MW}$ capacity now generate 70 TWh of electricity in the United States each year. Barriers to full utilization include intermittency and energy storage, power transmission, cost, objections to the impact of turbines on landscape aesthetics, and, for offshore turbines, operation in harsh environments. If successful, wind could replace $250-300 \mathrm{GW}$ of capacity by 2050 , about $20 \%$ of U.S. total of generating capacity (corresponding to approximately $50 \%$ of natural gas capacity, or $18 \%$ of coal capacity). 


\section{METHOD OF ANALYSIS}

Our approach addresses what Groves and Lempert ${ }^{24}$ have identified as two key methodological challenges for scenario analysis: (1) the best means of choosing scenarios to summarize a wide range of uncertainty and (2) the best way to include probabilistic information with such scenarios. The method used here is not intended to be a general solution to the problem of uncertainty in scenario analysis. Rather, it is intended to provide new (albeit limited) insights into the importance of technological progress to protecting the global climate and achieving oil security.

The selected set of advanced technologies is intended to comprise the full range of known technological options for achieving the national energy goals of mitigating emissions of carbon dioxide and securing oil independence while supporting increased economic prosperity. Every technology faces barriers to full implementation, and it is not clear that all can successfully overcome these barriers, even given our best efforts at R\&D. It is therefore of great interest to know whether there are subsets capable of solving our national energy challenges and which technologies make up those solution sets. It is also useful to develop insights into how certain we must be that the key energy technologies will succeed in order for us to be confident of solving both energy challenges.

The method of analysis recognizes that it is not possible to know in advance which technologies will succeed and which will fail, nor is it possible to confidently estimate the probabilities of success. Thus, we begin with a full set of technologies $(i=1, N)$, each having an unknown probability of success $P_{i}$. The first step is to enumerate all potential combinations of successful technologies - that is, all possible combinations of technologies. For 11 energy technologies, there are $2^{11}=2,048$ possible combinations (unique subsets) of these technologies, including the possibilities that all or none might be successful. The next step is to determine which combinations have the potential to achieve both the climate change and energy security goals simultaneously.

The analytical approach described in Sects. 6.1-6.3 was implemented as an Excel ${ }^{\mathrm{TM}}$ spreadsheet model and is available from the authors on request. The version used for Monte Carlo simulation requires the@ $@$ Risk $^{\mathrm{TM}}$ add-in software ${ }^{1}$, or equivalent, to function properly.

\subsection{Calculating Impacts on Carbon Emissions and Oil Dependence}

Reductions in $\mathrm{CO}_{2}$ are estimated by applying technology impacts to sectoral carbon emissions by energy type. The method is similar to the wedges method of Pacala and Socolow ${ }^{22}$ but relies instead on the analogous mathematical equation of Kaya. ${ }^{13}$

Pacala and Socolow define their wedges in terms of reductions in gigatons $(\mathrm{Pg})$ of $\mathrm{CO}_{2}$ emissions referenced to a specific projection of future energy supply and demand. All of their wedges are approximately equal in size. Wedge analysis is, intentionally, a highly simplified method. Three parameters define a wedge: the year of initial introduction (zero impact), the year in which the ultimate impact occurs, and the rate of increase between the initial year and the ultimate year.

The Kaya identity, or equation, allows us to specify the potential of a technology in terms of a relative reduction in carbon intensity, energy intensity, energy type share, oil use, or oil supply, applied to the relevant sector and energy type in a future year. It also allows us to avoid double counting and to include first-order interactions among technology impacts. For example, the application of CCS to coal-fired electricity generation would significantly reduce the carbon mitigation benefits of more efficient energy use in buildings, or of greater use of nuclear energy, and vice versa. Such issues are automatically accounted for in the Kaya identity.

The Kaya identity expresses total carbon emissions $E$ (million metric tons of $\mathrm{CO}_{2}$ ) as the sum over end-use sectors $u$ and energy forms $f$ of the product of the carbon intensity of the type of energy $C$ (million metric tons $\mathrm{CO}_{2} /$ quad), the energy type's share of energy use in the sector $S$ (fraction of

\footnotetext{
${ }^{1} @$ Risk $^{\mathrm{TM}}$ is a trademark of the Palisade Corporation.
} 
total quads), the energy intensity per unit of activity $I$ (ratio to reference case projection), the quantity of the activity per unit of GDP $Q$, per capita GDP $G$, and population $P$ :

$$
E=\sum_{u=1}^{U} \sum_{f=1}^{F} C_{f} S_{u f} I_{u f}\left(Q_{u} G P\right) \text {. }
$$

In the spreadsheet calculations activity $\left(\mathrm{Q}_{\mathrm{u}} \mathrm{GP}\right)$ is replaced by total energy use (quads).

Impacts are created by reducing the carbon intensity or energy intensity of a form of energy use or by increasing the share of a less carbon-intensive or more energy-efficient form. Here $Q, G$, and $P$ are assumed to be given by the reference scenario. Potential feedbacks between GHG mitigation or oil dependence and GDP are not considered. An equation of similar form can be written for oil use by omitting the carbon intensity factor and limiting the equation to a single energy form, $f=$ petroleum.

An advantage of the wedges method is that each wedge represents an integrated reduction in GHG emissions over time. The Kaya identity is used here only to calculate the total annual reduction in GHGs in 2050 or the annual change in the U.S. petroleum balance in 2030. However, all of the technologies considered here require a substantial lead time to implement; thus, there is an implied wedge of gradually increasing GHG reductions preceding each target year.

Technologies are defined as either mutually exclusive (e.g., electric power from coal-fired IGCC power plants or from Generation IV nuclear power plants, transportation energy from biofuel or petroleum, etc.) or fully compatible (e.g.., energy efficiency improvements to buildings and the aforementioned electricity generation technologies). Other interdependences may also be significant. For example, if hydrogen for use in vehicles is produced from fossil fuels without CCS, the carbon emissions from hydrogen vehicles will be no better than those from advanced internal combustion engine (ICE) vehicles. But if CCS is used, emissions would be reduced by about $90 \%$ vs advanced ICE vehicles. Computing of impacts within a spreadsheet enables representation of such conditional technology-specific interactions.

The climate change goal requires a subset of technologies to reduce $\mathrm{CO}_{2}$ emissions from energy use by $50-80 \%$ by 2050 . The analysis was carried out using alternative goals of $50 \%, 60 \%, 70 \%$ and $80 \%$. If the quantity of $\mathrm{CO}_{2}$ emissions in 2050 is less than or equal to $20-50 \%$ of 2005 emissions (depending on the specific goal), the technology subset passes the climate change test. Each sector and energy form has an associated carbon intensity $C$, energy intensity $I$, and share of sectoral activity $S$, as shown in Eq. (1). Each technology could, in principle, have an impact on each of the three factors for every sector and energy form. Assuming 4 sectors (buildings, industry, transportation, and electricity generation), an average of 5 energy forms per sector, and 3 factors $(C, I, S)$ implies 60 potential impacts per technology. In practice, however, a technology's impacts will frequently be limited to one sector and one energy form.

Oil independence as defined by Greene ${ }^{8}$ can be achieved by reducing oil demand and increasing domestic liquid fuels supply. We used the ORNL Oil Security Metrics Model of Greene and Leiby, ${ }^{7}$ which provides a tool for quantifying a probability distribution of future costs of oil dependence, given an uncertain world oil market, to estimate the combinations of changes in U.S. oil demand $\left(q_{d}\right)$ and supply $\left(q_{s}\right)$ in 2030 that produce economic costs of U.S. oil dependence of $\leq 1 \%$ of GDP with 95\% probability. To a good approximation, the points define a straight line with $q_{d}+q_{s}=11 \mathrm{mmbd}$. Any result lying on or above this line passes the oil independence test.

For carbon intensity and energy intensity, impacts are specified as relative changes from the reference forecast. These changes are added to 1.0 to create multipliers that are then applied to the reference case carbon and energy intensities:

$$
E=\sum_{u=1}^{U} \sum_{f=1}^{F}\left[\prod_{i=1}^{N}\left(1+\Delta_{\text {iufC }}\right) C_{f} \prod_{i=1}^{N}\left(1+\Delta_{\text {iufS }}\right) S_{u f} \prod\left(1+\Delta_{\text {iuf }}\right) I_{u f}\left(Q_{u} G P\right)\right]
$$


By specifying relative changes and multiplying effects, double counting of reductions is avoided to a first approximation. For example, suppose that one technology cuts energy intensity by half while another reduces carbon intensity by half. The combined result will be $(1-0.5)(1-0.5)=0.25$, a $75 \%$ reduction in carbon emissions rather than a $100 \%$ reduction.

The Kaya methodology has been implemented as a set of spreadsheet tables, one for each energy sector, in which the rows are technologies and the columns are the relative changes for each fuel type. The final column is a vector of 0 's and 1's, indicating whether a particular technology is included in the current technology subset. (In fact, the final column is a binary number between 0 and $2^{N}$, where $N$ is the total number of advanced technologies.) Let these binary numbers be $\delta_{i}=1$ if technology $i$ is in the current subset and $\delta_{i}=0$ if it is not; the impacts of a particular technology set can be calculated as:

$$
E=\sum_{u=1}^{U} \sum_{f=1}^{F}\left[\prod_{i=1}^{N}\left(1+\delta_{i} \Delta_{\text {iufC }}\right) C_{f} \prod_{i=1}^{N}\left(1+\delta_{i} \Delta_{\text {iufS }}\right) S_{u f} \prod\left(1+\delta_{i} \Delta_{\text {iuf }}\right) I_{u f}\left(Q_{u f}\right)\right]
$$

In equation $3 \mathrm{Q}_{\mathrm{uf}}$ is the reference case energy use.

The Kaya equation for petroleum is analogous to the carbon emissions equation but does not include fuel type, since it applies only to fuel type $\mathrm{f}=\mathrm{O}$, oil (units are the same as the emissions equation). In the analysis described below, for example, the change in the petroleum fuel share for the buildings sector, $\Delta_{\mathrm{iBOS}}=-1$, indicates that one of the impacts of buildings energy technologies would be to eliminate petroleum use in buildings. Again, the Kaya equation for petroleum applies to 2030, while the equation for carbon emissions applies to 2050.

$$
O=\sum_{u=1}^{U}\left[\prod_{i=1}^{N}\left(1+\delta_{i} \Delta_{i u O S}\right) S_{u O} \prod_{i=1}^{N}\left(1+\delta_{i} \Delta_{i u O I}\right) I_{u O}\left(Q_{u O} G P\right)\right]
$$

\subsection{Inferring the Necessary Probabilities of Success for Essential Energy Technologies}

A critical premise of the study is that there is no guarantee that all of the key energy technologies will be successfully developed. Yet enough must succeed if we are to solve the twin energy problems of oil dependence and climate protection. By generating all of the potential combinations of technologies and identifying those sets capable of solving both problems, we completely describe the solution space. Given all of the goal-fulfilling sets, we can formulate an exact equation for the probability of solving both problems as a function of the probabilities of success of each of the 11 technologies. We begin by letting $i=1,2, \ldots, N$ index the key technologies that in various combinations might be able to solve oil dependence and climate protection, and simultaneously letting $J=1,2, \ldots, M$ index sets of technologies that solve both problems. All combinations that solve both are enumerated, even those that "oversolve."

If, as noted, $P_{i}$ is the probability that technology $i$ is successfully developed, then $\left(1-P_{i}\right)$ is then the probability that technology $i$ is not successful. The probability that set $J$ is successful is the probability that all of its members succeed:

$\prod_{i \in J} P_{i}$

The probabilities of success are assumed to be independent for all technologies. If any one of the members of set $J$ is not successful, then set $J$ is not successful, given by:

$$
1-\prod_{i \in J} P_{i} .
$$

The probability that there will be no set that can solve the problem is therefore: 


$$
P_{0}=\prod_{J=1, M}\left(1-\prod_{i \in J} P_{i}\right)
$$

It is to be hoped that $P_{0}$ is a small number; if not, more aggressive action on longer term technologies not included in this analysis (e.g., nuclear fusion), behavioral change or greater economic costs would be necessitated. The assurance level - that is, the probability that at least one set exists that can solve both problems - is $\left(1-P_{0}\right)$. If the probabilities of success were known or could be reasonably estimated, the chances of solving both problems could be computed by making use of Eq. (4).

Consider technology sets $\{1,2,3\}$ and $\{1,2,3,4\}$, both of which are capable of solving the two energy problems. Now suppose that technology 4 is unsuccessful. Then, set $\{1,2,3$, not 4$\}$ is the same as $\{1,2,3\}$. To accurately estimate the potential for technologies 1,2 , and 3 to solve the two energy problems, both sets $(\{1,2,3\}$ and $\{1,2,3,4\})$ need to be counted among the possible solutions. It is both necessary and sufficient to completely enumerate all sets capable of solving the problem to compute $P_{0}$ correctly.

Unfortunately, there is no known way to calculate the probability that any particular technology will be successful. A useful alternative is to assume maximum uncertainty, i.e., that nothing is known about the probabilities, either their absolute or relative values. Maximum uncertainty implies assuming equal probabilities of success, $P_{i}=P$ for all $i$. With this additional assumption it becomes possible to calculate $P$, given $p=1-P_{0}$, a desired assurance probability:

$$
p=1-\prod_{J=1, M}\left(1-\prod_{i \in J} P_{i}\right) \text {. }
$$

As an illustration, suppose there are three technologies and that the sets $\{1,2\}$ and $\{1,2,3\}$ solve both problems. For $P_{1}=P_{2}=P_{3}=0.5, P_{0}=\left(1-0.5^{2}\right)\left(1-0.5^{3}\right)=0.654$.

This implies an assurance probability of 0.336 , which would likely be considered too low. To reach an assurance probability of $0.99, P_{1}=P_{2}=P_{3}=0.6$ would be required.

For any given level of assurance, the "leverage" of technology $i$ can be measured by the relative change in $p$ for a relative change in $P_{i}, d \ln (p) / d \ln \left(P_{i}\right)$ - in other words, the elasticity of $p$ with respect to $P_{i}$. For the example above, starting with $P=0.96$, the elasticity of $p$ with respect to $P_{1}$ or $P_{2}$ is 0.19 , while the elasticity with respect to $P_{3}$ is 0.07 , less than half as large.

Alternatively, the "contribution" of technology $i$ can be estimated by the change in $p$ that occurs when all successful subsets containing technology $i$ are eliminated. For example, if either technology 1 or 2 is eliminated in the above example, the assurance probability is 0 . If technology 3 is eliminated, the assurance probability falls from 0.99 to 0.92 .

\subsection{Uncertainty and Sensitivity Analysis}

The technology impacts shown in Table 1 are by no means known with certainty. The possibility that impacts might be larger or smaller and the consequences for achieving our energy goals can be explored via Monte Carlo simulation. This is accomplished by specifying all impacts not as singlepoint estimates but as uniform probability distributions ranging from $+20 \%$ to $-20 \%$ of the single-point estimate. The Excel spreadsheet model is then run 100 to 1,000 times using the @ Risk ${ }^{\mathrm{TM}}$ add-in software.

\subsection{Weaknesses of the Method}

This analysis has several important limitations. It is not intended as a replacement for traditional scenario analysis or energy-economic models. Its purpose is to generate insights about the importance of technology R\&D success with respect to achieving our climate protection and oil independence goals. 
The likelihood of partially successful $R \& D$ is not considered. Partial success implies that costs will be higher and policies will have to be that much more stringent. If genuine technological breakthroughs are needed to make a technology viable, the difference between partial success that can make a difference and complete success as defined here might not be great. Nonetheless, success is likely to be a matter of degree. This is only partly addressed by the sensitivity analysis in which technology impacts are specified as random variables.

Costs are not explicitly considered. Costs are implicitly considered by requiring that technology success include cost-effectiveness; however, this provides no insights with respect to trade-offs between our energy goals and other objectives. Fortunately, others have studied the issue and concluded that the value of advanced technology for solving the climate change problem is very high. The issue of the value of advanced technologies has not been as rigorously addressed with respect to energy security.

While lack of explicit attention to costs is clearly an important limitation of this analysis, lack of explicit representation of technological uncertainty is an important limitation of energy-economic models, as noted by Richels and Blanford, ${ }^{17}$ who observe that achievement of technological advances is a highly uncertain outcome and further note that "insights can be obtained from analyses that analyze the implications of uncertain technological success, conditional on cost-effectiveness, as well as from analyses of cost-effectiveness conditional on technological success."

The analysis is performed at a high level of generality. The energy technologies defined in this analysis are very broad and typically include many individual research challenges. Details of how the technologies will penetrate the market, what helping policies might be necessary, etc., are not addressed. Drilling down to the fundamental technological advances required, even to the level of basic science, would very likely prove enlightening. Although that subject is beyond the scope of this study, it has been considered in detail elsewhere (see Ref. 25 and supporting documents).

Interdependences among the probabilities of success of the various technologies are not considered. The probabilities of success of some technologies appear to be related. For example, both solar and wind energy require advances in energy storage. This issue is closely related to the degree of generalization; it deserves more attention than it has received to date. 


\section{RESULTS}

Taking a 60\% reduction in $\mathrm{CO}_{2}$ emissions (compared to 2005 levels) by 2050 and an $11 \mathrm{mmbd}$ reduction in the U.S. petroleum supply-demand balance as a reference point scenario for achieving our national energy goals, we find that, of the 2,048 possible combinations of successful energy technologies, 128 meet the $\mathrm{CO}_{2}$ mitigation goal, 208 meet the oil independence goal, and only 40 sets reach both objectives. The smaller number meeting both goals is due to the limited overlap between the key technologies with impacts on oil use and those that contribute to meeting the GHG objective. If the $\mathrm{CO}_{2}$ reduction goal is increased to $-70 \%$, no sets meet both goals. One set meets the $\mathrm{CO}_{2}$ reduction goal but not the oil independence goal. That set includes all technologies except AFL. The conflict between producing more liquid hydrocarbons and curbing $\mathrm{CO}_{2}$ emissions is a far less important factor than it may appear, as discussed below.

Successful development of a majority of the 11 technologies is necessary to meet the energy objectives (Fig. 3). Five successful sets include as few as seven technologies. Common to all seven are BIO, EVH2, AFL, CCS, buildings energy efficiency (BLDG) and transportation energy efficiency (TRAN). The varying seventh members are industrial energy efficiency (IND), efficient electricity generation and distribution (ELEC), solar energy (SOL), wind energy (WIND), and nuclear energy (NUC).

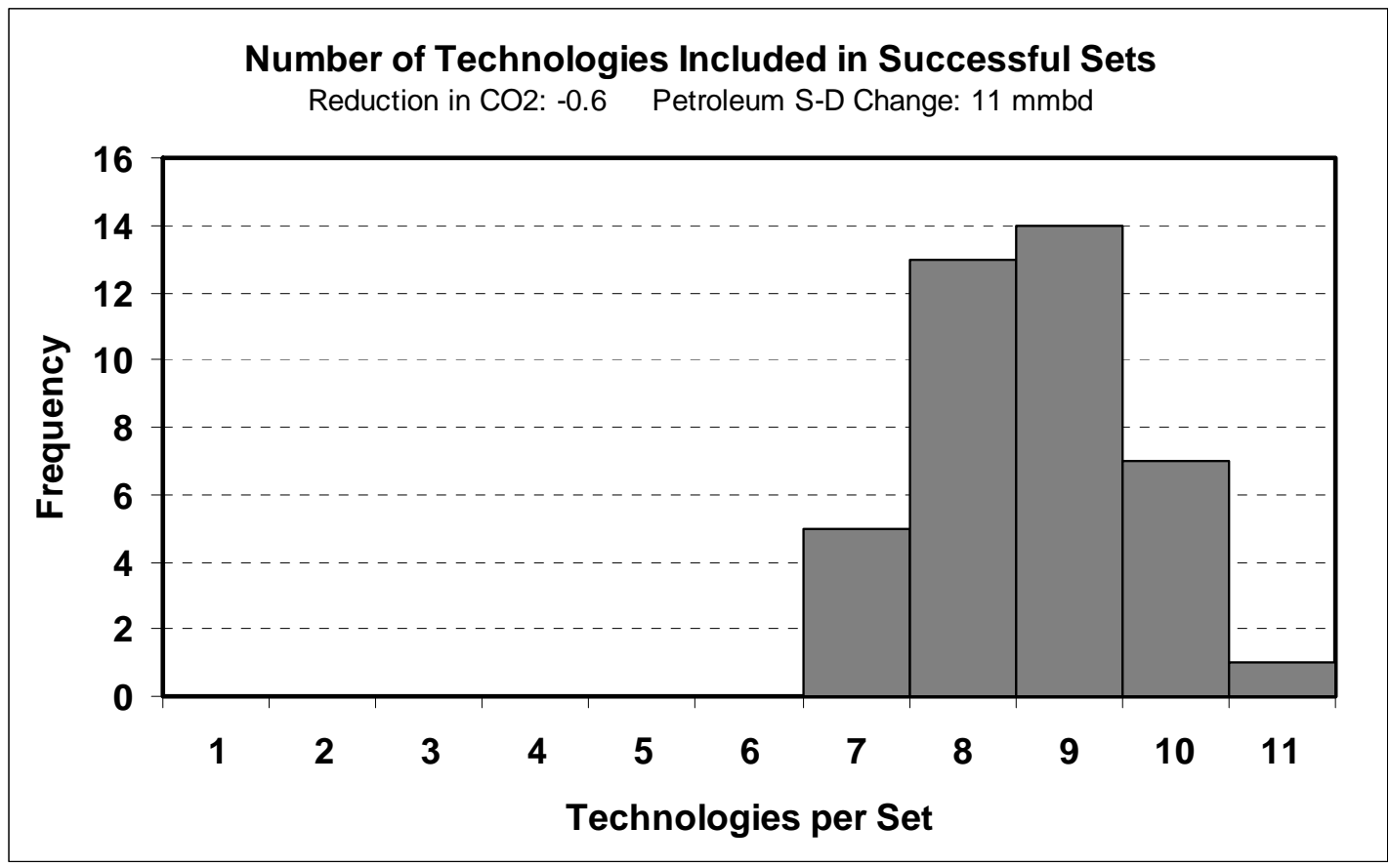

Fig. 3. Number of technologies included in successful sets.

Again using the $-60 \% \mathrm{CO}_{2}$ mitigation goal, in the 40 successful sets (i.e., those that meet both goals), CCS, BIO, EVH2 and AFL appear 40 times, implying that achieving both goals cannot be achieved without successful development and deployment of all four of these technologies (Fig. 4). BLDG appears 38 times, and TRAN appears 33 times. No technology appears in fewer than half of the successful sets. 


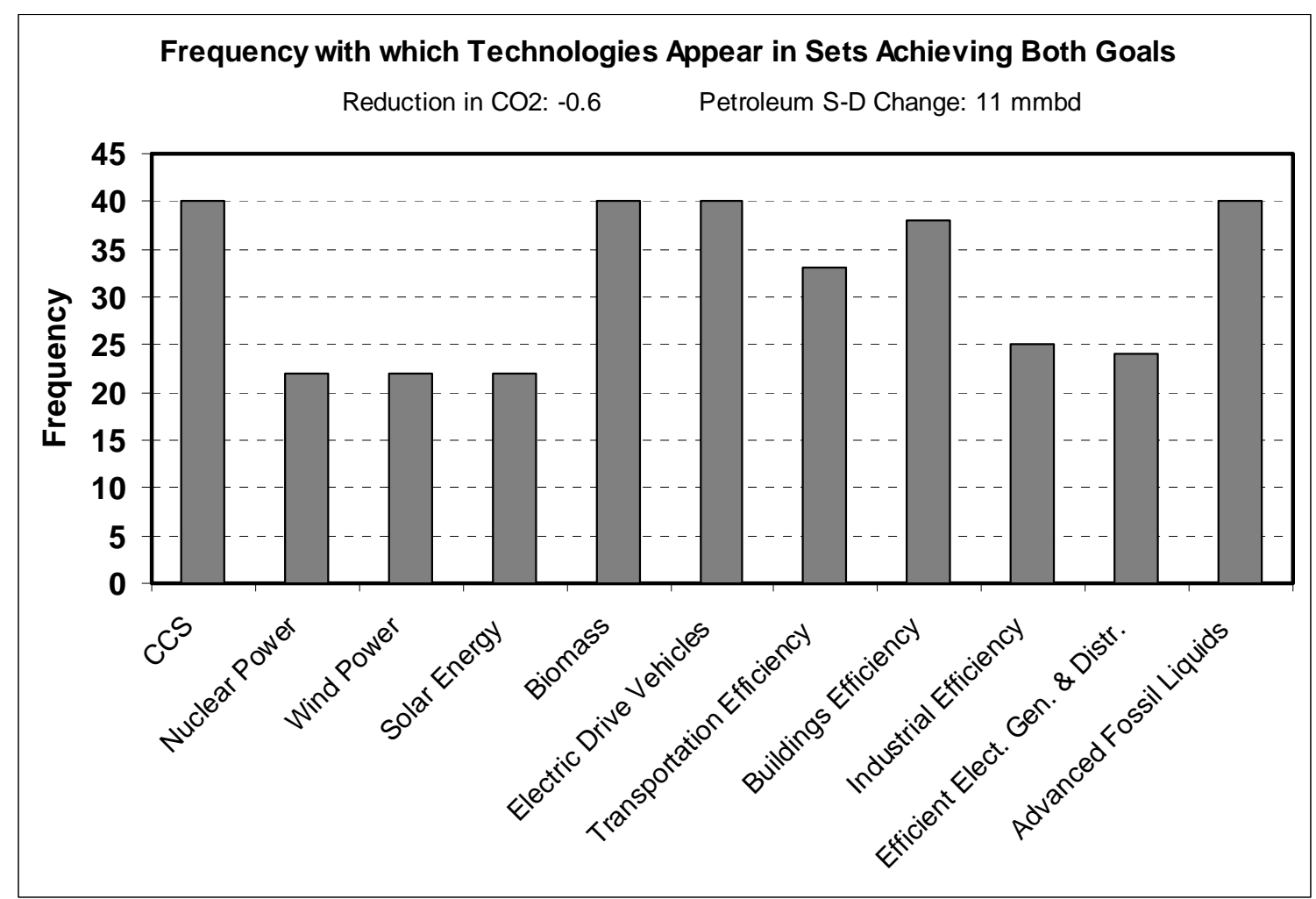

Fig. 4. Frequency with which technologies appear in the $\mathbf{4 0}$ successful sets of technologies (i.e., those that meet both energy goals).

If the policy goal is to be $95 \%$ certain of meeting both energy goals, we must have a much better than $70 \%$ chance of successfully developing each and every technology (assuming that each technology is equally likely to succeed). Assuming all technologies are equally likely to succeed, the common probability of success for each technology must be $73 \%$ to produce an overall probability of successfully achieving both energy goals of $95 \%$. Given a $73 \%$ probability of success for each technology, it is possible to compute the impact of the failure of any given technology on the overall probability of meeting the energy goals (Fig. 5). It is no surprise that without CCS, AFL, BIO or EVH2 the goals cannot be met. Without BLDG, the probability of overall success drops from $95 \%$ to $10 \%$, and without TRAN, the likelihood of achieving both goals falls to $39 \%$. Failure of any one of the other technologies decreases the odds of achieving both goals by $16 \%$ to $22 \%$. 


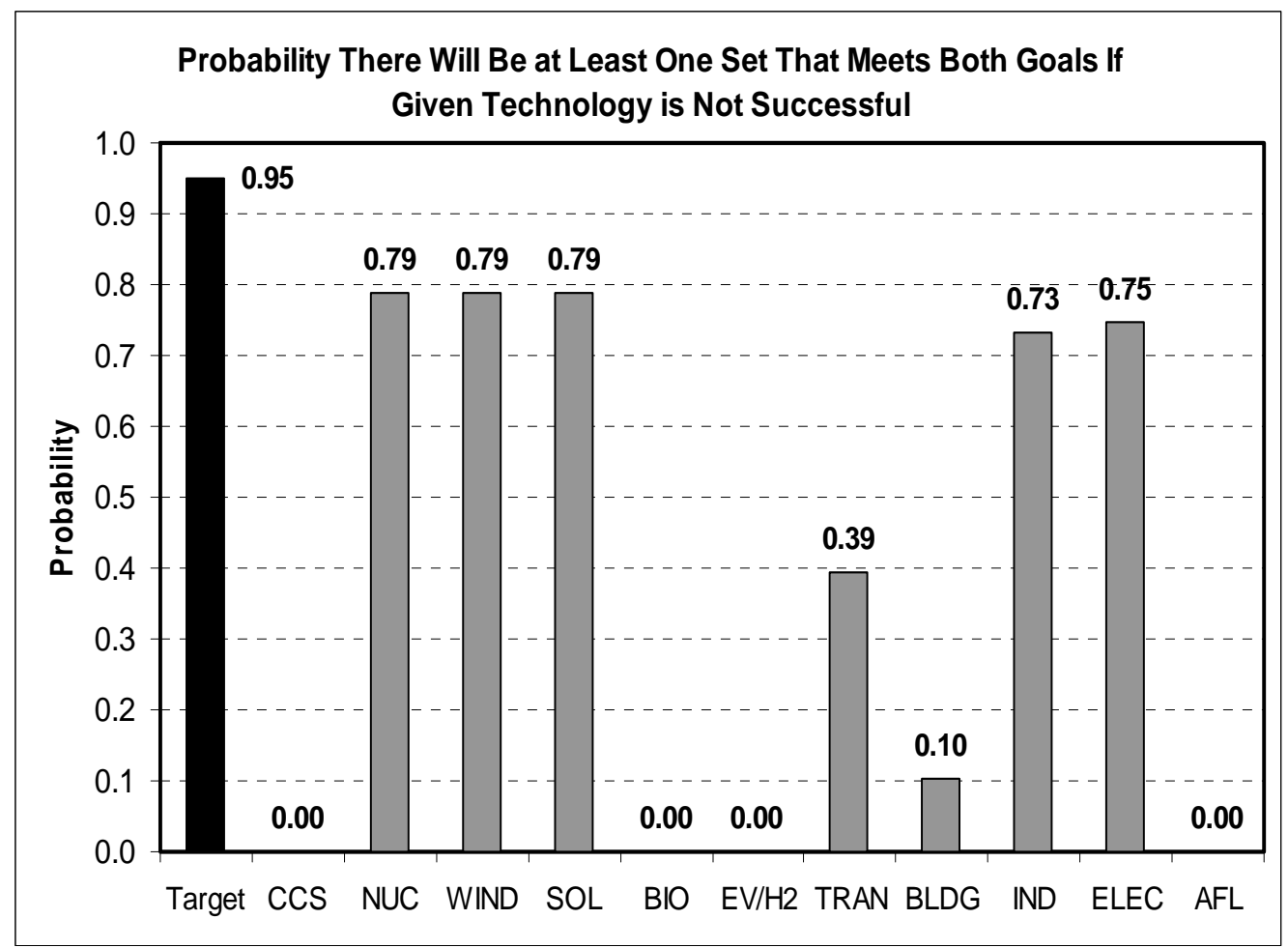

Fig. 5. Probability that both energy goals can be met if a given technology is not successful $\left(-60 \% \mathrm{CO}_{2}, 11 \mathrm{mmbd}\right)$.

Relaxing the GHG emission goal to a 50\% reduction in $\mathrm{CO}_{2}$ emissions (compared to 2005 levels) by 2050 but retaining the $11 \mathrm{mmbd}$ improvement in the U.S. petroleum supply/demand balance increases to 103 the number of sets that could achieve both goals; 481 sets can meet the less demanding goal for $\mathrm{CO}_{2}$ emissions but not necessarily the oil independence goal, while 208 can achieve the oil independence goal but not necessarily the emissions goal. The required probability of success for any given technology declines to $63 \%$, and all but one of the successful sets (i.e., those meeting both goals) include six or more of the technologies (Fig. 6). Three technologies are in every successful set: CCS, BIO and AFL. Relaxing the mitigation goals to -50\% diminishes the importance of electric drive vehicles (EVH2) relative to the $-60 \% \mathrm{CO}_{2}$ mitigation goal. If $\mathrm{EVH} 2$ technology were not available, the probability of achieving both goals would drop to $67 \%$ from $95 \%$ (Figure 7 ). 


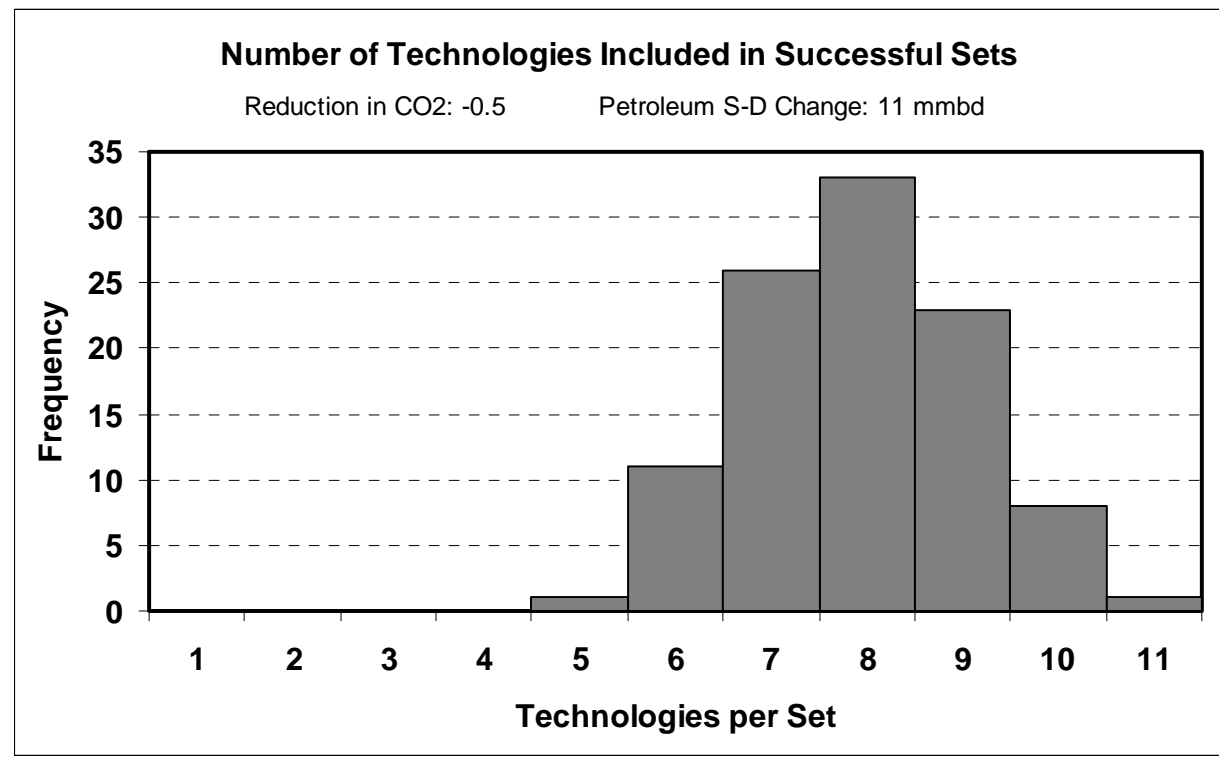

Fig. 6. Number of technologies in sets meeting a relaxed GHG emission goal (50\% reduction in $\mathrm{CO}_{2}$ emissions by 2050) and the baseline oil independence goal.

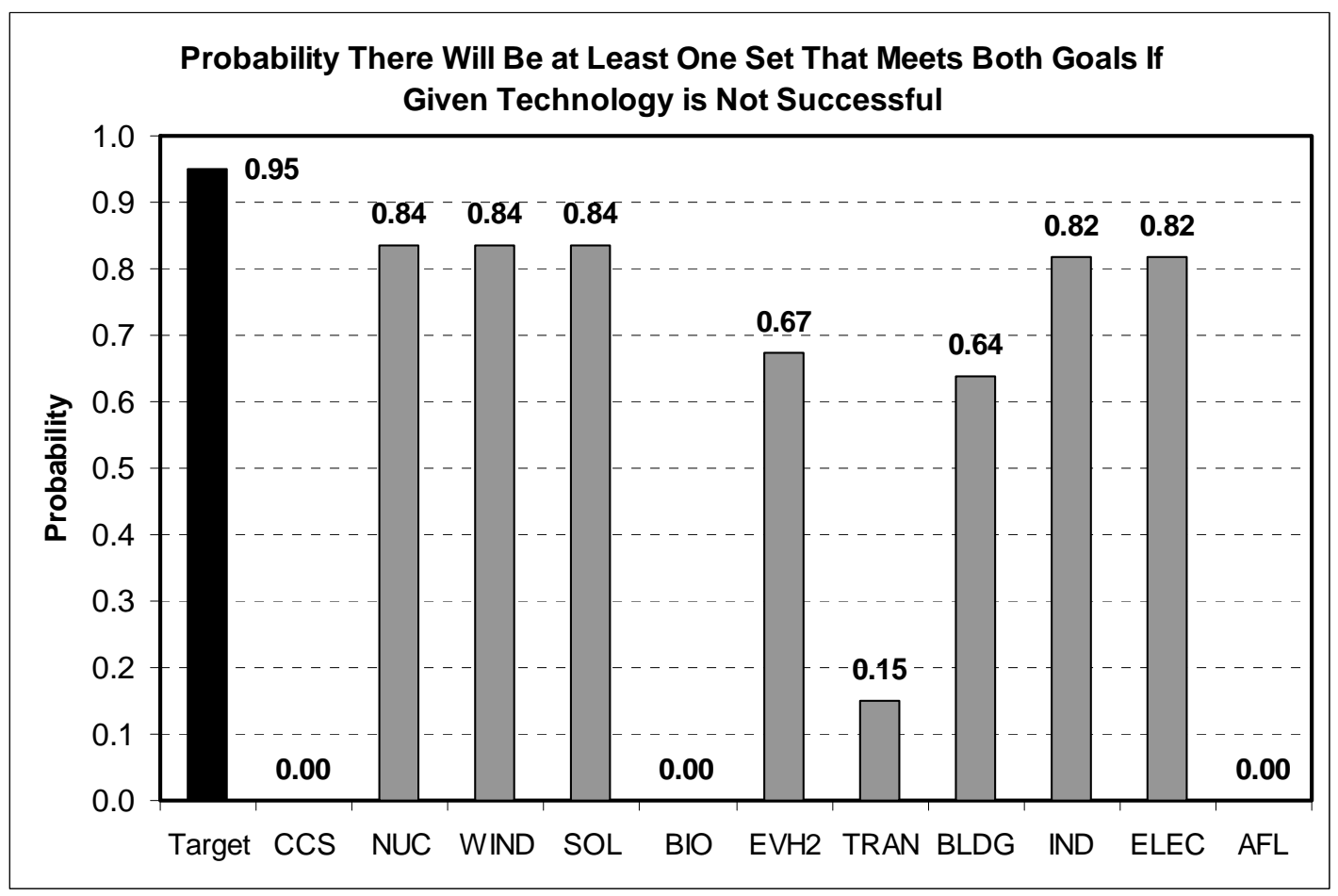

Fig. 7. Probability that both energy goals can be met if a given technology is not successful (-50\% $\mathrm{CO}_{2}$ mitigation, 11 mmbd change in oil S-D balance). 
If, in addition to the $-50 \%$ mitigation goal, the oil independence goal is also relaxed, to $9 \mathrm{mmbd}$, 184 sets of technologies meet both goals. The required probability of success for each technology decreases to $57 \%$. Both CCS and AFL appear in every successful set and are the only two technologies essential to meeting both goals. If the oil dependence goal is further relaxed to $7 \mathrm{mmbd}$, both goals can be met without AFL, but the necessary probability of success for individual technologies decreases only to $54 \%$. Even for this case, there are no successful technology sets that do not include CCS. (Fig. 8).

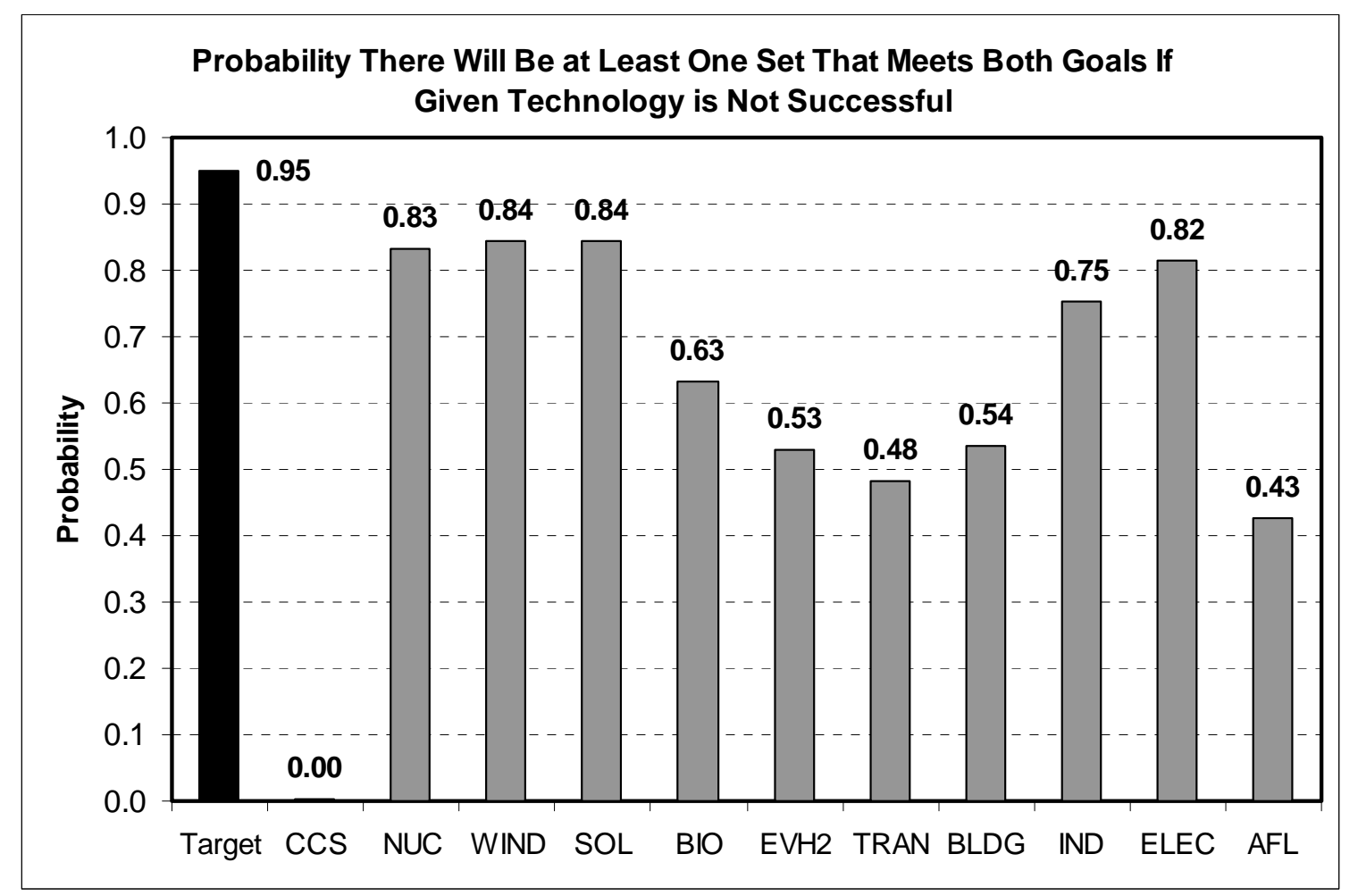

Fig. 8. Probability that relaxed goals $\left(50 \%\right.$ reduction in $\mathrm{CO}_{2}$ emissions by $2050,7 \mathrm{mmbd}$ improvement in oil supply/demand balance by 2030) can be met if a given technology is not successful.

If the GHG mitigation goal is increased to a $70 \%$ reduction in $\mathrm{CO}_{2}$ while the energy security goal is held at $11 \mathrm{mmbd}$, no sets meet the combined goals. Four sets can achieve a $68 \% \mathrm{CO}_{2}$ reduction and an $11 \mathrm{mmbd}$ change in the petroleum balance. Only a two percentage point reduction in the $\mathrm{CO}_{2}$ mitigation goal was needed to make it just possible to achieve both goals. No successful set includes fewer than ten technologies and no technology appears in fewer than three sets. AFL is in all four successful sets. The probability of success for individual technologies required to assure a $95 \%$ probability of meeting both goals increases to $94 \%$.

To achieve a $70 \%$ reduction in $\mathrm{CO}_{2}$ emissions the energy security goal must be relaxed all the way to $8 \mathrm{mmbd}$ from $11 \mathrm{mmbd}$. Even then, only one set is able to achieve both goals. Every technology except AFL becomes essential: the required probability of success for individual technologies climbs to $99.5 \%$. There must be near certainty that every one of the 10 technologies succeeds. Significantly compromising the oil dependence goal enables only a $2 \%$ additional reduction in $\mathrm{CO}_{2}$ emissions, and this only if all the remaining technologies are virtually certain to succeed. On the other hand, a very large improvement in energy security can be purchased for a very small increase in $\mathrm{CO}_{2}$ emissions, provided that CCS is successful. While there is a trade-off between 
meeting our climate protection and energy security goals, from the perspective of technology policy it is very minor, essentially negligible concern.

A Monte Carlo simulation was carried out to test the sensitivity of the results described above to the assumptions about technology impacts shown in Table 1. The single-point estimates for all of the technology impacts on carbon intensity, energy intensity, and energy shares by energy type were replaced with uniform probability distributions encompassing $\pm 20 \%$ of the original estimate, and 100 to 1,000 model simulations were run for 4 cases:

1. A $60 \%$ reduction in $\mathrm{CO}_{2}$ emissions and an $11 \mathrm{mmbd}$ change in the U.S. petroleum balance $(1,000$ simulation runs)

2. A $50 \%$ reduction in $\mathrm{CO}_{2}$ emissions and an $11 \mathrm{mmbd}$ change in the U.S. petroleum balance (100 simulation runs)

3. A $60 \%$ reduction in $\mathrm{CO}_{2}$ emissions and a 9 mmbd change in the U.S. petroleum balance (100 simulation runs)

4. A $70 \%$ reduction in $\mathrm{CO}_{2}$ emissions and an $11 \mathrm{mmbd}$ change in the U.S. petroleum balance $(1,000$ simulation runs)

For the reference goals, Case 1, the average number of successful sets was 42, just slightly more than the 40 successful sets in the deterministic model run. The smallest number of sets was 8 , and the largest was 100. Every one of the successful sets in all the simulations included both CCS and AFL. The average probability of success for individual technologies required to assure a $95 \%$ probability of accomplishing both energy goals was $74 \%$. In no case was the necessary probability of success for individual technologies less than 63\% (Fig. 9).

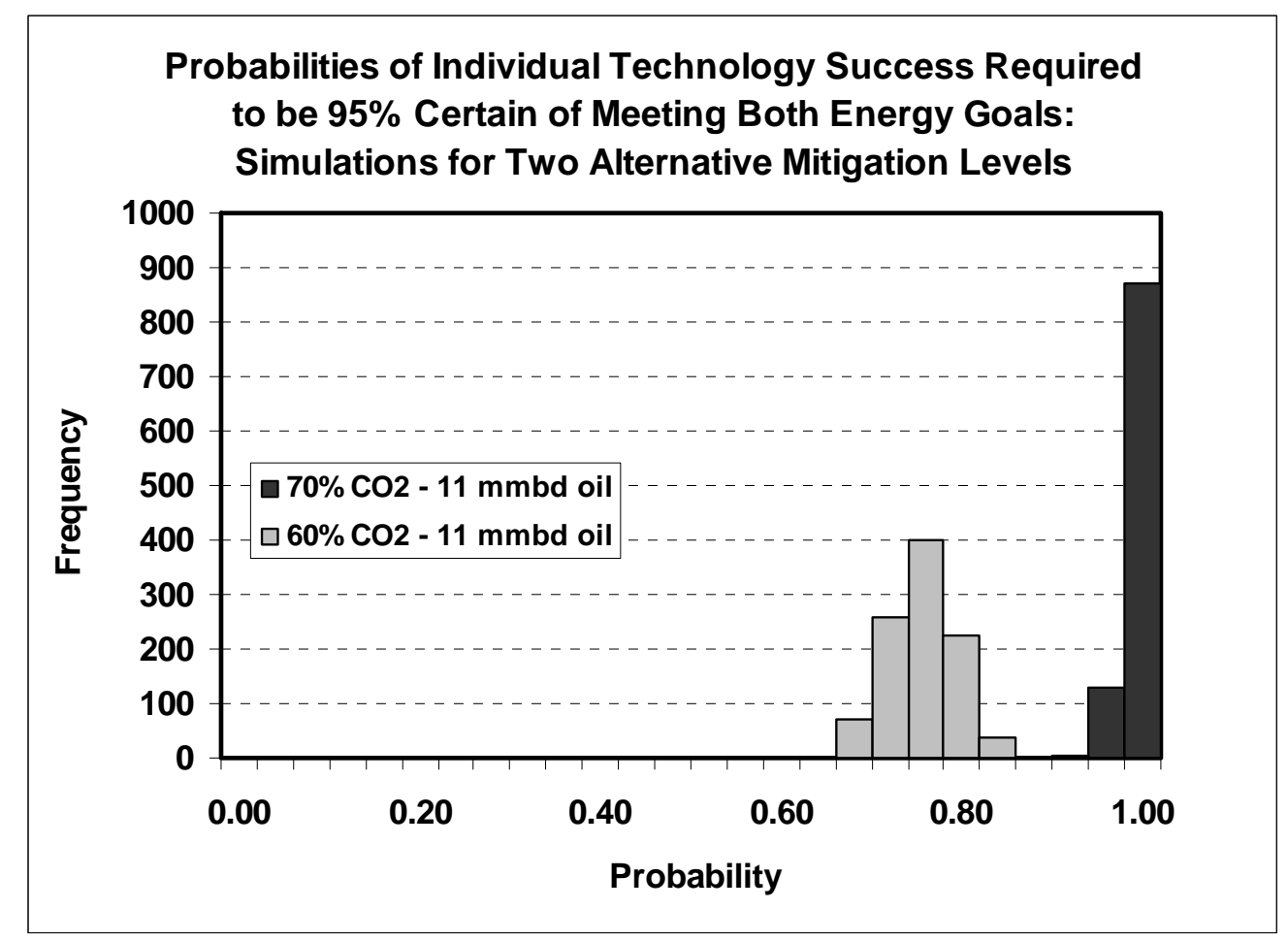

Fig. 9. Probability of individual technology success required for $95 \%$ assurance that reference case goals $\left(60 \% \mathrm{CO}_{2}\right.$ reduction, 11 mmbd change in petroleum balance) will be met. 
If the $\mathrm{CO}_{2}$ mitigation goal is relaxed to a $50 \%$ reduction by 2050 (Case 2), a few of the simulation runs are able to achieve both goals without CCS. However, the average probability is less than $1 \%$ $(0.9 \%)$, as in the deterministic case, and the range of probabilities is from $0 \%$ to $2.2 \%$.

Holding the $\mathrm{CO}_{2}$ mitigation goal at $-60 \%$ but relaxing the oil dependence goal to $9 \mathrm{mmbd}$ (Case 3) results in an average of 56 successful sets, with a range of 49 to 64 . Every successful set included both CCS and AFL, and most ( $>80 \%)$ included BIO, EVH2 and TRAN. The average probability of success required is 0.7 , with a narrow range of 0.69 to 0.72 .

Case $4\left(70 \% \mathrm{CO}_{2}\right.$ reduction and $11 \mathrm{mmbd}$ petroleum balance) was run with 1,000 simulations because the combined goals were not met using the reference assumptions and therefore the chances of finding successful sets was expected to be small. Meeting these goals would require a coincidence of favorable deviations from the reference assumptions. The average number of sets meeting both energy goals was 1.1 (out of 2,048 possible sets), and in no case did more than 5 sets meet the combined goals. In every case, every set meeting both energy goals included CCS and AFL. The average number of technologies in a successful set was 9.9 and the minimum set size was 8 .

In order to be $95 \%$ certain of achieving both goals, we must be almost certain of each individual technology's success. The average probability of success for individual technologies required to assure $95 \%$ likelihood of overall success was $98 \%$. In $95 \%$ of the simulation runs, individual probabilities greater than $95 \%$ were required (Fig. 9). 


\section{DISCUSSION AND CONCLUSIONS}

\subsection{Summary}

This analysis has explicitly incorporated uncertainty about technological progress into assessing our ability to meet two important national energy goals. Understanding the implications of addressing both our climate and energy security goals simultaneously is important. The two objectives are sometimes seen as conflicting. This analysis suggests that from the perspective of technology R\&D policy, the conflict is negligible. Developing the technologies that we need to expand domestic liquid hydrocarbon production in an environmentally responsible way will have a minimal impact on our ability to meet $\mathrm{CO}_{2}$ mitigation goals provided that $\mathrm{CCS}$ is also successfully developed.

Perhaps the most important implication of this analysis is that meeting both energy goals requires a high probability of success $(>70 \%)$ for energy technologies in general. The majority of technologies must succeed. The larger the number of successful technologies, the better our chances are. Our inability to predict the rate and extent of technological progress means that uncertainty about our ability to achieve our energy goals is inescapable. In the face of that uncertainty, this analysis has addressed the question: How sure must we be of progress in key areas of technology to be confident of reaching our energy goals? The answer suggests that we must be relatively certain of success in all 11 key technology areas if we are to be reasonably confident of achieving both of our national energy goals.

Several technologies appear to be almost indispensable if both goals are to be accomplished: CCS and AFL are perhaps the most crucial. The more stringent the goals, the more certain we must be of the success of each technology. While it is not surprising that CCS is important, the fact that it appears in every successful technology set may be. Only when the mitigation goal was relaxed to a $50 \%$ reduction in $\mathrm{CO}_{2}$ did sets without CCS appear in sensitivity analyses, but even then the chances of success without CCS were on the order of $1-2 \%$. Establishing CCS for use on a massive scale appears to be absolutely critical.

Likewise, increasing the domestic supply of advanced fossil fuels appears to be essential to achieving oil security. Again, only when the energy security goal is greatly relaxed (to a $7 \mathrm{mmbd}$ change in the petroleum balance from a baseline value of $11 \mathrm{mmbd}$ ) do successful sets without AFL appear.

Other technologies that appear essential to meeting both energy goals are BIO and EVH2.

Energy efficiency, especially TRAN and BLDG, have enormous impacts on the chances for achieving our energy goals. Energy efficiency improvements, in general, are extremely important. Only a very few technology sets do not include one or two of the energy efficiency technologies. Without advanced technology for energy efficiency, the chances of overall success are minuscule.

Every technology set has an important impact on the overall probability of success. While technologies pertinent to the electric utility sector appear to have smaller impacts on the chances for success, this is undoubtedly due to their assumed substitutability. The Kaya identity method is not sophisticated enough to deal with intermittency and other important features of electricity technologies. It would be a serious mistake to conclude that, as a group, nuclear and renewable technologies for electricity generation were less important than others.

These general results appear to be robust to the specific impact estimates chosen. They are substantially unchanged by a Monte Carlo simulation that allows impacts to vary by $\pm 20 \%$.

It has become a cliché to say that there is no "silver bullet"- no single technology that can solve our energy problems. This study has examined the importance of successful technology development in 11 broad areas identified by energy experts at ORNL. Not only is it clear that there is no silver bullet but, given the uncertainty of success in any particular area, we must be reasonably confident of success in every one of the 11 areas if we are to be confident of achieving both energy goals. While 
two technologies appear to be indispensable, the loss of any one of the technologies from the solution set significantly reduces the probability of success.

\subsection{Methodological Issues}

When interpreting the results presented in this report, it is important to bear in mind the key assumptions made and the important limitations of the methodology. The reference scenario to which the 11 energy technologies are applied assumes continued and full adoption of existing state-of-the-art technology. It assumes that policies in place in 2008, including new fuel economy standards for passenger cars and light trucks, are fulfilled. It assumes moderately high prices for crude oil and other fossil energy resources. Continued, steady economic growth and the evolution of the U.S. economy away from energy-intensive heavy industry toward services are also implicit in the projection. As a consequence of these reference scenario assumptions, future $\mathrm{CO}_{2}$ emissions are far lower than they would be if a constant ratio of $\mathrm{CO}_{2}$ per dollar of GDP had been assumed. Finally, the EIA's Frozen 2008 Technology case was extrapolated from 2030 to 2050 by continuing the rates of change in the scenario from 2025 to 2030.

Only the impacts of technological advances are considered, supported as needed by policies to overcome barriers to market acceptance. Technological success by definition requires costeffectiveness at carbon prices in the vicinity of $\$ 50 / \mathrm{Mg} \mathrm{CO}_{2}$, implying that policies necessary to induce such a price are also in place. However, no attempt has been made to estimate the impacts of such policies on consumer behavior or on substitution among energy sources. Furthermore, states of partial success are not considered, except as reflected in the Monte Carlo simulations, where deviations of $\pm 20 \%$ are tested.

The Kaya identity is used to calculate first-order interactions among the technologies. If one technology greatly improves energy efficiency, then the impact of another that substitutes a lower GHG energy source will have an appropriately reduced impact. The analysis is therefore heavily dependent on the realism of the technology impact assumptions described in detail in Appendix A. The simplicity of the Kaya equation probably has its greatest limitations when evaluating technologies for electricity generation. No attempt has been made to distinguish baseload from intermittent electricity generation, nor is the complexity of the electric utility sector represented in any way. The substitutability of nuclear, solar, and wind energy is therefore undoubtedly overstated in this analysis, with the result that each may appear to be less critical than it actually is. 


\section{REFERENCES}

1. N. Tanaka, p. 3 in Energy Technology Perspectives 2008: Summaries and Strategies to 2050, Organisation for Economic Cooperation and Development, Paris, 2008.

2. J. A. Edmonds et al., Global Energy Technology Strategy: Addressing Climate Change, Phase 2 Findings from an International Public-Private Sponsored Research Program, Battelle Memorial Institute, College Park, MD, 2007.

3. J. G. Hemminger, G. Crabtree, M. Kastner, "New Science for a Secure and Sustainable Energy Future: A Report of a Subcommittee to the Basic Energy Sciences Advisory Committee," U.S. Department of Energy, Washington, DC, 2008, http://www.sc.doe.gov/BES/ reports/files/NSSSEF_rpt.pdf.

4. Climate Change 2007: Mitigation. Contribution of Working Group III to the Fourth Assessment Report of the Intergovernmental Panel on Climate Change, ed. B. Metz et al., Intergovernmental Panel on Climate Change, Cambridge University Press, Cambridge and New York, 2007), http://www.ipcc.ch/ipccreports/ar4-wg3.htm (accessed July 8, 2009).

5. N. Stern, The Economics of Climate Change: The Stern Review, Cambridge Univ. Press, Cambridge, 2007.

6. International Energy Agency, Energy Technology Perspectives 2008: Summaries and Strategies to 2050, Organisation for Economic Cooperation and Development, Paris, 2008.

7. D. L. Greene, P. N. Leiby, "Oil Independence: Achievable Goal or Empty Slogan?" http://lugar.senate.gov/energy/links/commentary/08_greene_summary.cfm, 2008 (accessed July 10, 2009).

8. D. L. Greene, "Measuring energy security: Can the United States achieve oil independence?," Energy Policy, in press (doi:10.1016/j.enpol.2009.01.041).

9. Basic Energy Sciences Advisory Committee, Basic Research Needs to Assure a Secure Energy Future, U.S. Department of Energy, Washington, DC, 2003, http://www.sc.doe.gov/bes/reports/files/SEF_rpt.pdf.

10. L. Clarke et al., Climate Change Mitigation: An Analysis of Advanced Technology Scenarios, PNNL16078, Pacific Northwest National Laboratory, Washington, DC, 2006.

11. McKinsey and Company, Reducing U.S. Greenhouse Gas Emissions: How Much at What Cost? December 2007, http://www.mckinsey.com/clientservice/ccsi/pdf/US_ghg_final_report.pdf, 2007 (accessed July 7, 2009).

12. International Petroleum Industry Environmental Conservation Association, International Policy Approaches to Address the Climate Change Challenge: Summary Report of an IPIECA Workshop, Beijing, China, 25-26 October 2005; www.ipieca.org/activities/climate_change/downloads/workshops/oct_05/report.pdf

13. Y. Kaya, "Impact of Carbon Dioxide Emission Control on GNP Growth: Interpretation of Proposed Scenarios," paper presented to IPCC Energy and Industry Subgroup, Response Strategies Working Group, Paris, 1990.

14. D. L. Greene, P. N. Leiby, Oil Security Metrics Model, ORNL/TM-2006/505, Oak Ridge National Laboratory, Oak Ridge, TN, 2006.

15. Energy Information Administration, International Energy Outlook 2008, DOE/EIA-0484(2008), U.S. Department of Energy, Washington, DC, September 2008.

16. R. T. Pielke, T. Wigley, C. Greene, Nature 452 (7187) 531-532 (2008).

17. R. G. Richels, G. J. Blanford, "The Value of Technological Advance in Decarbonizing the U.S. Economy", Working Paper 07-19, AEI-Brookings Joint Center for Regulatory Studies, Washington, DC, November 2007.

18. A. E. Farrell, A. R. Brandt, Environ. Res. Lett. 1, 1-6 (2006).

19. M. Q. Wang et al., Well-to-Wheels Energy Use and Greenhouse Gas Emissions of Advanced Fuel/Vehicle Systems - North American Analysis, Vol. 1, ANL/ES/RP-104528, Argonne National Laboratory, Argonne, IL, 2001, http://www.ipd.anl.gov/anlpubs/2001/04/39097.pdf.

20. National Research Council, Prospective Evaluation of Applied Energy Research and Development at DOE (Phase One): A First Look Forward, National Academies Press, Washington, DC, 2005.

21. P. N. Leiby, Estimating the Energy Security Benefits of Reduced U.S. Oil Imports, ORNL/TM-2007/028, Oak Ridge National Laboratory, Oak Ridge, TN, 2007.

22. S. Pacala, R. Socolow, Science 305, 968-972 (2004). 
23. P. Taylor, "Energy Technologies for a Low Carbon Future," paper presented at the International Symposium on Global Technology Perspectives and the Role of CHP/DHC in Global Warming Prevention, Sapporo, Japan, July 4, 2008.

24. D. G. Groves, R. J. Lempert, Global Environ. Change 17, 73-85 (2007).

25. New Science for a Secure and Sustainable Energy Future: A Report from the Basic Energy Sciences Advisory Committee, U.S. Department of Energy, Washington, DC, 2008, www.sc.doe.gov/bes/reports/files/NSSSEF_rpt.pdf. 
APPENDIX A. TECHNOLOGY BRIEFS 


\title{
A.1 ADVANCED FOSSIL FUEL LIQUIDS
}

\author{
David L. Greene
}

\section{A.1.1 Technology Description}

The United States possesses vast fossil energy resources other than petroleum that could be developed to produce conventional petroleum fuels. These include oil shale, coal, petroleum producible via enhanced oil recovery (EOR), heavy oil, and tar sands. In addition, petroleum resources exist in areas that are now off limits to development because of concerns about potential environmental impacts, exacerbated by the difficulties of operating in extreme environments. Advanced technologies are needed to reduce the costs of developing these resources and eliminate or greatly reduce their environmental risks.

A February 2006 report to the U.S. Department of Energy (DOE) estimated the volume of technically recoverable conventional oil in the United States at 400 billion bbl, including yet-to-be discovered oil, reserve growth, and EOR. ${ }^{1}$ Agreeing with this assessment, a National Petroleum Council (NPC) advisory committee to the Secretary of Energy concluded in 2007 that application of known EOR techniques could make 100 billion bbl of the technically recoverable U.S. oil resources developable and that advanced EOR technologies could double that amount. ${ }^{2}$

Conventional liquid fuels can be made from coal via gasification and Fischer-Tropsch synthesis. However, without carbon capture and sequestration (CCS), well-to-wheel (WTW) carbon emissions will be 2 to 2.5 times higher than fuels derived from conventional petroleum. ${ }^{3}$ Adding $30 \%$ biomass as a feedstock to be gasified with the coal could reduce WTW carbon emissions to below the level of conventional petroleum fuels. Coal-biomass gasification with CCS could reduce WTW carbon emissions by almost $50 \%$ (Ref. 4 ).

Oil shale consists of a host rock and kerogen, fossil organic matter that has not been subjected to sufficient temperature and pressure to convert it into petroleum. The hydrogen content of kerogen is about the same as that of petroleum. About one-third of the world's estimated 3 trillion bbl of shale oil are located in relatively high quality deposits in Colorado, Utah, and Wyoming (p. 1 of Ref. 5). Historically, oil shale has been mined and then retorted at the surface at temperatures of about $500^{\circ} \mathrm{C}$ for about 1 hour. The high heat used in this process degrades the hydrocarbons, which must then be upgraded. In addition, enormous quantities of spent rock are left at the surface. More recently, attention has turned to in situ processes that use the shale oil formation itself as a retort. Wells are drilled in the reservoir and it is heated to only about $350^{\circ} \mathrm{C}$. This process produces a predominantly distillate product that needs little or no upgrading.

Technological advances have enabled significant reductions in the environmental "footprint" of oil exploration and production (up to 70\%) while increasing the volume of oil deposits that can be accessed (p. 8 of Ref. 6). An array of new technologies could be developed between now and 2030 that would increase recovery rates, reduce the number of wells that needed to be drilled, and improve environmental performance and safety, especially in arctic and offshore environments (pp. 1-2 of Ref. 7). Undiscovered U.S. conventional oil resources have been estimated at 360 billion bbl, most of which is in deep offshore waters or arctic regions and about half of which could be recoverable with advanced technology (Table 1.1 of Ref. 6).

\section{A.1.2 Barriers to Realizing Full Potential}

\section{A.1.2.1 Technical Barriers}

Efficient development of conventional oil resources in arctic and deepwater offshore areas with minimal environmental impact will benefit from technological advances in methods of characterizing reservoirs and monitoring and modeling production, advanced materials and equipment for producing 
safely and reliably in harsh environments, and extended and more reliable subsea architectures, among others (p. 9 of Ref. 7).

The NPC report lists 23 future technologies that could have significant impacts on increasing oil production from conventional petroleum resources over the 2015 to 2020 time frame and 13 future technologies that could magnify enhanced oil recovery between 2020 and 2030 (Tables IV.1 and IV.2 of Ref. 6). Among these are the ability to monitor and control a $\mathrm{CO}_{2}$ flood; advanced simulation modeling of reservoirs, horizontal, multilateral and fishbone well structures; and steam-assisted gravity drainage with alkaline-surfactant-polymers.

In situ production of oil shale seems to hold the most promise because heavier hydrocarbons can be left behind yielding a lighter, more valuable product. Controlling and optimizing the heating of the kerogen below the ground is a technical challenge; however, the greatest technical challenges appear to be environmental, especially protection of groundwater. Shell has tested its in situ process on a very small scale in the Piceance Basin of Colorado, and the results indicate that the process may be scalable provided that subsurface environmental and groundwater issues can be addressed. ${ }^{8}$

Coal-to-liquids (CTL) plants have been operating in South Africa for decades. However, advanced co-generation of CTL and electricity, at scale and with CCS, has yet to be demonstrated. Gasification of coal and biomass to produce liquid fuels with CCS is another interesting possibility for mitigating the high $\mathrm{CO}_{2}$ emissions of CTL fuels.

\section{A.1.2.2 Economic Barriers}

Enhanced oil recovery via $\mathrm{CO}_{2}$ injection appears to require about twice as much $\mathrm{CO}_{2}$ as conventional methods. This is helpful in terms of sequestering carbon but creates additional economic challenges.

Mining and surface retorting of oil shale suffer an economic penalty because the resulting product requires further upgrading. Research into improved retorting methods is directed at solving this problem. The economics of in situ methods appears promising but is not well understood at this time.

The economics of CTL production via gasification and Fischer-Tropsch synthesis is uncertain despite the fact that transportation fuels have been produced by this method for decades in South Africa. MIT's study estimates a cost per barrel of syncrude of \$50 without CCS and \$55 with carbon capture but not including sequestration. ${ }^{3}$ However, the study notes that past estimates have been wildly optimistic, and any estimates made today are contingent on a number of uncertain conditions.

\section{A.1.2.3 Social and Environmental Barriers}

Arctic and deepwater oil development poses special challenges to reduce the environmental footprint and maximize the reliability and safety of operations. At present, the public perceives significant risks that might be mitigated with advanced technology.

Oil shale may be strip mined or mined underground. Strip mines destroy the pre-existing topology and ecosystems and require extensive remediation. ${ }^{8}$ Both types of mining produce vast quantities of spent rock since the host rock expands in the retorting process. Water and water quality are major environmental concerns with all oil shale mining and retorting processes. The environmental impacts of in situ mining are less well understood. Protection of ground water from residual chemicals such as heavy metals and hydrocarbons left behind is a very serious concern and experimental methods have proposed different approaches to dealing with the problem. The U.S. oil shale resources are located in areas that currently enjoy high air quality and that will tolerate only small increases in ambient pollutants. Moreover, the most promising U.S. oil shale deposits are within the Colorado River basin, whose water quality and quantity are of great concern to downstream communities and protected environments. ${ }^{8}$ 
Without CCS, indirect synthesis of liquid fuels from coal would emit about $150 \%$ more carbon than conventional fuels from petroleum. ${ }^{3}$ With CCS, fuel cycle emissions are about the same as those of conventional distillate fuel.

\section{A.1.3 Potential to Reduce $\mathrm{CO}_{2}$ Emissions by 2050}

Increased deepwater and arctic conventional oil production will result in lifecycle carbon emissions equivalent to those for conventional fuels.

Enhanced oil recovery employing $\mathrm{CO}_{2}$ injection has the potential to sequester significant quantities of carbon if the process secures the $\mathrm{CO}_{2}$ in the oil well and does not recycle it. According to studies conducted for DOE, approximately $2,000 \mathrm{ft}^{3}$ of $\mathrm{CO}_{2}$ would be required to produce 1 barrel of oil using advanced technology EOR (Table 14a and p. 28, Ref. 9). Production of 1 billion barrels could potentially sequester $140 \mathrm{Tg}$ of $\mathrm{CO}_{2}$, and production of 100 billion barrels could sequester $14,000 \mathrm{Tg}$ of $\mathrm{CO}_{2}$. Since combustion of a billion barrels of oil would produce about $430 \mathrm{Tg}$ of $\mathrm{CO}_{2}$, advanced EOR could reduce the carbon intensity of petroleum produced by that process by about onethird.

CTL without CCS will increase the well-to-wheel $\mathrm{CO}_{2}$ emissions for fuels produced by that process, by a factor of 2 to 2.5 (Ref. 3). With CCS, the $\mathrm{CO}_{2}$ emissions will be similar to those from conventional petroleum fuels. A possible exception is co-gasification of coal and about $30 \%$ biomass with CCS. In that case, the lifecycle $\mathrm{CO}_{2}$ emissions could be $40 \%$ to $50 \%$ lower. However, this would likely make a quantity of biomass resources unavailable for other uses.

\section{A.1.3.1 Total potential by 2050}

The Task Force on Strategic Unconventional Fuels (TFSUF) envisioned 7 mmbd (14.8 quads) of additional unconventional supply in 2035, with an additional $1.7 \mathrm{mmbd}$ available from EOR with advanced technology (p. I-39 of Ref. 10). Converting to quads, interpolating for the year 2030, subtracting the production projected in the Frozen 2008 Technology scenario and extrapolating oil shale and CTL linearly to 2050 yields a total potential incremental supply of 22.4 quads (Table A.1.1). Since tar sands and heavy oil are not specifically broken out in the Frozen 2008 Technology scenario and since U.S. resources of these are much more limited, no estimate of incremental production resulting from advanced technology is made for these resource types. The estimated incremental production from advanced technology EOR $(1.7 \mathrm{mmbd})$ in 2035 is held constant through 2050.

Unconventional resources could potentially provide almost 20 quads of synthetic petroleum fuels by 2050 , with almost half of that from CTL. The noncoal portion (10.6 quads) would slightly reduce $\mathrm{CO}_{2}$ emissions versus conventional oil production due to the increased sequestration of $\mathrm{CO}_{2}$ in $\mathrm{EOR}$ fields (Table A.1.2). Fuel production via CTL could greatly increase $\mathrm{CO}_{2}$ emissions if CCS were not available and would be approximately equivalent to conventional petroleum if it were.

\section{A.1.4 Potential to Reduce Oil Use by 2030}

If an annual production rate of $1 \%$ of the 100 billion barrels of U.S. oil resources that are potentially recoverable using advanced EOR methods could be produced in 2030, that would increase U.S. petroleum supply by $2.7 \mathrm{mmbd}$. The ARI report (p. A-4 of Ref. 1) estimates $2.0 \mathrm{mmbd}$ of EOR production by 2030. The TFSUF estimated a production rate of $3.0 \mathrm{mmbd}$ in 2035 given advanced technology but only 1.3 mmbd with current technology. ${ }^{10}$ Scaling this back to 2030 produces an estimate of $2.3 \mathrm{mmbd}$ with advanced technology and $1.0 \mathrm{mmbd}$ with current technology. The net increase due to advanced technology is $1.3 \mathrm{mmbd}$ (Table A.1.1). 
Table A.1.1. Estimated increase in unconventional petroleum supply

\begin{tabular}{lcccccccccc}
\hline & \multicolumn{2}{c}{2035} & \multicolumn{2}{c}{2030} & \multicolumn{2}{c}{$\begin{array}{c}\text { Frozen } \\
\text { technology, 2030 }\end{array}$} & \multicolumn{2}{c}{ Net 2030 } & \multicolumn{2}{c}{2050} \\
\cline { 2 - 11 } Oil shale & mmbd & quads & mmbd & quads & mmbd & quads & mmbd & quads & mmbd & quads \\
\cline { 2 - 11 } CTL & 2.5 & 5.3 & 1.9 & 4.1 & 0.0 & 0.0 & 1.9 & 4.1 & 4.2 & 8.9 \\
EOR & 2.6 & 5.5 & 2.0 & 4.3 & 0.5 & 1.0 & 1.5 & 3.3 & 4.4 & 9.3 \\
Tar sands & 0.5 & 1.1 & 0.4 & 0.9 & $\mathrm{U}$ & $\mathrm{U}$ & 0.0 & 0.0 & 0.0 & 0.0 \\
Heavy oil & 0.8 & 1.6 & 0.6 & 1.2 & $\mathrm{U}$ & $\mathrm{U}$ & 0.0 & 0.0 & 0.0 & 0.0 \\
Total & 9.4 & 19.9 & 7.2 & 15.4 & - & - & 4.7 & 10.2 & 10.3 & 21.8 \\
\hline
\end{tabular}

Notes: Start date is 2013; linear interpolation used to estimate 2030, linear extrapolation to 2050.

$\mathrm{U}=$ unknown.

1 quad $=2.117 \mathrm{mmbd}$.

TFSUF estimates $1.3 \mathrm{mmbd}$ of EOR without advanced technology, and $3.0 \mathrm{mmbd}$ with advanced technology.

Table A.1.2. Energy supply and WTW carbon intensity of unconventional fossil fuels

\begin{tabular}{lcc}
\hline & $\begin{array}{c}\text { Energy supply } \\
\text { (quads) }\end{array}$ & $\begin{array}{c}\text { Carbon intensity } \\
\text { relative to base }\end{array}$ \\
\hline Enhanced oil recovery $\left(\mathrm{CO}_{2}\right)$ & 1.7 & 0.70 \\
Oil shale in situ & 8.9 & 1.0 \\
CTL without CCS & 9.3 & 2.0 \\
CTL with CCS & 9.3 & 1.0 \\
CTL + biomass without CCS & 9.3 & 0.95 \\
CTL + biomass + CCS & 9.3 & 0.55 \\
\hline
\end{tabular}

With accelerated technological development and supporting policies, TFSUF estimates that a single in situ oil shale project in Colorado could be producing $0.5 \mathrm{mmbd}$ of synthetic petroleum by 2020 (Ref. 11). By 2030, projects in Colorado, Utah, and Wyoming could be producing more than $2 \mathrm{mmbd}$ of synthetic crude from oil shale. CTL production is anticipated at $1.4 \mathrm{mmbd}$ by 2030 . The same study projects a potential to supply $0.8 \mathrm{mmbd}$ from U.S. heavy oil resources and lesser amounts with earlier production dates from tar sands (pp. 27-28 of Ref. 11). We assume no increase in these two sources due to advanced technology, however.

The total increase in petroleum supply in 2030 due to advanced fossil energy sources is therefore: $1.3 \mathrm{mmbd}$ from EOR $+2 \mathrm{mmbd}$ from oil shale $+1.4 \mathrm{mmbd}$ from $\mathrm{CTL}=4.7 \mathrm{mmbd}$ or 9.95 quads.

\section{A.1.5 Interactions with Other Technologies}

On a WTW basis, CTL without CCS is likely to produce twice the carbon emissions of conventional petroleum fuels. Thus, the carbon intensity impact of CTL will strongly depend on the success of CCS.

$\mathrm{CTL}+30 \%$ biomass with sequestration would draw 2.8 quads of biomass away from other uses. Thus, we include CTL + biomass only if advanced biofuels are not successful. There is little difference in net carbon emissions if the biomass is separately converted to liquid fuel or is converted jointly with coal (Table 2 of Ref. 12). The key differences are the scale economies of the process and the fact that CTL itself, without CCS and without co-gasification of biomass, is a proven technology. 


\section{References}

1. Advanced Resources International, Undeveloped Domestic Oil Resources, report to the Office of Fossil Energy, Office of Oil and Natural Gas, U.S. Department of Energy, Washington, DC, February 2006.

2. National Petroleum Council (NPC), Hard Truths: Facing the Hard Truths about Energy, Report of the Oil and Natural Gas Advisory Committee to the Secretary of Energy, Washington, DC, July 2007.

3. Massachusetts Institute of Technology, The Future of Coal: Options for a Carbon-Constrained World,, Cambridge, MA, 2007, http://web.mit.edu/coal/The_Future_of_Coal.pdf (accessed July 10, 2009).

4. R. D. Boardman, "Plant Modeling and Emissions Comparative Analysis Approach: Coal/Biomass Gasification with Fischer-Tropsch Diesel Production,” Idaho National Laboratory, Idaho Falls, ID, May 2007.

5. National Petroleum Council, "Topic Paper 27: Oil Shales," Report of the Oil and Natural Gas Advisory Committee to the Secretary of Energy, Washington, DC, July 2007.

6. National Petroleum Council, "Topic Paper 19: Conventional Oil and Gas (Including Arctic and Enhanced Oil Recovery)," Report of the Oil and Natural Gas Advisory Committee to the Secretary of Energy, Washington, DC, July 2007.

7. National Petroleum Council, "Topic Paper 20: Deepwater," Report of the Oil and Natural Gas Advisory Committee to the Secretary of Energy, Washington, DC, July 2007.

8. J. T. Bartis, T. LaTourrette, L. Dixon, D. J. Peterson, and G. Cecchine, Oil Shale Development in the United States: Prospects and Policy Issues, Rand Corporation, Arlington, VA, 2005.

9. Advanced Resources International, Evaluating the Potential for "Game Changer" Improvements in Oil Recovery Efficiency from $\mathrm{CO}_{2}$ Enhanced Oil Recovery, report to the U.S. Department of Energy, Office of Fossil Energy, Office of Oil and Natural Gas, Washington, DC, February 2006.

10. Task Force on Strategic Unconventional Fuels, America's Strategic Unconventional Fuels: Volume IPreparation Strategy, Plan and Recommendations, Report to the Secretary of Energy, Washington, D.C. September 2007.

11. Task Force on Strategic Unconventional Fuels, "Development of America's Strategic Unconventional Fuels Resources," Report to the President and Congress of the United States, Washington, D.C., September 2006.

12. R. H. Williams, E. D. Larson, and H. Jin, "F-T Liquids Production from Coal and Coal + Biomass with $\mathrm{CO}_{2}$ Capture and Alternative Storage Options: Aquifer $\mathrm{CO}_{2}$ Storage vs. $\mathrm{CO}_{2}$-Enhanced Oil Recovery", Princeton Environmental Institute, Princeton University, Princeton, NJ, January 13, 2006. 


\title{
A.2 BIOMASS ENERGY
}

\author{
Philip R. Boudreaux \\ Robin L. Graham
}

\section{A.2.1 Technology Description}

Biomass used for bioenergy can come from many sources: residues or waste from ordinary crops and forest products; dedicated crops grown primarily for their lignocellulosic content; dedicated crops including algae grown for their oil; forest thinning to reduce forest fuel loads; and waste, such as municipal solid waste (MSW), urban wood wastes, and waste food oils.

Together, these sources can supply a substantial amount of low-carbon feedstock for transportation fuel, chemicals, heat, and electricity generation. According to a report sponsored by the U.S. Department of Agriculture and the U.S. Department of Energy, the United States could produce one billion tons of dry biomass a year by 2030 (Ref. 1). This study assumes the existence of a large-scale bioenergy industry by mid-21st century; this would require increased land use and revised agriculture and forestry practices. Estimates for global biomass potential vary widely. In Energy Technology Perspectives 2008, ${ }^{2}$ the International Energy Agency (IEA) assumes the production of $150 \mathrm{EJ}$ $(\approx 150$ quads) of primary global energy from biomass in the "Blue" scenario. Imported biofuel could play a significant role in the U.S. energy portfolio. Importing biofuels would potentially help lower greenhouse gas (GHG) emissions but would not contribute to energy independence aside from expanding and diversifying the energy supplier pool.

The GHG emissions and petroleum savings of biomass are dependent on the process used to convert biomass to bioenergy and on the biomass feedstock itself. For example corn-based biofuels yield a GHG emission reduction of only $20 \%$ compared with gasoline, whereas cellulosic biofuels potentially have an $89 \%$ reduction, according to DOE estimates. ${ }^{3}$ These figures consider GHG emissions from fuel combustion, as well as upstream emissions from cultivation, transportation of feedstocks, and fuel processing. However, they do not take into account emissions from induced landuse conversion. When cropland is diverted from food production to production of feedstock for biofuel, food prices may be expected to rise, inducing land conversion elsewhere to replace at least part of the lost food supply. If forest land is converted to cropland, for example, the release of carbon sequestered in the biomass and soil would be large in relation to the reduction in emissions from fuel combustion. Depending on the type of land that is converted to new cropland, biofuels could be a worse polluter than conventional petroleum fuels. ${ }^{4}$ Feedstocks such as MSW, crop waste, algae, and other feedstocks not grown on lands that must be cleared of carbon-sequestering plants that have lived for decades do not suffer from the problem of induced land use change. ${ }^{4}$

Depending on the mix of feedstocks and conversion methods, implications for enhancing the supply of transportation fuel and reducing $\mathrm{CO}_{2}$ emissions will differ. Using nonfood biomass could help to achieve sustainable, low-GHG-emitting, and cost-effective biofuels. Biofuels produced through what the IEA calls "second-generation conversion methods," such as converting cellulose for ethanol, and biomass conversion through a Fischer-Tropsch method (biomass-to liquid method) for biodiesel have great potential to decrease GHG emissions while avoiding the displacement of Ref. 2. These technologies will enable the conversion of the most difficult biomass and waste carbon material into liquid fuels. However, these technologies are not yet commercially viable. 


\section{A.2.2 Barriers to Realizing Full Potential}

\section{A.2.2.1 Technical Barriers}

Many technical barriers exist, driven by the diversity of potential feedstocks coupled with the diversity of conversion technologies and potential end products. Most technologies are at demonstration phase. Table A.2.1 lists some of these technologies.

Table A.2.1. Biomass technologies

\begin{tabular}{|c|c|c|}
\hline Sector & Conversion method & Feedstock \\
\hline Power generation & $\begin{array}{l}\text { Combustion (grate boilers, } \\
\text { fluidized bed combustion, } \\
\text { co-firing) } \\
\text { Gasification (with air, oxygen, } \\
\text { or steam) }\end{array}$ & $\begin{array}{l}\text { - Wood pellets, straw, plywood, } \\
\text { municipal solid waste } \\
\text { - Almost any organic material, } \\
\text { wood }\end{array}$ \\
\hline Combined heat and power (CHP) & - Biomass fired CHP plant & - Wood \\
\hline Transportation & $\begin{array}{ll}\text { - } & \text { Fermentation (first } \\
& \text { generation) } \\
\text { - } & \text { Pyrolysis } \\
\text { - } & \text { Biomass-to-liquid } \\
\text { - } & \text { Algecond generation) } \\
\text { - } & \text { Algel }\end{array}$ & $\begin{array}{l}\text { - Sugar- or starch-heavy } \\
\text { biomass, vegetable oil } \\
\text { and animal fat } \\
\text { - Farming waste } \\
\text { - Cellulosic material } \\
\text { - Algae }\end{array}$ \\
\hline
\end{tabular}

A central issue facing all biomass technologies is the transport problem. Biomass typically has a high moisture content and a low energy density, making it expensive to transport over long distances. Accordingly, biofuel plants must typically source raw materials from within a 50-75 mile radius, ${ }^{5}$ and economies of scale may be limited. This problem can be mitigated by high-intensity farming and higher-yielding crops or by improved methods of concentrating feedstock material for transport, though potentially at higher cost for increased fertilizer use, irrigation, and pre-processing. Ethanol cannot be shipped in mild steel pipelines and is currently shipped by rail or truck in stainless steel tankers, thus requiring substantial expansion of the transport infrastructure for greatly increased ethanol use. Lower cost materials would help to reduce costs. Other unconventional biofuels, such as butanol, are more compatible with existing fuel transportation infrastructure.

Technical issues for biomass include inefficient harvest and transport technology, lack of technologies for removing residues while ensuring that site productivity is not impaired, lack of crops designed for specific bioenergy end uses, and lack of know-how in moving from food crop production to energy-crop production. Lignocellulosic ethanol and biomass-to-liquid (BTL) technologies (second-generation biofuels) need significant cost reduction and need to be demonstrated and deployed to establish their commercial viability.

\section{A.2.2.2 Economic Barriers}

Biomass currently provides almost $10 \%$ of the global energy supply, ${ }^{2}$ but the great majority of use is simple combustion for heat, largely in developing economies. Biomass costs are highly sensitive to a number of factors, including feedstock, process, and crop yield. ${ }^{6}$ Sugar-cane ethanol from Brazil stands out among BTL products for cost-effectiveness. It is produced at $\$ 0.25-0.35$ per liter of gasoline equivalent (lge), making it economically competitive with oil at $\$ 40-60 / \mathrm{bbl}$. Other BTL technologies have costs in the range \$0.70-1.0/lge and cannot compete with oil below $\$ 100$ 150/bbl. Projections for 2030 anticipate substantial cost reductions that will bring the price for a variety of ethanol and biodiesel products down to $\$ 0.40-0.60 /$ lge. At present, the worldwide marginal cost of production for oil is around $\$ 25 / \mathrm{bbl}$, with the lowest cost of around $\$ 14 / \mathrm{bbl}$ in the Middle 
East. ${ }^{2}$ Because no BTL technology can compete with oil for production cost at present, investments in BTL can be undermined by fluctuations in the market price for oil.

Harvesting technology needs to become more cost-effective. There is an insufficient availability of low-cost biomass. When the biomass in question is also a food product, food prices can be driven up when the food crop is produced for fuel. Currently bioenergy costs about $\$ 62-185 / \mathrm{MWh}$, and biofuel costs $\$ 10-31 /$ GJ (Ref. 2). According to the IEA, the cost could be reduced to $\$ 49-123 / \mathrm{MWh}$ for bioenergy and \$4-19/GJ for biofuel if technological advances are achieved. ${ }^{2}$

\section{A.2.2.3 Social Barriers}

To avoid negative impacts on food and feed prices, food crops should not be used for bioenergy; these foods include corn, grain, and oil seeds. Dedicated bioenergy crops, harvested on land not needed for food, should be produced. Competition for water use is another important concern. For biomass to become an important source of energy, its production must be environmentally sustainable.

\section{A.2.3 Technological Advances Needed to Meet Full Potential}

Dedicated species of biomass should be developed to maximize the conversion efficiency of biomass to energy and biofuels. These developments could include reduction of lignin or crystalline cellulose in the biomass for biofuel conversion or reduction of silica or potassium in the biomass for energy conversion. Improvement of production chains, which will depend on local conditions, will help to increase the efficiency of harvesting and transporting biomass materials. Development of technologies that will remove residues without disturbing site integrity, such as novel crop rotation, will enable better crop yield. Development of more hardy oil and lignocellulosic crops with high yields, to survive diverse soil and climates and require minimal tending, will help increase biomass potential. Second-generation biofuel, cellulosic ethanol, and BTL biodiesel need to be demonstrated and deployed, and the costs reduced. Biomass integrated gasification combined cycle (IGCC) and co-combustion plants need to become more reliable and cost-effective, with demonstration and deployment.

\section{A.2.4 Potential to Reduce $\mathrm{CO}_{2}$ Emissions by 2050}

Biomass is a versatile material, and all four sectors considered in this study will compete for it: industry, transportation, electricity generation, and buildings. The industrial sector uses wood and other agriculture residues burned in co-generation for steam and power; biomass could also displace petroleum as a material for making chemicals and other bioproducts. The transportation sector uses biomass for ethanol and biodiesel and could use it to produce other liquid fuels, as well. The electricity sector uses biomass/coal co-firing plants and biomass-only plants to produce electricity. Finally, the buildings sector uses biomass for space heating, electricity, and cooking fuels. Also, each of these sectors uses a multitude of different biomass feedstocks and conversion processes, making it very difficult to compute the potential of biomass to reduce GHG emissions and oil dependence. One source estimates that by 2030 , biomass can reduce emissions in the transportation industry by $100 \mathrm{Tg}$ of $\mathrm{CO}_{2}$ using cellulosic biofuels and by $50 \mathrm{Tg}$ of $\mathrm{CO}_{2}$ in the power sector through biomass co-firing. ${ }^{7}$ The "Vision Goals" of the Biomass Technical Advisory Committee ${ }^{8}$ call for biomass to produce 5\% of power (5 quads), $20 \%$ of transportation fuels ( 9.5 quads), and $25 \%$ of chemicals and biobased products by 2030. In the power sector, 5 quads of coal power, at $95 \mathrm{Tg} \mathrm{of} \mathrm{CO}_{2} /$ quad, represent $475 \mathrm{Tg}$ of $\mathrm{CO}_{2}$. Likewise, in the transportation sector, 9.5 quads of motor gasoline, at $70 \mathrm{Tg}$ of $\mathrm{CO}_{2} /$ quad represent $665 \mathrm{Tg}$ of $\mathrm{CO}_{2}$. The question is then the cleanliness of biomass compared with traditional methods of energy generation. If land-use changes are taken into account, then biofuel (corn and biomass ethanol) may actually pollute more that traditional fuels. ${ }^{9}$ If cellulosic ethanol or BTL diesel 
fuel produced by gasification and synthesis is used, the reduction in GHG emissions could be as much as $70 \%$.

\section{A.2.5 Potential to Reduce Oil Use by 2030}

The Energy Independence and Security Act of 2007 (Ref. 10) requires the United States to produce 36 billion gallons of biofuel per year by 2022. If all 36 billion gallons are used as ethanol, and assuming 84,000 Btu/gal EtOH, then this amount of biofuel could displace 3.0 quads of transportation fuels.

If the United States can produce 1 billion tons of biomass a year, then $20 \%$ of transportation fuels could come from biofuels by 2030 , meaning a 9.5 quad reduction in petroleum use. ${ }^{1,10}$ Overall, by 2030 biomass could replace $30 \%$ of petroleum use, assuming that annual production of 1 billion tons of biomass provides $5 \%$ of the nation's power, $20 \%$ of its transportation fuels, and $25 \%$ of its chemicals. ${ }^{1}$

\section{A.2.6 Interactions with Other Technologies}

Biomass interacts with the following sectors: advanced fossil fuels, industrial, transportation, electricity generation, and buildings. How biomass contributes will depend on technological development, local issues, the price of carbon, and needs for transportation fuel.

\section{References}

1. R. Perlack et al., Biomass as Feedstock for a Bioenergy and Bioproducts Industry: The Technical Feasibility of a Billion-Ton Annual Supply. ORNL/TM-2005/66, Oak Ridge National Laboratory, Oak Ridge, TN, 2006.

2. International Energy Agency, Energy Technology Perspectives 2008: Summaries and Strategies to 2050, Organisation for Economic Cooperation and Development, Paris, 2008.

3. U.S. Department of Energy, "Biofuels \& Greenhouse Gas Emissions: Myths versus Facts," http://energysavingtips.gov/media/BiofuelsMythVFact.pdf (accessed July 7, 2009).

4. J. Fargione et al., Science 319, 1235-1238 (2008).

5. D. Morris, The Carbohydrate Economy, Biofuels and the Net Energy Debate, Institute for Local SelfReliance, Minneapolis, MN, 2005.

6. “IEA Energy Technology Essentials: Biofuel Production,” ETE02, International Energy Agency, 2007, http://www.iea.org/Textbase/techno/essentials2.pdf (accessed July 7, 2009)

7. Scott Nyquist, "Reducing U.S. Greenhouse Gas Emissions: How Much at What Cost?" presented at the James A. Baker III Institute for Public Policy, Rice University, February 8, 2008, http://www.rice.edu/energy/publications/presentations/climatechange/cc_Nyquist_020908.pdf (accessed July 7, 2009).

8. Biomass Technical Advisory Committee, "Vision for Bioenergy \& Biobased Products in the United States," October 2002, http://www.climatevision.gov/sectors/electricpower/pdfs/bioenergy_vision.pdf (accessed July 7, 2009).

9. T. Searchinger et al., Science 319, 1238-1240 (2008).

10. Energy Independence and Security Act of 2007, Public Law 110-140, December 19, 2007. 


\title{
A.3 CARBON CAPTURE AND SEQUESTRATION
}

\author{
Robert Standaert
}

\section{A.3.1 Technology Description}

Capture and permanent sequestration of anthropogenic $\mathrm{CO}_{2}$ would allow continued reliance on fossil fuels with substantially reduced atmospheric emissions of $\mathrm{CO}_{2}$. This study considers carbon capture and sequestration (CCS) only as applied to large, stationary sources of $\mathrm{CO}_{2}(\geq 0.1 \mathrm{Tg}$ $\mathrm{CO}_{2}$ /year each), not from small, stationary sources, mobile sources or the atmospheric pool. Given that most of the large, stationary sources of $\mathrm{CO}_{2}$ use coal, an abundant domestic fuel, successful implementation of CCS technology will both reduce $\mathrm{CO}_{2}$ emissions and enhance energy independence.

U.S. anthropogenic $\mathrm{CO}_{2}$ emissions are currently $6 \mathrm{Pg}$ annually, of which $4.1 \mathrm{Pg}$ are from stationary (nontransportation) sources. ${ }^{1}$ The International Energy Agency (IEA) has identified 1,497 large, stationary sources in the United States that are collectively responsible for $2.8 \mathrm{Pg} / \mathrm{year}$ of $\mathrm{CO}_{2}$ emissions; this data is shown in Table A.3.1 (Ref. 2). Electric generation accounts for the majority of stationary source emissions, with 1,073 large sources contributing $2.4 \mathrm{Pg} /$ year of $\mathrm{CO}_{2}$ ( $86 \%$ of the large source total), and most technology analyses have focused on this sector. Several industries, notably petroleum refining, iron- and steel-making, cement manufacture, and petrochemicals production (chiefly of ethylene and ethylene oxide) also contribute large, stationary $\mathrm{CO}_{2}$ sources that are potential targets for CCS.

Table A.3.1. Large ( $\geq 100 \mathrm{Gg} / \mathrm{year}$ ), stationary sources of $\mathrm{CO}_{2}$ in the United States

\begin{tabular}{|c|c|c|c|}
\hline \multirow[b]{2}{*}{ Industry } & \multicolumn{2}{|c|}{$\mathrm{CO}_{2}$ emissions } & \multirow[b]{2}{*}{ Sources } \\
\hline & Gg/year & Percent of total & \\
\hline \multicolumn{4}{|l|}{ Electricity generation } \\
\hline Coal & 1,998 & 72.4 & 514 \\
\hline Gas & 295 & 10.7 & 466 \\
\hline Oil & 79 & 2.8 & 73 \\
\hline Biomass/waste & 4 & 0.1 & 20 \\
\hline Total, electricity generation & 2,375 & 86.0 & 1,073 \\
\hline Refineries & 159 & 5.7 & 134 \\
\hline Iron and steel & 81 & 2.9 & 44 \\
\hline Cement manufacture & 63 & 2.3 & 106 \\
\hline Ethylene and ethylene oxide & 62 & 2.2 & 45 \\
\hline Other & 22 & 0.8 & 95 \\
\hline Total & 2,762 & 100.0 & 1,497 \\
\hline
\end{tabular}

CCS has the potential to capture $90 \%$ of the $\mathrm{CO}_{2}$ in flue emissions from point sources such as power plants. However, actual abatement will be less, perhaps $85 \%$, because of the energy demands of $\mathrm{CO}_{2}$ capture and compression, which would require that CCS power plants consume $10-40 \%$ more fuel than a conventional plant for the same electrical output. ${ }^{3,4}$

\section{A.3.2 Barriers to Realizing Full Potential}

The process of CCS involves three distinct phases: capture and compression of $\mathrm{CO}_{2}$, transport to sequestration sites, and sequestration with long-term monitoring. For each phase, there are existing technologies that are in demonstration or commercial use. However, each also faces barriers of at least one kind, and integration of the technologies on the scale of a large power plant has yet to be 
achieved. Thus, there is a lack of experience with CCS and an incomplete understanding of its costs and benefits. A full-scale demonstration is an essential step toward practical implementation of CCS.

The largest current U.S. CCS project captures $\mathrm{CO}_{2}$ from coal gasification at the Great Plains Synfuels Plant in Beulah, North Dakota, and transports it $325 \mathrm{~km}$ via pipeline to the Weyburn oil field in Weyburn, Saskatchewan, Canada. There, it is injected into oil wells for enhanced oil recovery (EOR), and its fate underground will be monitored under the auspices of the International Energy Agency (IEA) Greenhouse Gas R\&D Programme. The amount of $\mathrm{CO}_{2}$ captured has grown to $8,000 \mathrm{Mg} / \mathrm{day}$ ( 3 Tg/year), about half of the plant's emissions. This scale is equivalent to capturing half the emissions from a large coal-fired power plant, such as the Tennessee Valley Authority's 950 MW(e) Bull Run plant. The largest coal-fired plants in the United States have a capacity of around $3,500 \mathrm{MW}(\mathrm{e})$ and emit more than $50,000 \mathrm{Mg}$ /day of $\mathrm{CO}_{2}$.

\section{A.3.2.1 Technical Barriers}

\section{Capture}

$\mathrm{CO}_{2}$ is captured on an industrial scale from a variety of gas streams, notably in natural gas refining, coal gasification and fertilizer manufacture. It can also be captured from coal-fired power plant exhaust. For example, approximately $2-3 \%$ of the exhaust stream from the $180 \mathrm{MW}$ Warrior Run plant in Cumberland, Maryland, is withdrawn to produce 150 tons of food-grade commercial $\mathrm{CO}_{2}$ per day. ${ }^{5}$

Several technologies are used to separate $\mathrm{CO}_{2}$ from other gases, and there is considerable room both for improvement of existing technologies and for new technologies. Capture of all $\mathrm{CO}_{2}$ emitted from a process is prohibitively difficult, and a target of $90 \%$ is used in many studies and in the Intergovernmental Panel on Climate Change (IPCC) Special Report on Carbon Dioxide Capture and Storage. ${ }^{4}$ The main problems with all current capture approaches are that they are capital and energy intensive, so they are expensive and increase fuel consumption. They also require increased water use, which could be problematic at some installations.

The preferred technology for $\mathrm{CO}_{2}$ capture depends on the physical and chemical characteristics of the gas stream, as well as the extent of $\mathrm{CO}_{2}$ removal required and the transport method. As there are several combustion fuels and techniques, $\mathrm{CO}_{2}$ capture technology must be matched to the combustion method, so several technologies will need to be developed. $\mathrm{CO}_{2}$ can be captured either after or before combustion depending on the type of plant (e.g., after gasification of coal, gas, or biomass fuel to $\mathrm{H}_{2}$ $+\mathrm{CO}_{2}$ ). In a third scenario, fuel would be burned in pure oxygen rather than air. This approach, termed oxycombustion, shifts the separation burden to one of extracting oxygen from air. Combustion of fuel with pure oxygen produces an exhaust stream of nearly pure $\mathrm{CO}_{2}$ and water, which is easily removed.

The main capture method considered for postcombustion capture is chemical absorption using amines, such as monoethanolamine (MEA), which is well suited to the relatively low pressure and $\mathrm{CO}_{2}$ content of power plant exhaust (12-14\% for coal, 3-4\% for natural gas). ${ }^{6}$ This process, which was patented in 1930 and was mature by the 1970 s for industrial processes, ${ }^{7}$ is employed at Sleipner West, an offshore natural gas processing facility that is home to a large CCS demonstration project. Each day at Sleipner, 2,800 $\mathrm{Mg}$ of $\mathrm{CO}_{2}$ are extracted from natural gas on an offshore platform and pumped into a saline aquifer $900 \mathrm{~m}$ beneath the sea bed.

The main drawback of the amine capture approach is its energy intensity, which adds a large parasitic load to capture-equipped power plants. Additional problems include large capital cost, increased land use, and capture agent degradation, which decreases capture efficiency, accelerates equipment corrosion, and adds an ongoing cost burden for fresh solvent, repurification of the agent, and disposal of hazardous waste. ${ }^{8}$

For precombustion capture, physical absorption in solvents (e.g., the Rectisol ${ }^{\circledR}$ and Selexol ${ }^{\circledR}$ processes) is typically considered. $\mathrm{CO}_{2}$ dissolves in refrigerated solvent at high pressure and low 
temperature, and it is subsequently released at lower pressure and higher temperature. Physical absorption has been in commercial use since the 1950s and is widely employed in industry. The Great Plains Synfuels plant in North Dakota uses the Rectisol ${ }^{\circledR}$ process to capture $8,000 \mathrm{Mg} / \mathrm{day}$ of $\mathrm{CO}_{2}$, which is transported by pipeline to an EOR and carbon sequestration project in Weyburn, Saskatchewan, Canada. ${ }^{9}$

Oxycombustion is not yet used for electricity generation. The largest oxycombustion pilot facility, Vattenfall's $30 \mathrm{MW}$ thermal plant in Spremberg, Germany, became operational in September 2008. It does not have a generator, but it integrates the other key components of an oxycombustion CCS power plant: an air separation unit, a boiler, and $\mathrm{CO}_{2}$ compression unit. Pure oxygen for the combustor is produced in the air separation unit by cryogenic distillation. This technology is also long established in industry, but it is highly energy intensive. Much of the active research in oxygen separation is focused on membrane technologies. ${ }^{10}$

The greatest technology challenge facing $\mathrm{CO}_{2}$ capture is reducing its cost and energy penalty, and a number of approaches are being pursued. The IPCC expects that costs for conventional technologies can be reduced $20-30 \%$ in ten years, while the U.S. National Energy Technology Laboratory anticipates that $30-45 \%$ cost reductions can ultimately be achieved. ${ }^{4,11}$ Improved absorbents and process designs for physical and chemical absorption technologies are being actively pursued, as are a range of additional technologies, including solid sorbents, membrane separation, hybrid membraneabsorbent systems and mineralization. ${ }^{4,12}$

\section{Transport}

$\mathrm{CO}_{2}$ can be moved via pipeline, truck, rail, or ship. The technology is largely mature, but widespread implementation of CCS would require a vast expansion in infrastructure. The overall cost for transportation is estimated at $\$ 1-8 / \mathrm{Mg}$, and some safety risks are associated with transport of $\mathrm{CO}_{2}$ (Ref. 4). At a 4\% concentration in air, $\mathrm{CO}_{2}$ is considered immediately dangerous to life or health (IDLH), while levels of $7-10 \%$ produce unconsciousness in a few minutes. ${ }^{13}$ Because $\mathrm{CO}_{2}$ is denser than air, dangerous local concentrations could quickly develop in the vicinity of a leak. $\mathrm{CO}_{2}$ is transported either at high pressure (pipelines) or at cryogenic temperature (tankers and ships), creating additional physical hazards to those nearby.

Pipelines are the most efficient means of transporting large quantities of $\mathrm{CO}_{2}$, though they have large capital costs and require clean $\mathrm{CO}_{2}$ free from corrosive impurities. Some losses to the atmosphere are inevitable for any transport system, but for a well-maintained pipeline system, they will be small. For the U.S. natural gas transmission network, to which a $\mathrm{CO}_{2}$ pipeline network might be comparable in size, total losses are about $0.5 \%$ (Ref. 14). Both physical and social geography complicate pipeline routing. ${ }^{15}$ Mountains, rivers, and other physical obstacles make pipelines much more expensive. Large pipelines in densely populated areas would pose some risk to residents and might be opposed on the bases of perceived risk and aesthetics. Diligent maintenance and security efforts would be needed to minimize risks to populations. The nature of a pipeline system needed for transporting $\mathrm{CO}_{2}$ depends on the nature of sequestration sites employed. ${ }^{16}$ The limiting scenarios, with very different pipeline needs, are centralized sequestration at a few large sites and distributed sequestration at or near individual sources.

\section{Sequestration and monitoring}

Three main approaches for sequestration are widely discussed. Geological sequestration would use underground structures such as depleted oil and gas fields, saline aquifers, and unmineable coal seams. In the United States, total sequestration capacity is estimated to be at least 3,300 Pg, enough for hundreds of years. ${ }^{17}$ The ocean is considered to have vast capacity for $\mathrm{CO}_{2}$, and sequestration approaches envision deposition of $\mathrm{CO}_{2}$ in the lower layer of the ocean (depth $>1000 \mathrm{~m}$ ) or in the ocean sediment. There is considerable uncertainty, however, about the permanency and possible 
environmental impacts of deep sea storage. The third approach, mineral carbonation, would employ alkaline minerals that would react irreversibly with $\mathrm{CO}_{2}$.

Natural reserves of methane, $\mathrm{CO}_{2}$, and oil have been sequestered underground for millennia. It is believed that with careful site selection, $\mathrm{CO}_{2}$ can likewise be sequestered for a long time, with $\geq 99 \%$ retention for periods ranging from 100 years (very likely) to 1000 years (likely). ${ }^{4}$ Techniques for drilling deep wells and injecting $\mathrm{CO}_{2}$ underground have been developed for EOR, and injecting $\mathrm{CO}_{2}$ into underground reservoirs is not a problem. The greater challenges lie in site selection and monitoring to assure safe, permanent storage. A number of problems could potentially emerge in a sequestration reservoir. Leakage of $\mathrm{CO}_{2}$ could occur through a number of mechanisms and have adverse local impacts including contamination of groundwater and mineral resources, soil and water acidification, toxicity to plants and animals, and mobilization of heavy metals. ${ }^{418}$ Geomechanical effects, such as rock fracture, fault activation, and earthquakes, are also possible. Overall, the behavior of $\mathrm{CO}_{2}$ in reservoirs other than oil and gas fields is not adequately understood.

Monitoring and verification of sequestration reservoirs must be performed for many years, but no standards for such monitoring exist. Comprehensive monitoring will likely require a network of methods, including seismic and infrared imaging; pressure measurements; soil, water and air analyses; plant stress surveys and other ecosystem assessments; and modeling and simulation. Existing methods are considered adequate, but less expensive methods and additional noninvasive measurement methods are needed. Overall, geological sequestration is projected to be the least expensive sequestration approach, with a cost of $\$ 0.5-8 / \mathrm{Mg}$ stored, plus $\$ 0.1-0.3 / \mathrm{Mg}$ for monitoring.

The ocean is already a major sink for anthropogenic $\mathrm{CO}_{2}$ and annually absorbs $7 \mathrm{Pg}$ from the atmosphere. ${ }^{19}$ However, the ocean is stratified, and $\mathrm{CO}_{2}$ absorbed from the atmosphere remains largely in the upper ocean due to the slow mixing of upper and lower ocean layers. The increased concentration of $\mathrm{CO}_{2}$ in the upper ocean has resulted in slight acidification, and the amount of $\mathrm{CO}_{2}$ absorbed each year by the upper ocean may be declining. ${ }^{20}$ Schemes for ocean sequestration therefore target the lower ocean and sediments, which have far greater volume and $\mathrm{CO}_{2}$ capacity. Several approaches for direct introduction of $\mathrm{CO}_{2}$ into the lower ocean have been proposed, among them shipborne diffusers that would deposit $\mathrm{CO}_{2}$ at a depth of about $1000 \mathrm{~m}$; fixed pipelines that would pump $\mathrm{CO}_{2}$ to a depth of $3000 \mathrm{~m}$, where it is denser than seawater and would sink; and injection in deep-sea sediments. ${ }^{21-23}$ Indirect approaches proposed include adding alkaline minerals to seawater to capture $\mathrm{CO}_{2}$ and fertilizing the ocean with iron to encourage growth of phytoplankton. ${ }^{24,25}$ For the direct approaches, injected $\mathrm{CO}_{2}$ would ultimately equilibrate between the ocean layers and with the atmosphere, but the process will take several hundred years, during which time $\mathrm{CO}_{2}$ will have been removed from the atmosphere. The IPCC concludes that there are no major technical barriers to ocean disposal, though it is projected to cost more than geological disposal at \$5-30/Mg injected. High concentrations of $\mathrm{CO}_{2}$ near injection sites are expected to have harmful effects on marine life, which engenders resistance to the approach.

$\mathrm{CO}_{2}$ in the air reacts slowly with alkaline minerals, and this reaction is an important component of rock weathering. Mineral carbonation is an accelerated version of the same process: $\mathrm{CO}_{2}$ would be reacted with pulverized minerals such as limestone and silicate rock. Reaction of these materials with $\mathrm{CO}_{2}$ is essentially irreversible, making it safe and permanent, and there is a vast amount of suitable rock for the process. The approach is in the development phase and faces several barriers. From the technical perspective, the key barriers include making the process faster and reducing its energy requirement. ${ }^{26}$ Mining, transporting, and processing the rock, along with performing the capture reaction itself, would involve significant energy consumption. In the best-studied case examined by the IPCC, wet carbonation with the mineral olivine for power plant capture, the mineralization process added a 30-50\% energy penalty on top of the capture penalty. The net cost of sequestration was about $\$ 80 / \mathrm{Mg}$ of $\mathrm{CO}_{2}$ stored, but an additional $27.5 \% \mathrm{CO}_{2}$ was generated, raising the effective cost to $\$ 110 / \mathrm{Mg}$ of $\mathrm{CO}_{2}$ stored. Overall plant energy use increased by $60-180 \%$. Another difficulty is 
that large-scale mineral carbonation would entail mining and pulverizing billions of tons of rock, reaction with $\mathrm{CO}_{2}$, and disposal of the residue. Depending on the type of rock, $1.6-4.7 \mathrm{Mg}$ of rock would be required per ton of $\mathrm{CO}_{2}$ captured, and the volume of the waste would be 1.5-2 times the volume of the rock. ${ }^{4}$

\section{A.3.2.2 Social Barriers}

Sequestration of $\mathrm{CO}_{2}$ on a large scale will require social and legal adaptation at state, national, and global levels. ${ }^{27-29}$ The absence of a regulatory framework with predictable rules and costs is a major barrier. In the absence of economic incentives, mandates, or restrictions on carbon emissions, CCS will not be implemented. Economic incentives could take the form of a tax credit for sequestration, a tax on emissions, or a market price for emissions under a cap-and-trade scheme. A dozen states have little or no potential for sequestration of $\mathrm{CO}_{2}(\leq 10 \mathrm{Tg}$ total), and whole states (as well as a number of nations) could be effectively stranded from geological sequestration options unless other states or nations could be enticed into accepting their $\mathrm{CO}_{2}$ (Ref. 17).

The risks and benefits of CCS are not fully understood, which makes establishing a regulatory framework challenging. Public resistance can be expected for policies that impose large costs (e.g., a $50-100 \%$ increase in the cost of electricity) with no immediate benefit and uncertain long-term benefit, particularly if restrictions, mandates and costs are not equitable at the global level. Likewise, local public resistance can be expected toward pipelines, sequestration sites, and other CCS infrastructure. Geological sequestration is accepted, though in some instances reluctantly, as a necessity by most U.S. environmental nongovernmental organizations (NGOs) ${ }^{30}$ Ocean disposal of $\mathrm{CO}_{2}$ is not allowed under international law and is strongly opposed by many NGOs. ${ }^{31}$

Several issues must be addressed, a major one being the ownership of sequestered $\mathrm{CO}_{2}$, with attendant liabilities and the responsibility for long-term monitoring. For any sequestration strategy, a high level of safe retention over a long period of time (centuries) is required. Monitoring must be performed continuously for decades, yet the responsibility for monitoring, and the standards by which it is to be performed, have not been established. Serious issues may develop many years after $\mathrm{CO}_{2}$ is initially sequestered, from release of $\mathrm{CO}_{2}$ to groundwater contamination to seismic events that might be blamed, rightly or wrongly, on sequestration. The ramifications of incidents could be international in scope. Large releases of stored $\mathrm{CO}_{2}$ could, for example, have an impact on treaty obligations, while seismic events and groundwater contamination could cause damage in neighboring countries. ${ }^{4}$

\section{A.3.2.3 Economic Barriers}

Cost is a major barrier to implementation of CCS, as is the uncertainty in costs and rewards that comes from lack of a predictable regulatory environment. Capture and compression of $\mathrm{CO}_{2}$ are expected to account for about $75 \%$ of the total cost, with the remainder going to transport, storage, and monitoring. ${ }^{32,33}$ Estimates of $\mathrm{CO}_{2}$ capture costs for power generation, cement manufacture, steel making, and refineries are similar. Available estimates fall within the range \$20-60/Mg (Refs. 4 and 34 ) but costs are sensitive to commodity prices. Electricity generation is the major application for CCS, and the IPCC's estimate for increased cost of electricity (COE) is $40-70 \%$ for new pulverized coal or natural gas combined cycle (NGCC) plants, plus the cost of transport and storage, with an $85 \%$ reduction in $\mathrm{CO}_{2}$ emitted per kilowatthour. ${ }^{4}$ For a new integrated gasification combined cycle (IGCC) coal plant, the estimate is a $20-55 \%$ increase in $\mathrm{COE}$ for $\mathrm{CO}_{2}$ capture. ${ }^{4}$ In a survey of studies on retrofit of $\mathrm{CO}_{2}$ capture to existing pulverized coal plants, the IPCC found a $149-291 \%$ increase in the $\mathrm{COE}$ for $\mathrm{CO}_{2}$ reductions per kilowatthour of $63-87 \%$ (Ref. 4). Cost estimates are subject to considerable uncertainty, and actual costs will depend strongly on the price of fuel at a given installation. Transportation is projected to cost $\$ 1-8 / \mathrm{Mg}$. Geological storage is projected to cost $\$ 0.5-$ $8 / \mathrm{Mg}$ (plus $\$ 0.1-0.3 / \mathrm{Mg}$ for monitoring); ocean storage, $\$ 5-30 / \mathrm{Mg}$; and mineral carbonation, $\$ 50$ 
100/Mg. ${ }^{4}$ Application of CCS to small sites may be difficult due to absence of transport infrastructure and economies of scale.

To be commercially viable, the cost of $\mathrm{CO}_{2}$ capture must be offset by other benefits. These benefits today include marketable products; in the future, they could include sequestration credits or avoidance of imposed carbon costs in the form of taxes or $\mathrm{CO}_{2}$ emissions permits. A large and potentially expandable market for $\mathrm{CO}_{2}$ lies in EOR, where $\mathrm{CO}_{2}$ is injected into mature oil fields to recover additional oil. In the United States, $50 \mathrm{Tg}$ of $\mathrm{CO}_{2}$ is used each year for this purpose, $80 \%$ of which is natural (geologic) and the remainder anthropogenic. ${ }^{35}$ A substantial part of the injected $\mathrm{CO}_{2}$ can remain underground, and it is estimated that with current practices, the stored $\mathrm{CO}_{2}$ is on average equivalent to $70 \%$ of the $\mathrm{CO}_{2}$ emitted from burning the recovered oil. In the future, it may be possible to increase this level to $100 \%$, making oil produced by EOR nearly carbon-neutral. ${ }^{35}$ A related possibility is to recover methane from unmineable coal seams by $\mathrm{CO}_{2}$ injection. ${ }^{36}$

\section{A.3.3 Potential to Reduce $\mathrm{CO}_{2}$ Emissions by 2050}

The important criterion for CCS technologies is avoided $\mathrm{CO}_{2}$, which is distinct from captured $\mathrm{CO}_{2}$. CCS technologies typically target $90 \%$ capture. However, they require the consumption of additional fuel for the same output of product (e.g., electricity) and thereby generate more $\mathrm{CO}_{2}$, only $90 \%$ of which is captured. The result is that net $\mathrm{CO}_{2}$ emissions are reduced to less than $90 \%$. For electric generation, the IPCC projections for $\mathrm{CO}_{2}$ avoided are around $85 \%$. Further reductions will result from fugitive emissions (leaks) and uncaptured, indirect emissions. The latter include emissions associated with extra fuel production and transport; extra scrubbing; $\mathrm{CO}_{2}$ transport and storage, infrastructure construction, and maintenance; solvent manufacture; and hazardous waste processing. It is hard to quantify the magnitude of indirect emissions, but they are substantial. Several studies indicate that for coal as a fuel, indirect emissions are about $10 \%$ of combustion emissions, with the main components being emissions associated with mining and transport, methane emitted from coal mining (expressed as $\mathrm{CO}_{2}$ equivalents toward global warming potential), and emissions associated with limestone manufacture and transport. ${ }^{37-39}$ If indirect emissions are $10 \%$ of combustion emissions, and $30 \%$ more fuel is used, then $90 \%$ capture of combustion emissions produces $76 \%$ avoidance.

For this study, we assume that $85 \%$ avoidance of $\mathrm{CO}_{2}$ emissions is achievable through CCS. In the hypothetical extreme where all large stationary sources were fitted with CCS, it would be possible to reduce $\mathrm{CO}_{2}$ emissions in the United States by $2.3 \mathrm{Pg} /$ year. However, CCS is not ready to deploy, and will not be until 2020 ( \pm 5 years). Electric generation is the prime target for CCS, and the design life of fossil power plants is typically around 40 years. It is often economical to extend the plant life another 10-20 years, but if there is a cost to carbon emissions, it could likewise become economical to accelerate turnover in favor of more efficient plants, or plants incorporating CCS. The average age of coal-fired power plants in the United States is about 40 years, indicating the possibility for largescale turnover in the coming decades, although plant lifetimes can be extended substantially by continuous upgrading. During the 1970s (the heyday of large coal-fired power plants), an average of 25 coal-fired power plants entered service each year, including 10-15 large ( $\geq 500 \mathrm{MWe}$ ) plants, with a total capacity of $125 \mathrm{GWe}$. With a return to the rate of construction that persisted during that decade, all U.S. coal-fired generating capacity could be replaced between 2020 and 2050.

There is no agreed-upon timetable in place for deployment of CCS, and different groups offer differing projections on how quickly CCS may be implemented depending primarily on the timing and scale of climate policy. One of the most aggressive scenarios has been put forth by Shell, in which $90 \%$ of power generation in the developed world would be equipped with $\mathrm{CCS}^{40}{ }^{4}$ The European Commission's World Energy Technology Outlook projects that $66 \%$ of fossil electric generation is equipped with $\mathrm{CCS}^{41}$ A slightly less aggressive level of $50 \%$ is anticipated by the World Business Council for Sustainable Development. ${ }^{42}$ The IEA has generated several different scenarios; one of these, ACT (achievable with current technology), targets global stabilization of $\mathrm{CO}_{2}$ 
emissions in 2050 and considers abatement options costing up to $\$ 50 / \mathrm{Mg}$ of $\mathrm{CO}_{2}$. In this scenario, CCS is applied to $900 \mathrm{GW}$ of global power generation. The IEA "Blue" scenario is more aggressive, targeting a $50 \%$ reduction in global $\mathrm{CO}_{2}$ emissions through use of abatement options costing up to $\$ 200 / \mathrm{Mg}$. In this scenario, CCS is applied to $1,500 \mathrm{GW}$ of power generation. ${ }^{43}$

\section{A.3.4 Potential to Reduce Oil Use by 2030}

Few scenarios project substantial deployment of CCS by 2030. Regardless of deployment pace, CCS will not greatly reduce oil use, though an abundant supply of $\mathrm{CO}_{2}$ from capture, coupled with high oil prices, could lead to additional domestic oil production through EOR. Little petroleum is used to generate electricity, and liquid petroleum products for electricity generation are used primarily in diesel generators, which are not immediate candidates for CCS. To the extent that CCS is employed at larger petroleum-burning installations, it would increase the amount of petroleum used due to the added energy need of capture.

\section{A.3.5 Interactions with Other Technologies}

CCS is linked to a number of different technologies. It is most directly tied to electricity production. CCS technologies will be developed simultaneously with advanced generating technologies and may have a considerable impact on technology choices for generation (e.g., pulverized coal vs IGCC). CCS coupled with biomass for electricity generation could produce negative net GHG emissions. If the transportation sector becomes more heavily electrified, CCS will have increased potential for $\mathrm{CO}_{2}$ abatement. It is also tied strongly to advanced fossil fuels through the use of $\mathrm{CO}_{2}$ for EOR and coal-bed methane. Hydrogen is produced primarily by gasification of natural gas or coal and could be produced through gasification of biomass. To the extent that hydrogen becomes a major transportation fuel, CCS could become an important abatement technology for the transportation sector. Finally, CCS is tied to industrial energy efficiency; its application to industrial processes will make them more energy-intensive while reducing $\mathrm{CO}_{2}$ emissions.

\section{References}

1. Energy Information Administration, Emissions of Greenhouse Gases Report, DOE/EIA-0573(2007), U.S. Department of Energy, December 2008.

2. IEA Greenhouse Gas R\&D Programme, $\mathrm{CO}_{2}$ Emissions Database (January 2008 update), http://www.co2captureandstorage.info/co2emissiondatabase/co2emissions.htm (accessed July 7, 2009).

3. National Energy Technology Laboratory, Technologies: Carbon Sequestration, http://www.netl.doe.gov/technologies/carbon_seq/index.html (accessed July 7, 2009).

4. IPCC Special Report on Carbon Dioxide Capture and Storage, ed. B. Metz et al., Intergovernmental Panel on Climate Change, Cambridge University Press, New York, 2005, http://www.ipcc.ch/ipccreports/srccs.htm (accessed July 7, 2009).

5. IEA Greenhouse Gas R\&D Programme, International Test Network for $\mathrm{CO}_{2}$ Capture: Report on a Workshop, PH3/33, International Energy Agency, 2000.

6. IEA Greenhouse Gas R\&D Programme, Building the Cost Curves for $\mathrm{CO}_{2}$ Storage, Part 1: Sources of $\mathrm{CO}_{2}$, PH4/9, International Energy Agency, July 2002.

7. R.R. Bottoms, "Process for Separating Acidic Gases," U.S. Patent 1,783,901, 1930.

8. B. R. Strazisar, R. R. Anderson, C. M. White, Energy \& Fuels 17, 1034-1039 (2003).

9. Basin Electric Power Cooperative, "International $\mathrm{CO}_{2}$ Sequestration Success Story," http://www.basinelectric.com/Energy_Resources/Gas/CO2_Sequestration/(accessed July 7, 2009).

10. J. W. Phair, S. P. S. Badwal, Sci. Technol. Adv. Mat. 7, 792-805 (2006).

11. Carbon Sequestration Technology Roadmap and Program Plan 2007, U.S. Department of Energy, Office of Fossil Energy, National Energy Technology Laboratory, 2007, http://www.netl.doe.gov/technologies/carbon_seq/refshelf/project\%20portfolio/2007/2007Roadmap.pdf (accessed July 7, 2009). 
12. G. S. Esber III, "Carbon Dioxide Capture Technology for the Coal-Powered Electricity Industry: A Systematic Prioritization of Research Needs," thesis, Massachusetts Institute of Technology, Cambridge (2006).

13. U.S. National Institute of Occupational Safety and Health, "Carbon Dioxide: IDLH Documentation," http://www.cdc.gov/niosh/idlh/124389.html (accessed July 10, 2009).

14. U.S. Environmental Protection Agency, Inventory of U.S. Greenhouse Gas Emissions and Sinks: 19902004, USEPA 430-R-06-002, Washington, DC, 2006.

15. V. Vandeginste, K. Piessens, Int. J. Greenhouse Gas Control. 2, 571-581 (2008).

16. P. W. Parfomak, P. Folger, Pipelines for Carbon Dioxide $\left(\mathrm{CO}_{2}\right)$ Control: Network Needs and Cost Uncertainties, RL34316, Congressional Research Service, 2008, http://assets.opencrs.com/rpts/RL34316_20080110.pdf.

17. National Energy Technology Laboratory, Carbon Sequestration Atlas of the United States and Canada, 2nd ed., 2008, http://www.netl.doe.gov/technologies/carbon_seq/refshelf/atlasII/atlasII.pdf (accessed July 10, 2009).

18. S. Bachu, Prog. Energy Combust. Sci. 34, 254-273 (2008).

19. C. Le Quere et al., Tellus B. 55, 649-656 (May, 2003).

20. U. Schuster, A. J. Watson, J. Geophys. Res. Oceans 112, 10 (2007).

21. M. Ozaki, Waste Manage. 17, 369-373 (1998).

22. C. Marchetti, Climatic Change 1, 59-68 (1977).

23. K. Z. House, D. P. Schrag, C. F. Harvey, K. S. Lackner, Proc. Natl. Acad. Sci. USA 103, 12291-5 (2006).

24. H. S. Kheshgi, Energy 20, 915-922 (1995).

25. G. H. Rau, K. Caldeira, Energy Convers. Manage. 40, 1803-1813 (1999).

26. E. H. Oelkers, S. R. Gislason, J. Matter Elements 4, 333-337 (2008).

27. D. M. Reiner, H. J. Herzog, Energy 29, 1561-1570 (2004).

28. G. Marland, K. Fruit, R. Sedjo, Environ. Sci. Policy 4, 259-268 (2001).

29. J. P. Nicot, I. J. Duncan, Environ. Sci. Policy 11, 14-24 (2008).

30. G. Wong-Parodi, I. Ray, A. E. Farrell, Environ. Res. Lett. 3, 024007 (2008).

31. P. Verma, J. C. Stephens, "Environmental Advocacy Groups' Perspectives on Carbon Capture and Storage," EIC Climate Change Technology, 2006, IEEE , 2007 (doi: 10.1109/EICCCC.2006.277270)

32. J. David, thesis, Massachusetts Institute of Technology (May 2000).

33. S. J. Benson, F. M. Orr Jr., MRS Bull. 33, 303-305 (2008).

34. J. J. Dooley et al., Carbon Dioxide Capture and Geologic Storage: A Core Element of a Global Energy Technology Strategy to Address Climate Change, Battelle Joint Global Change Research Institute, 2006, http://www.pnl.gov/gtsp/docs/ccs_report.pdf.

35. V. Kuuskraa, R. Ferguson, Storing $\mathrm{CO}_{2}$ with Enhanced Oil Recovery, DOE/NETL-402/1312/02-07-08, National Energy Technology Laboratory, 2008.

36. C. M. White et al., Energy Fuels 19, 659 (2005).

37. N. A. Odeh, T. T. Cockerill, Energy Convers. Manage. 49, 212220 (2008).

38. H. Hondo, Energy 30, 2042-2056 (2005).

39. P. L. Spath, M. K. Mann, D. R. Kerr, Life Cycle Assessment of Coal-Fired Power Production, NREL/TP570-25119, National Renewable Energy Laboratory, Golden, CO, 1999.

40. "Shell Energy Scenarios to 2050," Royal Dutch Shell, PLC, 2008, http://wwwstatic.shell.com/static/aboutshell/downloads/our_strategy/shell_global_scenarios/SES\%20booklet $\% 2025 \%$ 20of\%20July\%202008.pdf.

41. World Energy Technology Outlook-2050, European Commission, 2008, http://ec.europa.eu/research/energy/pdf/weto-h2_en.pdf.

42. Pathways to 2050 - Energy \& Climate Change, World Business Council for Sustainable Development, 2005, http://www.wbcsd.org/web/publications/pathways.pdf.

43. International Energy Agency, Energy Technology Perspectives 2008: Summaries and Strategies to 2050, Organisation for Economic Cooperation and Development, Paris, 2008. 


\title{
A.4 EFFICIENT ELECTRICITY GENERATION AND DISTRIBUTION
}

\author{
Philip R. Boudreaux \\ Robert Standaert
}

\section{A.4.1 Description of Efficient Electricity Generation and Distribution}

The U.S. has about $968 \mathrm{GW}$ of generating capacity (1) and produced 4.2 trillion kwh (14.2 quads) of net electricity in 2007 (2). Primary energy sources for electric generation are dominated by coal, natural gas and nuclear, with the remainder coming from hydroelectric, oil and non-hydro renewables (Figure 1). Fossil fuels collectively accounted for 3 trillion kWh (10.2 Quads) of electricity in 2007, nuclear for 0.8 trillion $\mathrm{kWh}$ (2.8 Quads) and renewables for 0.4 trillion $\mathrm{kWh}$ (1.2 Quads). Primary energy used for the 14 Quads of net electricity was 42 Quads, out of a total of 100 Quads used across all sectors. Because electric is such a large sector, and the net conversion efficiency of primary energy to electricity is not near achievable limits, improvements in net efficiency would have a major impact on U.S. primary energy consumption and greenhouse gas emissions. Moreover, electricity use is projected to grow significantly. The Energy Information Administration projects in its reference case that by 2030 , net generation will be 4.8 trillion $\mathrm{kWh}$ (16.4 Quads) per year (1).

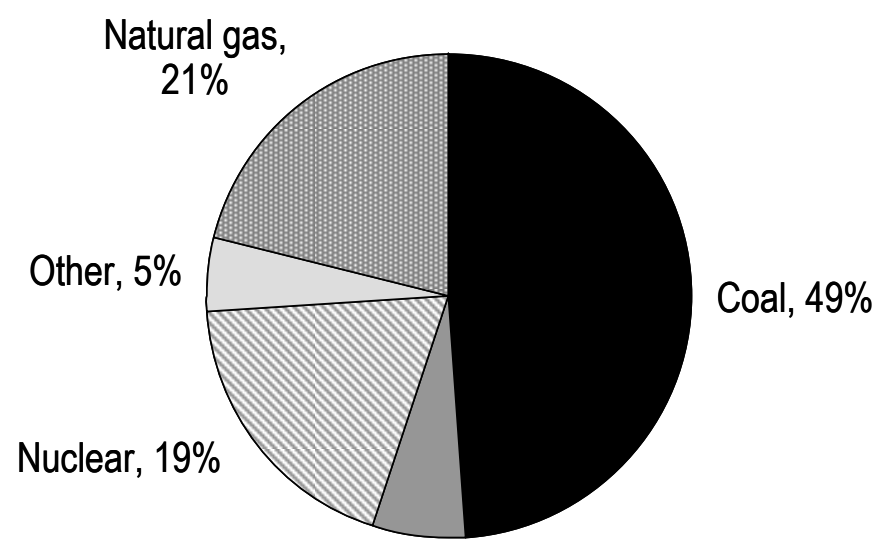

Hydroelectric, 6\%

A.4.1. Total U.S. electric generation in 2007 broken up by source. The "Other" category includes other gases, petroleum, biomass, geothermal, solar, and wind.

The main opportunity for efficiency improvement in the electric sector lies at the generation level (converting primary energy to electricity). While this statement is true of all generating technologies, the present report will focus on thermal efficiency for fossil fuel-based generation, where substantial reductions in $\mathrm{CO}_{2}$ emissions can be realized. Electrical transmission and distribution (T\&D) losses are smaller but still significant. In 2007, T\&D losses totaled 300 billion kwh, or about $7 \%$ of net generation for the U.S. (2), with $60 \%$ of the total due to lines and $40 \%$ due to transformers (3). These losses consume 3 Quads of primary energy and lead to $170 \mathrm{Mmt}$ of $\mathrm{CO}_{2}$ emissions, so even incremental improvements can have a significant impact.

It would certainly be possible to realize gains by upgrading the current T\&D network to state-ofthe-art technology. However, there is considerable impetus to restructure the T\&D network into what is termed a smart grid of national scope. Such a revamped grid would integrate conventional 
generation, renewable generation, distributed generation and storage systems, while also modulating demand. A successful system of this nature could displace a significant amount of fossil-based electric generation. It could also deliver indirect efficiency improvements for fossil electricity sources by shifting production to the most efficient plants, minimizing output swings and reducing use of inefficient peaking generators.

Without such grid improvements, the full benefits of renewables and advanced generating technologies will not be realized. Natural gas-fired generators operate most efficiently at full load, and their great potential efficiency cannot be fully realized at light load. Advanced coal plants have less operational flexibility than their traditional counterparts. Supercritical (SC) and ultrasupercritical (USC) pulverized coal plants operate at high temperature and do not cycle well. The consequence of frequent cycling with these plants is decreased plant life and reduced efficiency, which defeats the purpose of building the plants (4). Another advanced coal technology, integrated gasificationcombined cycle (IGCC), requires a period of several days for a cold start and has substantially reduced efficiency at low load, making IGCC plants suitable for base-load generation only.

\section{A.4.2 Barriers to Realizing Full Potential}

Increasing the efficiency of electric generation is a broad task since different technologies are used to convert different fuels to electricity. Not only do different fuels have different efficiencies, but the projected increase in efficiency is different for each fuel type. One constant in all areas is the need for improved materials, whether for boilers, turbine blades, fuel cells or superconductors. An assessment of prospects and barriers, broken down by major fuel source is as follows.

\section{A.4.2.1 Coal}

Coal is the dominant primary energy source for electricity in the United States. The current fleet average for U.S. coal-fired power plants is $33-34 \%$ net thermal efficiency (5), ${ }^{2}$ and there is considerable room for improvement through advanced generation technologies. The current coal fleet is aging, and essentially complete turnover could be accomplished by 2050 . Aside from technology, a number of barriers are inhibiting the construction of new or replacement coal power plants. Cost is a big one, as it will be extremely expensive to replace the coal fleet. Power plant construction costs have escalated dramatically in the last five years for most technologies (coal, wind, nuclear and geothermal) due to sharply rising costs for concrete, steel and other metals (especially copper and nickel). Current estimates for a new coal-fired plant construction are around $\$ 3,000 / \mathrm{kW}$ for conventional coal and $\$ 4,000 / \mathrm{kW}$ for IGCC coal (6). At these prices, the cost for replacing the U.S. coal fleet (336 GW) becomes astronomical (over one trillion dollars). Prices will increase further for advanced technology plants, which use more exotic materials, and if CCS is implemented. Capital cost increases for carbon dioxide capture at electric plants are estimated by the IPCC to be $44-74 \%$ for pulverized coal (PC) plants, 19-66\% for new integrated gasification-combined cycle (IGCC) coal plants, and $64-100 \%$ for natural gas-combined cycle (NGCC) plants (7). Many planned new coal plants are being cancelled or postponed in the face of political opposition, rising costs, uncertainty about future policy on carbon dioxide emissions, and uncertainty about the technical, economic and political prospects for CCS.

Nonetheless, technology for coal-based power generation continues to advance, with promise of considerable reduction in emissions of $\mathrm{CO}_{2}$, as well as fugitive emissions of methane from coal mining. Advanced coal technologies can be divided into two main groups.

\footnotetext{
${ }^{2}$ Efficiencies in this report are quoted on a higher heating value (HHV) basis. Published figures using a lower heating value (LHV) basis were multiplied by 0.955 for coal and 0.90 for natural gas. Lowe, A. (1998).

"Comparing $\mathrm{CO}_{2}$ Emissions for Power Generation in NSW. Australian Coal Review, Issue 5 (April, 1998)
} 
Pulverized coal (PC) systems burn coal directly for heat to power steam turbines, and the vast majority of current coal-fired plants are of this type. Efficiency improvements in steam-turbine plants come primarily from increased steam temperature and pressure, though also from other refinements. Traditional plants operate with steam at about $538^{\circ} \mathrm{C} / 2400 \mathrm{PSI}$, supercritical (SC) steam plants operate at around $565{ }^{\circ} \mathrm{C} / 3500 \mathrm{PSI}$, and ultra-supercritical (USC) plants at $593{ }^{\circ} \mathrm{C} / 4500 \mathrm{PSI}$ and up. SC technology is mature, with operating efficiencies of up to $40 \%$. USC plants operate in Europe and Japan with efficiencies up to about $43 \%$. A new design, targeting steam conditions of $700{ }^{\circ} \mathrm{C} / 5000$ PSI, is under development in Europe and targets 47-48\% efficiency, while the U.S. 2008 Annual Energy Outlook anticipates $46 \%$ efficiency by 2025 . A recent analysis concluded that a steam temperature of $775{ }^{\circ} \mathrm{C}$, with a net efficiency of $50 \%$, is reasonably achievable by 2020 , and that further improvement to $52 \%$ efficiency is reasonably achievable by 2050 (8). The main impediment to progress is lack of boiler and turbine materials that will withstand the extreme conditions.

Integrated gasification-combined cycle (IGCC) power plants gasify feedstock, such as coal or biomass, to a mixture of hydrogen, carbon monoxide and carbon dioxide. The gas mixture (synthesis gas, or syngas) is cleaned and burned in a combustion turbine (Brayton cycle) that drives a generator, and the hot turbine exhaust is used to provide heat for a steam turbine (Rankine cycle) that generates additional power. IGCC is a recent and immature technology. There are only two, relatively small (260 MWe) IGCC plants operating in the U.S., though 6 new plants are in progress and an additional 22 are proposed (9). IGCC plants are believed to be capable of greater efficiency than PC plants, and to be more amenable to carbon dioxide capture, though neither of these potential benefits has been realized. IGCC also offers several other benefits, largely realized, that are driving its development (10). One is reduced emission of pollutants $\left(\mathrm{SO}_{2}, \mathrm{NO}_{\mathrm{x}}, \mathrm{CO}\right.$, mercury and particulates). Another is that IGCC plants produce less solid waste and use less water.

Though current IGCC plants have efficiencies comparable to an SC coal plant (37.5\% and 39.7\% for the U.S. units), it is believed that they can ultimately be made 3\% (by 2020) to 5\% (by 2050) more efficient than PC plants $(11,8)$. Current performance targets reflect this belief. The Japanese Low Carbon Technology Plan targets an IGCC efficiency of $57 \%$ by 2050 (12), while the U.S. DOE is targeting an efficiency range of $50-60 \%$ by 2020 (3). The drawbacks to IGCC start with cost. In comparison to PC plants, capital costs are higher (about 20\%), maintenance requirements are higher, availability is lower, and startup time is longer. Key technical barriers to greater efficiency include more efficient air separation, improved high-temperature gas cleanup, and higher turbine inlet temperature. Improved materials and designs are needed for gas turbines optimized for hydrogen-rich syngas fuel (13).

Hopes for even greater efficiency with coal center on incorporation of solid oxide fuel cells (SOFC) into the cycle, such that the fuel cell serves as the primary combustor for a gas turbine. In this hybrid fuel cell-gas turbine approach, most of the syngas is oxidized in a pressurized fuel cell operating at $800-1000^{\circ} \mathrm{C}$. Some of the fuel's energy is converted directly to electricity by the fuel cell, while the remainder is converted to heat. Hot gas exiting the fuel cell, with additional boost from combustion of unconsumed or supplemental syngas, drives a gas turbine to produce more electricity. Efficiency goals for the integrated gasification-fuel cell (IGFC) hybrid plants are as high as $65 \%$ by 2050 (12). Fuel cell and hybrid approaches will be discussed further in the following section.

A third approach to advanced coal is pressurized fluidized bed combustion (PFBC) (14), which combines some aspects of PC, NGCC and IGCC plants. Atmospheric pressure fluidized bed combustion (AFBC) boilers for coal are well developed, though they came to maturity in the 1980s after the peak in construction of coal-fired plants in the U.S., and they have consequently made little penetration into the U.S. electric sector (15). Increasing pressure will allow fluidized bed combustors to take advantage of thermodynamically efficient combined cycles. In one incarnation of the PFBC approach, a pressurized, fluidized bed of sorbent (e.g., limestone) serves as a combustor for pulverized coal. In analogy to NGCC, hot, high-pressure gas exiting the combustor drives a gas 
turbine, and the turbine exhaust powers a steam cycle. In a second incarnation, the coal is first gasified into syngas and char. The syngas is used, as in IGCC, to power a gas turbine-steam combined cycle, while the char is burned in the fluidized bed to provide heat for steam and to pre-heat the turbine combustion gas. Fluidized bed combustors have the advantage that they be used with high-ash coal and biomass, and they offer reduced $\mathrm{SO}_{2}$ and $\mathrm{NO}_{\mathrm{x}}$ emissions compared to conventional coal combustors. Several demonstration systems have been built (16), and the National Energy Technologies Laboratory is targeting $\geq 50 \%$ ultimate efficiency for PFBC systems.

\section{A.4.2.2 Natural Gas}

Behind coal, natural gas is the largest primary energy source for electricity generation, and it is the least carbon-intensive of fossil fuels (approx $450 \mathrm{~g} \mathrm{CO}_{2} / \mathrm{kWh}$, versus 975 for coal). Its use has been growing steadily, from 13\% of net generation in 1996 to $22 \%$ in 2007 (5). There are two conventional types of natural gas generators. Combustion turbine (CT) generators use the gas as fuel for an internal-combustion gas turbine that drives the generator. CT generators can be stopped and started rapidly, making them ideal for peaking and backup generation. Their efficiency is modest, typically in the range of $20-35 \%$ (17), though the latest units, such as the General Electric LMS100, can reach $42 \%$ efficiency at full power, or $35 \%$ at half power. Gas turbines produce high-temperature exhaust, which can be exploited for CHP, with $80-85 \%$ recovery of energy. Another way to exploit the waste heat in the exhaust is to use it to power a steam cycle in a manner directly analogous to IGCC. Such natural gas combined cycle (NGCC) units provide the most efficient form of electrical generation currently available, with net thermal efficiencies up to about 54\% (18). Efficiencies at this level are realized only in the largest systems (e.g., $>300 \mathrm{MW}$ ), and only at full power, such that average efficiencies may be slightly less. The main source of improvement for NGCC has been and will continue to be increasing the turbine inlet temperature. The latest systems operate in the range $1400-1500{ }^{\circ} \mathrm{C}$, and one manufacturer (Mitsubishi Heavy Industries) recently completed development of a $1600{ }^{\circ} \mathrm{C}$ unit. Further increases, e.g., to $1700{ }^{\circ} \mathrm{C}$, are expected to yield efficiencies in the range $56-59 \%$ (19). The key challenges in reaching these goals include improved materials and coatings that can withstand the temperature, improved cooling for the turbine blades, and minimizing $\mathrm{NO}_{\mathrm{x}}$ formation as temperature increases.

Further efficiency gains, up to $70 \%$ for natural gas-fired generation, are targeted by DOE's Vision 21 roadmap (20) and others. To reach this level, hybrid natural gas fuel cell-gas turbine power plants (NGFC-GT) are the most promising candidate at present. In this approach, which is directly analogous to IGFC, natural gas is oxidized in a pressurized fuel cell operating at $800-1000{ }^{\circ} \mathrm{C}$, providing electricity directly, while hot exhaust and combustion of unspent fuel drive a gas turbine generator. Natural gas-powered simple fuel cell generators are commercially available in sizes up to the $2 \mathrm{MW}$ range. Most of these units use either phosphoric acid (PA) or molten carbonate fuel cells (MC), which operate at 35-45\% or $40-50 \%$ efficiency, respectively. Both types operate at relatively high temperature $\left(200{ }^{\circ} \mathrm{C}\right.$ for PA, $650-700{ }^{\circ} \mathrm{C}$ for MC) and are thus well-suited for CHP applications, where about $85 \%$ overall thermal/electric efficiency can be achieved. For NGFC-GT generators, even higher temperature is desirable, and solid oxide fuel cells (SOFC) are generally targeted. Simple SOFC and hybrid SOFC-GT generators are in the demonstration phase, with barriers to commercial deployment being primarily cost and long-term reliability. Further research is needed particularly in materials used for anodes, cathodes, electrolyte and interconnects (21).

Natural gas (predominantly methane) is a particularly convenient fuel for fuel cells, but a variety of other fuels can be used, including syngas, biogas, higher hydrocarbons (propane, gasoline or diesel), and alcohols (methanol and ethanol). The intrinsic fuel for most fuel cells is hydrogen. Other fuels, including methane, must be reformed to extract hydrogen from them, a process that may occur in an external reformer, as for PA and proton-exchange membrane (PEM) fuel cells, or internally for the higher-temperature fuel cells (MC and SO). Fuel cells can be poisoned to different degrees by 
contaminants in the fuel, notably carbon monoxide and sulfur. Natural gas as delivered is a clean fuel, having been sweetened to remove sulfur compounds and acids in processing, but some of the others need on-site cleanup to be suitable for fuel cells, and improved technologies are needed.

\section{A.4.2.3 Transmission and Distribution}

Electricity transmission and distribution also lead to energy losses (about 7\%, or 300 billion $\mathrm{kWh}$ in 2007) that have the potential to remedied to an extent. There are both existing technologies and emerging ones that can improve the situation significantly. Below, existing technologies are discussed separately for transformers and high-voltage transmission, followed by a description of hightemperature superconductor (HTS) technology, which could impact both areas.

\section{A.4.2.4 Transformers.}

Existing transformers have efficiencies in the range 95-99+\% (22). However, essentially all electricity is transformed two or more times, and cumulative losses are large (on the order of 120 billion kwh, or 0.4 Quad). In 2007, DOE published new energy efficiency requirements for distribution transformers that call for efficiencies in the range of 98.40-99.44\% for liquid-immersed distribution transformers and 97.5-99.31 for dry-type transformers (23). There are an estimated 50 million distribution transformers in the U.S. (24), and transformers have a life expectancy of about 30 years. Thus, turnover and resulting efficiency gains will be gradual but will have a substantial impact in the long term. The new regulations are projected to deliver annual savings of about 0.058 Quads (17 billion kwh) of electricity by 2038 , equivalent to nearly $1.9 \mathrm{GW}$ of generation capacity offset. The current technical limit (termed trial standard level 6) would allow higher savings by 2038, about 0.22 Quad/year, which is equivalent to $7.2 \mathrm{GW}$ of generation capacity offset. Implementing the technical limit was judged to be cost-prohibitive, potentially infeasible due to an insufficient prodution capacity for amorphous steel ribbon used in advanced cores, and likely to have a strong, adverse impact on the transformer industry. As electricity prices rise, advanced materials become more accessible and manufacturers retool, a higher standard could be implemented.

\section{A.4.2.5 High-voltage Transmission.}

The U.S. Climate Change Technology Program has identified three main technologies to improve the efficiency of transmission: high-voltage DC (HVDC) transmission, high-strength composite overhead conductors, and HTS materials (3). In addition, large-scale energy storage devices and realtime grid management are seen as essential technologies.

HVDC transmission is an old technology, but one that has largely occupied niche markets. Renewed interest in the technology stems in large part from the lower resistive losses for DC in comparison to AC. DC transmission can use fewer and smaller conductors because multiple phases need not be carried, and there is no skin effect with DC. Conversion of existing AC lines to DC would increase capacity, and because of its compactness, DC is well-suited for underground cables. HVDC is especially appropriate for remote energy sources (e.g., rural wind farms), and it has been proposed that a system of HVDC interconnectors on the AC grid could help average intermittent sources over a larger area. Moreover, HVDC can be used to interconnect asynchronous grids, facilitating power trade, and can potentially help stabilize an AC network (25).

The main disadvantage of $\mathrm{DC}$ is that it must be converted to $\mathrm{AC}$ for voltage transformation and end use. Conversion equipment is expensive, and conversion losses are greater than transformer losses, such that the lower cost of conductors and higher transmission efficiency are negated when short distances are involved. Integration of HVDC into the AC network will require careful engineering to assure reliability, and there are a number of technological improvements identified in reference 25 that would spur more widespread adoption. These include lower-cost, higher efficiency 
converters; low-cost AC harmonic filters to control harmonics induced in the AC networks by converters; and improved monitoring and control systems.

Both AC and DC transmission will benefit from improved transmission cable. A recent development in this area is composite-core, low-sag transmission conductors (26). These cables have a power capacity up to three times higher than conventional conductors over the same right-of-way and have lower resistive losses. Due to their higher ampicity and mechanical strength, upgraded cables of this nature can reduce brownouts and blackouts in addition to reducing resistive losses on the grid.

\section{A.4.2.6 High-Temperature Superconducting (HTS) Materials.}

Superconductors have almost no electrical resistance and have attracted great interest for electrical transmission lines and transformers, where they have reached development to demonstration phase. It is estimated that widespread use of HTS equipment could reduce transmission and distribution losses by up to about $25 \%$ in the U.S, or about $2 \%$ of total electric output (27). A recent analysis suggests that similar savings, about $1.2 \%$ of total electric output, can be realized in the EU (28).

In addition to reduced energy losses, HTS materials promise other benefits. For transmission lines, a significant advantage is increased power capacity (on the order of 5 times) for a given size of duct or right-of-way. This property allows, for example, increased power density in crowded urban areas. An additional advantage is the ability to carry higher current at a lower voltage, which can potentially eliminate transformer steps. For transformers, benefits include smaller size, less vibration, less heat dissipation and absence of flammable oils. Traditional superconductors operate at liquid helium temperature $(4 \mathrm{~K})$, which is costly, energy intensive and difficult to maintain. Hightemperature superconductors operate at liquid nitrogen temperature $\left(77 \mathrm{~K}\right.$, or $\left.-196{ }^{\circ} \mathrm{C}\right)$. Though cryogenic equipment is still required, the cost for liquid nitrogen is far less than for liquid helium, and the potential benefits are great. Fabricating HTS materials into wires with high current capacity has been challenging, but substantial progress has been made. The first HTS transmission line, $600 \mathrm{~m}$ long, entered commercial service in June, 2008, with the Long Island Power Authority (29).

Several barriers prevent more widespread implementation of HTS technology. Cost is a major one, though second generation $(2 \mathrm{G})$ cables made with silver-free YBCO (yttrium-barium-copper oxide) are being developed that will be significantly cheaper (30). An intrinsic limitation of current materials is that they function best with direct current (DC) and have significantly higher resistive loss with alternating current (AC). This factor reduces the benefits in transformer applications and requires conversion to $\mathrm{DC}$ to realize the maximum benefit in transmission. For transmission, a major problem is the difficulty of maintaining cryogenic temperatures over long distances. Other challenges include preventing fault current conditions and developing methods for expeditious repair and splicing of cable. For transformers, there is need for improved dielectric materials for winding insulation, and for preventing over-current that could lead to runaway heating.

\section{A.4.3 Potential to Reduce U.S. GHG emissions by 2050}

It is difficult to quantify potential savings, as they would depend on a large number of factors, particularly growth of nuclear and renewables, implementation of CCS, electrification of the transportation sector, and efficiency measures on the demand side. Many scenarios are possible, but in any of them, increased energy efficiency in the electric power sector by itself would have a substantial impact on GHG emissions. A useful reference case contemplates $1 \%$ annual growth in electric demand, as anticipated in the Annual Energy Outlook 2008 reference case, with coal and natural gas maintaining their share with respect to percent of net generation. Under this business-asusual scenario, total electric consumption would grow from 4.2 Quads in 2007 to 6.3 Quads in 2050, a $53 \%$ increase. Considering just the coal and natural gas contributions, $\mathrm{CO}_{2}$ emissions would grow 
from $2.3 \mathrm{Gmt} / \mathrm{yr}$ to $3.5 \mathrm{Gmt} / \mathrm{yr}$ at today's efficiency levels. If overall efficiency were improved $15 \%$ in absolute terms (from 33 to $48 \%$ efficiency for coal, and from 40 to $55 \%$ for gas), emissions would be reduced to $2.5 \mathrm{Gmt} / \mathrm{yr}$. In other words, generation efficiency gains would abate about $1 \mathrm{Gmt} / \mathrm{yr}$ of $\mathrm{CO}_{2}$ emissions that would otherwise have been emitted due to rising demand for electricity.

Assuming transmission and distribution losses could be halved, an additional $90 \mathrm{Mmt} / \mathrm{yr}$ could be saved.

\section{A.4.4 Potential to reduce oil use by 2030}

Petroleum has a small (1.6\%) and declining role in electricity generation in the U.S. overall. However there are regional variations, the most extreme of which is in Hawaii, where petroleum is the dominant primary energy source for electricity. The main petroleum derivatives used for largescale electricity generation, such as petroleum coke and residual fuel oil, are unsuitable for transportation uses. The demand overlap between electricity and transportation is largely confined to distillate fuel oil (DFO, e.g., Diesel fuel). An annual total of 16 million bbl of DFO was used for electricity generation in 2007 (2.4 million of it in Hawaii), compared to a daily total of 14 million bbl of refined petroleum for transportation. Thus, electricity generation consumes only $0.3 \%$ of potential transportation fuel.

In the electric sector, DFO is used principally for peaking, backup, portable and remote generation. Utilities retain fewer than a dozen oil-fired steam plants, all built in the period 19411973, with the two largest slated for retirement by 2012. There are almost 500 combustion-turbine installations in the range 1-200 MW in the U.S., and almost 3000 internal combustion engine installations in the range $0.1-12.5 \mathrm{MW}$. It is hard to estimate how much petroleum consumption by these installations could be eliminated by 2030. Many of the larger installations are dual-fuel systems that can use either natural gas or DFO, so generation in those cases could immediately be shifted to natural gas. The overall capacity factor (percent of actual output versus potential output) for petroleum generation is only $13 \%$ (5), indicating that much of the infrastructure is lightly used. The cost/benefit ratio for replacing or retrofitting such infrequently used generators is likely quite high.

\section{A.4.5 Interactions with other technologies}

Electricity is a central player in the energy sector that is connected to many other technologies. These include nuclear power, solar power, carbon dioxide capture and sequestration, industrial energy efficiency, building energy efficiency, biomass, electric drive vehicles, and advanced fossil fuels.

\section{References}

1. U.S. Department of Energy, Energy Information Agency (EIA), Annual Energy Outlook 2009 (prerelease). (DOE/EIA-0383(2009), 2008; http://www.eia.doe.gov/oiaf/aeo/).

2. U.S. Department of Energy, Energy Information Agency (EIA), Annual Energy Review 2007. (DOE/EIA-0384, 2007; http://www.eia.doe.gov/aer).

3. U.S. Climate Change Technology Program, Technology Options for the Near and Long Term. (2005; http://www.climatetechnology.gov/library/2005/tech-options/tor2005-212.pdf).

4. National Petroleum Council. Topic Paper \#4: Electric Generation Efficiency. (2007, http://www.npc.org/Study_Topic_Papers/4-DTG-ElectricEfficiency.pdf).

5. U.S. Department of Energy, Energy Information Agency (EIA), Electric Power Annual 2007. (DOE/EIA-0348(2007) http://www.eia.doe.gov/cneaf/electricity/epa/epa.pdf, 2009).

6. Federal Energy Regulatory Commission. Cost of Electric Generation. (Staff Report, 2008, http://www.ferc.gov/legal/staff-reports/06-19-08-cost-electric.pdf).

7. B. Metz et al., "IPCC Special Report on Carbon Dioxide Capture and Storage" (Intergovernmental Panel on climate Change, Cambridge University Press, Cambridge, United Kingdom and New York, NY, USA, 2005). 
8. P. Lako, "Coal-fired power technologies: coal-fired power options on the brink of climate policies." (Energy Research Center of the Netherlands, Rep. No. ECN-C-04-076. 2004).

9. National Energy Technology Laboratory. Tracking New Coal-Fired Power Plants. (2008 http://www.netl.doe.gov/coal/refshelf/ncp.pdf).

10. U.S. Environmental Protection Agency. Final Report: Environmental Footprints and Costs of CoalBased Integrated Gasification Combined Cycle and Pulverized Coal Technologies. (EPA-430/R06/006, $2006 \mathrm{http} / / / \mathrm{www}$. epa.gov/airmarkets/resource/docs/IGCCreport.pdf).

11. R. Peltier, "IGCC demonstration plant at Nakoso Power Station, Iwaki City, Japan." (Power Magazine, 15 October 2007. http://www.powermag.com/coal/IGCC-demonstration-plant-at-Nakoso-PowerStation-Iwaki-City-Japan 382.html).

12. Council for Science and Technology Policy. Environment \& Energy Technology Roadmap and Diffusion Scenario. http://www8.cao.go.jp/cstp/english/doc/low_carbon_tec_plan/ref_roadmap1.pdf, 2008)

13. I.G. Wright, T.B. Gibbons, Int. J. Hydrogen Energy. 32, 3610-3621. (November 2007).

14. U.S. Department of Energy, National Energy Technology Laboratory. Program Facts: Fluidized Bed Combustion Program. (2000, http://www.fossil.energy.gov/programs/powersystems/combustion/Fluidbed prog031.pdf).

15. S. Bañales-López, V. Norberg-Bohm, Energy Policy. 30, 1173-1180. (October 2002).

16. International Energy Agency, Clean Coal Centre. Pressurized Fluidized Bed Combustion. (http://www.iea-coal.org.uk/site/ieacoal/databases/ccts/pressurized-fluidized-bed-combustion-pfbc Accessed 16 March 2009).

17. U.S. Department of Energy, Fossil Energy Program. How Gas Turbine Power Plants Work. (http://fossil.energy.gov/programs/powersystems/turbines/turbines howitworks.html, Accessed 10 March 2009).

18. A.S. Lebedev, S.V. Kostennikov, Thermal Engineering. 55, 461-46. (June 2008).

19. M. Ishikawa, M. Terauchi, T. Komori, J. Yasuraoka, Development of High Efficiency Gas Turbine Combined Cycle Power Plant. (Mitsubishi Heavy Industries, Ltd., Technical Review Vol. 45 No. 1, March 2008).

20. U.S. Department of Energy, Fossil Energy Program. Vision 21 - the Ultimate Power Plant Concept. (http://www.fossil.energy.gov/programs/powersystems/vision21/, Accessed 11 March 2009).

21. A. Lashtabeg, S.J. Skinner. 2006. J. Mater. Chem. 16, 3161-3170 (June 2006).

22. U.S. Department of Energy, Energy Efficiency and Renewable Energy Office, "Framework Document For Distribution Transformer Energy Conservation Standards Rulemaking," (Draft for Public Comment, November 1, 2000 http://www1.eere.energy.gov/buildings/appliance_standards/commercial/pdfs/trans_framework.pdf).

23. Federal Register, 72(197) 58189-58242. 2007.

24. P.R. Barnes et al., "The feasibility of replacing or upgrading utility distribution transformers during routine maintenance." (Oak Ridge National Laboratory, Tech. Rep. ORNL-6804/R1, 1995).

25. B.R. Andersen, "HVDC Transmission - Opportunities and Challenges." (ACDC 2006. The 8th IEE International Conference on AC and DC Power Transmission, 28-31 March 2006, http://ieeexplore.ieee.org/stamp/stamp.jsp?arnumber $=1633606 \&$ isnumber $=34251$ )

26. A. Alawar, E.J. Bosze, S.R. Nutt, IEEE Transactions on Power Delivery. 20(3) 2193-2199 (July 2005).

27. A. M. Wolsky, IEEE Power Engineering Review. 20(6).12-15 (June 2000).

28. T. Hartikainen, J. Lehtonen, R. Mikkonen, Applied Energy, 78(2), 151-158 (June 2004).

29. J.F. Maguire et al., IEEE Transactions on Applied Superconductivity, 17(2), 2034-2037 (June 2007).

30. R.A. Hawsey, D.K. Physica C-Superconductivity. 445, 488-495 (October 2006). 


\title{
A.5 ELECTRIC DRIVE VEHICLES
}

\author{
David L. Greene \\ Ronald L. Graves
}

\section{A.5.1 Technology Description}

The introduction of the Toyota Prius in Japan in 1999 launched the hybrid electric drivetrain as a mainstream technology for mass-produced vehicles. In 2007, hybrid electric vehicles (EVs) comprised $2 \%$ of total vehicle sales in the United States, with approximately 325,000 units sold. ${ }^{1}$ Hybrids' share increased to $3 \%$ in 2008 . As recently as 2002, a committee of the National Research Council (NRC), formed to consider the potential for increasing fuel economy, judged hybrids too expensive and too limited in performance to be included in its assessment. ${ }^{2}$ Advances in battery technology, motors and controllers, and especially computer control of the hybrid system allowed the hybrid to succeed where previous EVs had fallen short.

While today's hybrid EVs provide a 30-50\% increase in fuel economy (with even greater potential in the future ${ }^{3}$ ), they still derive all of their energy from conventional petroleum fuels. Future electric drive systems would be able to take electricity directly from the grid ${ }^{4}$ or use fuel cells for onboard conversion of hydrogen to electricity. ${ }^{5}$ Plug-in hybrid EVs (PHEVs) are similar to hybrid EVs but have a greater capacity for storing electricity and can take electricity from the grid. Batterypowered EVs have no internal combustion engine and must obtain all of their energy from the grid. Hydrogen fuel cell vehicles (FCVs) store hydrogen on board and use low-temperature fuel cells to generate electricity; they can also be equipped with sufficient battery capacity to take electricity from the grid. All of these vehicles will use regenerative braking to convert part of the kinetic energy lost in braking to electricity.

Electricity from the grid or hydrogen will directly displace petroleum, since petroleum accounts for $>95 \%$ of transportation energy use but comprises less than $2 \%$ of the primary energy used to generate electricity. ${ }^{6}$ It is highly unlikely that hydrogen would be produced from petroleum, since it can be produced more cheaply from natural gas or coal. ${ }^{5}$ The impact of substituting grid electricity or hydrogen for petroleum, however, will depend strongly on whether carbon capture and sequestration (CCS) achieves technological success and can be widely deployed.

\section{A.5.2 Barriers to Realizing Full Potential}

\section{A.5.2.1 Technical Barriers}

\section{PHEVs and EVs}

PHEVs are likely to require 5 to 10 times the battery storage capacity of today's hybrid vehicles. Today's hybrid vehicle batteries are kept within a limited range of state of charge and are not permitted to experience deep discharges. This strategy is essential to ensuring battery lifetimes equivalent to normal vehicle lifetimes. PHEV and EVs, on the other hand, will require batteries that can survive repeated deep discharge cycles. ${ }^{7}$ At the same time, the batteries must be low in cost. Although several lithium-ion (Li-ion) battery technologies show promise and PHEVs using these technologies are planned for introduction in the next few years, there is still no fully satisfactory battery solution for PHEVs or EVs.

FCVs

In 2008, an NRC committee tasked to assess the potential of hydrogen vehicle technologies concluded, "To the best of this committee's knowledge, no vehicle fuel cell system has yet met the full set of rigorous automotive specifications required for high-volume sales to customers" (Ref. 8). 
Durability of the fuel cell stack and especially fuel cell membranes is still significantly below what is required for automotive applications. The cost of platinum is a significant problem, and it may well be that an entirely different catalyst will be necessary to enable FCVs to become predominant on a global scale.

At present, no on-board hydrogen storage technology meets the goals for mass production vehicles, and there is no consensus as to which alternative will be the best long-term option. Solid hydrogen storage systems with a low-pressure tank and thermal management system have the potential to be small and lightweight but are still in the research stage. ${ }^{8}$ Liquid hydrogen is currently the densest form of storage, but the fact that it must be kept at $-252^{\circ} \mathrm{C}$ creates serious problems of boiloff and container cost. Liquefaction also consumes a significant fraction of the energy content of hydrogen, increasing cost as well as greenhouse gas (GHG) emissions.

Hydrogen production at low cost and with low carbon emissions will be a challenge in the absence of CCS. The lowest cost hydrogen production pathways today use fossil fuels (natural gas or coal) as feedstocks. Fortunately, capturing the $\mathrm{CO}_{2}$ from coal gasification is relatively inexpensive due to the high partial pressure of $\mathrm{CO}_{2}$ in the exhaust gas stream, ${ }^{8}$ so if CCS can be proven to be reliable and safe, it is also likely to be economical for hydrogen production from fossil fuels or biomass.

\section{A.5.2.2 Economic Barriers}

\section{PHEVs and EVs}

The nickel-metal-hydride (NiMH) batteries used in hybrid EVs today cost about $\$ 1,000$ per kilowatthour $(\mathrm{kWh})$ of storage capacity. ${ }^{7}$ Because of their greater storage capacity, better cycling performance, and potential for lower cost, Li-ion batteries are expected to replace NiMH batteries in hybrid vehicle applications over the next few years. Even so, Li-ion batteries face challenges in improving durability and reducing costs by more than $50 \%$, from current levels of $\$ 800-1,000 / \mathrm{kWh}$ to about $\$ 300 / \mathrm{kWh}$ (Ref. 7). Still, this would make the cost of $12.5 \mathrm{kWh}$ of batteries for a $50-\mathrm{km}$ PHEV about $\$ 3,750$.

FCVs

The economic hurdles for FCVs are even greater. Today, proton exchange membrane (PEM) fuel cells rely on platinum as a catalyst. Although a great deal of progress has been made in reducing platinum loadings in PEM cells, platinum is expensive and loadings will need to be reduced by approximately a factor of 4 to make fuel cell costs competitive with internal combustion engines (ICEs). ${ }^{3}$ Projected costs of fuel cell stacks manufactured using today's best technology at full production scales are in the vicinity of $\$ 100 / \mathrm{kW}$. Even estimates for newer laboratory-based technologies are in the range of $\$ 65-70 / \mathrm{kW}$, about twice the cost per $\mathrm{kW}$ of advanced ICEs. ${ }^{8}$

Today, hydrogen can be produced via distributed natural gas reforming and delivered into a vehicle at $350 \mathrm{mPa}$ at a cost of $\$ 3.30 / \mathrm{kg}$, with the potential for further cost reductions to $\$ 2.60 / \mathrm{kg}$, untaxed. ${ }^{8}$ At such costs hydrogen could compete successfully with gasoline. Unfortunately, there is no known way to economically capture the $\mathrm{CO}_{2}$ emissions from distributed hydrogen production. Production from renewable energy via electrolysis presently requires electricity costs in the vicinity of $\$ 0.05-0.06 / \mathrm{kWh}$ to be competitive, well below current renewable electricity costs. Hydrogen production via large-scale biomass gasification is promising but requires validation of projected feedstock yields, logistics, preparation methods, and gasifier reliability. ${ }^{8}$ Production via coal gasification is likely to be cost-competitive with distributed steam methane reforming (SMR), but this will only reduce carbon emissions if implemented with CCS. In the long term, it may be possible to produce hydrogen thermochemically by using nuclear energy to dissociate water.

Hydrogen vehicles face the additional barrier of the lack of a hydrogen refueling infrastructure. 


\section{A.5.2.3 Social Barriers}

Some safety concerns remain about the risk of electrocution from high-voltage storage batteries and the possibility for Li-ion batteries to catch fire. Very high pressure $(70 \mathrm{mPa})$ onboard hydrogen storage and storage of hydrogen in liquid form also raise novel safety concerns for the general public.

EVs face the likelihood that consumers will perceive limited range between lengthy recharging times as a negative feature. Unless the energy density of onboard hydrogen storage can be improved to that of liquid hydrogen, FCVs may also have less range between refueling than advanced conventional vehicles.

\section{A.5.3 Technological Advances Needed to Realize Full Potential}

\section{A.5.3.1 PHEVs and EVs}

Advanced batteries are needed with lower cost, higher energy storage capacity, and longer life under conditions of repeated deep discharge. Promising energy storage options include Li-ion, Li-polymer, and Li-sulfur systems, ultracapacitors and flywheels, and systems that combine these elements. Advances are needed in materials, nanotechnology, and nanotechnology manufacturing processes. Continued improvement in motors and controllers is also important. ${ }^{7}$

Ultracapacitors could play an important role in providing short high-energy bursts for acceleration or absorbing energy from regenerative braking faster than batteries are capable of doing. Ultracapacitor costs have decreased by more than an order of magnitude over the past decade but another decrease by a factor of 10 to 20 would be necessary to make ultracapacitors competitive in the automobile market. ${ }^{7}$

\section{A.5.3.2 FCVs}

Advanced materials are needed for inexpensive, durable, high-temperature fuel cell membranes. Alternatives to platinum catalysts appear to be essential to bringing down costs for global FCV deployment. Because there is no clear consensus on the optimal method of storing hydrogen on board a vehicle, several alternative methods must be pursued. These include: (1) carbon fiber or other suitable materials for high-pressure storage tanks and methods for low-cost manufacture; (2) lowlifecycle-cost metal hydrides with increased energy density, low release energy, long life, and ease of recycling; and (3) lower cost, more energy-efficient liquefaction, minimization of boiloff, and safe handling of boiloff for liquid storage. ${ }^{7}$

\section{A.5.4 Potential to Reduce $\mathrm{CO}_{2}$ Emissions by 2050}

Although no one can know when new technologies will be ready for market introduction, existing studies $^{3,7,8}$ seem to agree on a range of plausible dates for possible mass-market introduction:

- for PHEVs, 2012-2020;

- for battery-powered EVs, 2012-2020; and

- for FCVs, 2015-2025

From the year of initial introduction, it would take a minimum of 5-8 years for the redesigning and retooling necessary to make all new vehicles with the new technology. ${ }^{2}$ In all likelihood, it would take substantially longer. Eight years after the first introduction of a mass-produced hybrid EV in the U.S. market, hybrids comprised only $2 \%$ of total light-duty vehicle (LDV) sales. With vehicle life expectancies now on the order of 15 years, it requires another 10-15 years to replace most of the vehicles on the road, taking into consideration the decline in vehicle usage with age and the growth of vehicle sales. 


\section{A.5.4.1 Total potential by 2050}

The International Energy Agency (IEA) developed four global scenarios, known as the Blue scenarios, in which emissions of $\mathrm{CO}_{2}$ are reduced $50 \%$ to $85 \%$. These scenarios assume a near-total dominance of electric drive technologies for passenger cars and light trucks by 2050 :

- PHEVs achieve market shares of $60-70 \%$ of all light-duty vehicles by 2030 , and $10-100 \%$ in 2050, depending on the technological and market success of battery-powered EVs and FCVs (Ref. 7);

- EVs take $0-75 \%$ of the LDV market in 2050; and

- FCVs claim 0-90\%.

Two scenarios developed for the United States by the $\mathrm{NRC}^{8}$ and the U.S. Department of Energy ${ }^{9}$ provide the quantitative estimates of the potential impacts of EVs used in Table A.5.1. (Note that the two scenarios assume different reference cases: in Ref. 8, the reference case $\mathrm{CO}_{2}$ emissions in 2050 are 1,710 $\mathrm{Tg} \mathrm{CO} \mathrm{CO}_{2}$ equivalent; in Ref. 9, the $2050 \mathrm{CO}_{2}$ emissions from LDVs amount to $1,530 \mathrm{Tg} \mathrm{CO}_{2}$ equivalent. The studies also make different assumptions about the effectiveness of CCS and the production of hydrogen from biomass with CCS.)

Table A.5.1. Potential reductions in U.S. $\mathrm{CO}_{2}$ emissions resulting from deployment of fuel cell vehicles

\begin{tabular}{lcc}
\hline Source & $\mathbf{2 0 3 0}$ & $\mathbf{2 0 5 0}$ \\
\hline NRC 2008 (Ref. 8), Table 6.10 & $200 \mathrm{Tg} \mathrm{CO}_{2}(14 \%)$ & $1,026 \mathrm{Tg} \mathrm{CO}_{2}(60 \%)$ \\
Greene et al. 2008 (Ref. 9) & $164 \mathrm{Tg} \mathrm{CO}_{2}(10 \%)$ & $1,345 \mathrm{Tg} \mathrm{CO}_{2}(88 \%)$ \\
\hline
\end{tabular}

\section{A.5.5 Potential to Reduce Oil Use by 2030}

As shown in Table A.5.2, estimates from two different sources (Refs. 8 and 9) of the potential of FCVs to reduce U.S. petroleum use by 2030 are relatively consistent: 2.4 quads and 2.9 quads. The need to linearly interpolate the NRC estimates in order to obtain a 2030 value may explain part of the difference in that year.

Table A.5.2. Potential reductions in U.S. petroleum use resulting from deployment of fuel cell vehicles

\begin{tabular}{lcc}
\hline Source & $\mathbf{2 0 3 0}$ & $\mathbf{2 0 5 0}$ \\
\hline NRC 2008 (Ref. 8), Table 6.9 & 2.9 quads (16\% of LDV energy) & 13.6 quads (69\% of LDV energy) \\
Greene et al. 2008 (Ref. 9) & 2.4 quads & 13.2 quads \\
\hline
\end{tabular}

Note: NRC estimates for 2015 and 2035 were linearly interpolated to estimate values for 2030. Estimates for Greene et al. are based on unpublished tables showing reductions in oil use, adjusted for prevalence of E10, of $1.124 \mathrm{mmbd}$ in 2030 and $6.244 \mathrm{mmbd}$ in 2050 .

PHEVs are more efficient than conventional vehicles and use less petroleum than hybrids. Starting with the NRC reference case assumptions ${ }^{8}$ for numbers of vehicles in operation and fuel economy, the energy use and energy savings of PHEVs can be calculated as a function of their share of the total vehicle fleet. If PHEVs comprise $75 \%$ of the vehicle fleet in 2050 -matching an EV Success assumption of the IEA (Ref. 7) - then they will save 6.3 quads of energy in 2050 by displacing 7.6 quads of petroleum fuel with 1.3 quads of electricity, as indicated in Table A.5.3. 
Table A.5.3. Estimated impacts of light-duty PHEVs on petroleum and electricity use

\begin{tabular}{|c|c|c|c|c|c|c|c|}
\hline \multirow{2}{*}{$\begin{array}{l}\text { PHEV } \\
\text { share of } \\
\text { fleet }\end{array}$} & \multicolumn{2}{|c|}{ Gasoline } & \multicolumn{2}{|c|}{ Electricity } & \multirow{2}{*}{$\begin{array}{c}\text { Base fuel } \\
\text { (quads) }\end{array}$} & \multirow{2}{*}{$\begin{array}{c}\text { Energy } \\
\text { saving } \\
\text { (quads) }\end{array}$} & \multirow{2}{*}{$\begin{array}{c}\text { Fuel } \\
\text { saving } \\
\text { (quads) }\end{array}$} \\
\hline & $10^{6} \mathrm{gal}$ & Quads & $10^{6} \mathrm{kWh}$ & Quads & & & \\
\hline $5 \%$ & 2,483 & 0.31 & 24,849 & 0.08 & 0.82 & 0.42 & 0.51 \\
\hline $15 \%$ & 7,449 & 0.93 & 74,548 & 0.25 & 2.45 & 1.26 & 1.52 \\
\hline $25 \%$ & 12,415 & 1.55 & 124,247 & 0.42 & 4.08 & 2.10 & 2.53 \\
\hline $35 \%$ & 17,381 & 2.17 & 173,946 & 0.59 & 5.71 & 2.94 & 3.54 \\
\hline $45 \%$ & 22,346 & 2.79 & 223,644 & 0.76 & 7.34 & 3.78 & 4.55 \\
\hline $55 \%$ & 27,312 & 3.41 & 273,343 & 0.93 & 8.97 & 4.62 & 5.56 \\
\hline $65 \%$ & 32,278 & 4.66 & 323,042 & 1.10 & 10.60 & 5.47 & 6.57 \\
\hline $75 \%$ & 37,244 & 4.66 & 372,741 & 1.27 & 12.23 & 6.31 & 7.58 \\
\hline $85 \%$ & 42,210 & 5.28 & 422,440 & 1.44 & 13.86 & 7.15 & 8.59 \\
\hline $95 \%$ & 47,176 & 5.90 & 472,138 & 1.61 & 15.50 & 7.99 & 9.60 \\
\hline
\end{tabular}

Note: Key assumptions are as follows. Base fuel use: 130,489 gal (16.31 quads). Base fuel economy:

31.7 miles/gallon. Base fuel energy: 125,000 Btu/gallon. Fleet size: 369 million vehicles. Vehicle use: 11,800 miles/year, 25.2 miles/day. PHEV fuel economy: 47.6 miles/gallon. PHEV electricity use: 4.01 miles/kilowatthour. Electricity storage: 4.1 kilowatthour. Average use of stored electric charge: 90\%. Electric energy: 3,412 Btu per kilowatthour. Local travel: 9,198 miles/year (5,401 miles using electricity, 3,797 miles using gasoline). Total travel on gasoline for PHEVs: 6,399 miles/year.

\section{A.5.6 Interactions with Other Technologies}

Without CCS in hydrogen production or similarly decarbonized electricity generation, FCVs, PHEVs, and EVs will have approximately the same $\mathrm{CO}_{2}$ emissions per mile as advanced technology ICE vehicles. With CCS, these technologies can produce $0-20 \%$ of the full fuel cycle $\mathrm{CO}_{2}$ emissions of ICE vehicles, depending on the effectiveness of CCS and the share of renewable energy used to produce electricity or hydrogen.

PHEVs and EVs will increase electricity demand on the grid. Assumptions proposed by Lemoine et al. ${ }^{10}$ can be used to calculate electricity demand by PHEV and EVs as a function of the numbers of these vehicles in the fleet in 2050. As Table A.5.3 shows, if 75\% of LDVs in 2050 were PHEVs, then electricity use would increase by 1.3 quads per year.

\section{References}

1. Electric Drive Transportation Association (EDTA), "Hybrid Sales Figures/Tax Credits for Hybrids," http://www.electricdrive.org/index.php?ht=d/Articles/cat_id/5514/pid/2549, accessed July 8, 2009.

2. National Research Council, Effectiveness and Impact of Corporate Average Fuel Economy (CAFE) Standards, National Academies Press, Washington, DC, 2002.

3. M. Kromer, J. Heywood, Electric Powertrains: Opportunities and Challenges in the U.S. Light-Duty Vehicle Fleet, LFEE 2007-02 RP, Sloan Automotive Laboratory, Massachusetts Institute of Technology, Cambridge, MA, 2007.

4. Comparing the Benefits and Impacts of Hybrid Electric Vehicle Options for Compact Sedan and Sport Utility Vehicles, 1006892, Electric Power Research Institute, Palo Alto, CA, 2002, http://mydocs.epri.com/docs/public/000000000001006892.pdf (accessed July 8, 2009).

5. National Research Council, The Hydrogen Economy, National Academies Press, Washington, DC, 2004.

6. Energy Information Administration, Annual Energy Review 2007, DOE-EIA-0384(2007), U.S. Department of Energy, June 2008, http://tonto.eia.doe.gov/FTPROOT/multifuel/038407.pdf (accessed July 8, 2009).

7. International Energy Agency, Energy Technology Perspectives 2008: Summaries and Strategies to 2050 (Organisation for Economic Cooperation and Development, Paris, 2008). 
8. National Research Council, Transition to Alternative Transportation Technologies: A Focus on Hydrogen, National Academies Press, Washington, DC, 2008.

9. D. Greene et al., Transition to Hydrogen Fuel Cell Vehicles and the Potential Hydrogen Energy Infrastructure Requirements, ORNL/TM-2008/30, Oak Ridge National Laboratory, Oak Ridge, TN, 2008.

10. D. Lemoine, D. Kammen, A. Farrell, Environ. Res. Lett. 3, 1-10 (2008). 


\title{
A.6 ENERGY-EFFICIENT BUILDINGS
}

\author{
Patrick Hughes \\ Abigail L. Gaddis
}

\section{A.6.1 Technology Description}

The topic of energy efficiency in buildings covers a broad portfolio of technologies used in both residential and commercial sectors for both new and existing buildings. Additionally, it involves the integration of small-scale renewable energy technologies into buildings as well as the integration of demand-responsive buildings into the grid.

Energy efficiency improvements to the principal end uses of residential and commercial energy would greatly reduce the energy use of buildings as a whole. For example, in 2006, the top consumers of energy in residential buildings were space heating and cooling, water heating, and refrigeration, which together make up about 55\% of residential energy use. ${ }^{1}$ For commercial buildings, the top consumers were space heating and cooling, lighting, and water heating, representing approximately $47 \%$ of commercial building energy use. ${ }^{1}$

For both sectors, maintenance of building temperature, humidity, and indoor environmental quality is important for energy consumption, and many technologies can improve energy use in this area: for example, highly insulated and airtight building envelopes; exterior roof and wall surfaces that reflect the sun's energy in hotter climates; high-performance windows; geothermal and electric heat pumps and other highly efficient heating, ventilating, and air conditioning (HVAC) technologies; and improved controls. Technologies to increase the energy efficiency of lighting include the incorporation of daylighting and controls, occupancy sensing controls, compact fluorescent light bulbs (CFLs) and tubes, and emerging solid-state lighting technologies. Since refrigeration and other appliance use is another important component of building efficiency, improvements in appliance efficiency are part of the solution, as is lowering consumption by miscellaneous electric loads (plug loads and others) through reduction of standby losses and improved controls.

Currently, depending on application and location, reductions of 30-50\% in the energy intensity of new homes and commercial buildings through efficiency are within reach and cost-effective compared to business-as-usual construction. With ubiquitous use of the whole-building integrated design process, fed by a pipeline of increasingly efficient and more affordable component and system technologies, reductions of $70-90 \%$ should be possible. At these savings levels, net zero-energy buildings that produce as much energy as they use in a year become technically feasible, since the roofs and other sunlit surfaces of buildings are large enough to accommodate sufficiently sized photovoltaic (PV) solar cells. Even if PV or other renewable energy sources of this magnitude are not affordable, the underlying efficiency savings of $70-90 \%$ will be. Savings potentials in the existing building stock are more realistically in the $30-50 \%$ range.

\section{A.6.2 Barriers to Realizing Full Potential}

\section{A.6.2.1 Economic Barriers}

Increasing consumer demand for energy-efficient building technologies is hampered in several ways. Many of these technologies have higher first costs than their business-as-usual counterparts; however, energy, maintenance, and operating costs over the lifetime of the technology are significantly lower, eventually offsetting the initial investment. Nevertheless, lowering the initial financial barrier would increase consumption of these products. A major barrier to energy efficiency in the buildings sector is the dislocated agent effect-e.g., the builder makes the decisions that determine energy use based on a desire to minimize first cost, with the consequences transferred to the owner/tenant who must pay the higher operating bills over time. 
A final important barrier is fragmentation in the buildings industry. Disconnects between the groups creating, building, and using a structure can cause a failure to implement technologies in the most streamlined, maximized way. Studies show that the most efficient buildings have collaboration and extensive communication between individuals involved in the design, construction, and operation of the building. ${ }^{2}$ Additionally, the earlier an energy efficiency goal is integrated into the design of the building, the more efficient the final result is. ${ }^{2}$

\section{A.6.2.2 Social Barriers}

A key social barrier is the low level of consumer awareness and understanding of the costs and consequences of energy use in buildings. This is not surprising, since the number of technologies encompassed in building efficiency creates an overwhelming complexity to consumers. A universal adoption of a whole-building rating, the equivalent of a building "mpg," would increase transparency to consumers.

Barriers in certain technologies are notable; for instance, the infrastructure to install groundsource (or geothermal) heat pumps is only well established in a few localities.

\section{A.6.3 Technological Advances Needed to Realize Full Potential}

The building envelope is critical for reducing building energy loads. It is the starting point for energy-efficient buildings and the main determinant of the amount of energy required to heat, cool, and ventilate. It can also significantly influence lighting energy needs in areas that are accessible to sunlight. Specifically, it determines how airtight a building is, how much heat is transmitted through thermal bridges (which breach insulation and allow heat to flow in or out), and how much natural light and ventilation can be used. Advances in materials, components, and subsystems promise highperformance, climate-optimized use of the building envelope as a filter that selectively accepts or rejects solar radiation and outside air, depending on the need for heating, cooling, ventilation, and lighting at a particular time, and uses the heat capacity of the building structure to shift thermal loads on a time scale of hours to days. Envelopes and partitions are a required sunk cost that, if multifunctional, can leverage greater benefits than just being high- $R$ and airtight, while also avoiding costs elsewhere in the building.

More practical and extensive building information modeling (BIM) can facilitate the needed whole-building integration of technologies, as well as the required cooperation and collaboration across disciplines in the design, construction, and operation of the building. BIM has the potential to break down the silos between architect, structural engineer, HVAC engineer, electrical engineer, plumbing engineer, building energy modeler, general contractor, construction subcontractor, commissioning agent, and building operator. BIM also allows others who are indirectly involved in the process (such as lenders, owners, conformity assessment entities, building regulators, and developers) to better understand buildings and more effectively participate and contribute.

The process of transitioning designs to constructed buildings accounts for the greatest share of the disparity between the predicted and as-built performance of buildings. It is time to fundamentally rethink our centuries-old methods for constructing and renovating buildings. Achieving net zeroenergy buildings will require a new level of whole-building design sophistication, the multifunctional envelopes and partitions discussed above, and construction techniques that can reliably implement these elegant designs and technologies. Needed are greater automation and improved controls in the construction process to reduce materials waste; make greater use of natural and recycled content and biobased materials; reduce injuries, cost, and building time; achieve greater durability and longevity; and achieve compatibility with emerging BIM-driven design, engineering, construction, operation, and repurposing lifecycle concepts. The energy-saving benefits of the new construction approaches derive from use of materials with reduced embedded energy, greater realization of the energy-saving 
potential of integrated whole-building designs, and more reliable implementation of advanced energysaving technologies.

The effective use of ground energy sources and heat sinks offers significant potential for energy savings and peak load reduction for buildings. Ground resources - including the Earth, surface water, recycled graywater, sewage treatment plant effluent, retention basin stormwater, harvested rainwater, and water from a subsurface aquifer-whether alone or in combination with outdoor air in a hybrid configuration, are generally more efficient than outdoor air for equipment heat exchange. Research is needed to develop and validate the necessary design tools and performance prediction models so that practitioners can confidently interface equipment in buildings to the most energy-efficient and affordable ground energy sources and heat sinks.

A key energy-saving strategy involves embedding greater intelligence in existing and new buildings. Embedded intelligence can make new energy-saving functionalities in buildings ubiquitous and affordable. These functionalities include energy-consuming devices that continuously commission themselves, detect and diagnose their own faults, request service, are demand responsive, and deliver amenities only when and where needed.

Research is needed to reduce the cost and enhance the performance of approaches to integrate renewable energy systems, such as PV, hydrogen fuel cells, and combined heat and power (CHP) from biofuel, with buildings. With many energy sources (PV, fuel cells), storage (batteries), and loads (solid-state lighting, computers, motors/drives) all being DC, it is also time to revisit building electrical power distribution architectures (AC/DC hybrid, DC) to avoid excessive energy conversion losses. For CHP from biofuel, research is needed to reduce costs, broaden size range, expand biofuel options, reduce emissions, reduce thermal distribution losses, and improve the use of recycled heat.

Research is also needed to capitalize on the energy-saving opportunities available from integrating intelligent buildings with the emerging "smart grid." The goal here is to reduce the cost of making buildings as demand responsive as possible. This will maximize availability of incentives that can help make many other energy efficiency features in buildings more attractive to consumers. Buildings consume $72 \%$ of the nation's electricity and their demand, especially for cooling during peak periods, is driving the need for expanded electricity supply infrastructure. Utilities across the nation are realizing that providing ratepayer-funded incentives to enable improvements in existing and new buildings fosters better load factors on existing electricity supply assets, defers new supply assets, and provides downward pressure on utility rates. Peak load reduction through demand response (DR) is important for securing for building owners the largest possible ratepayer incentives to accelerate the pace of energy efficiency improvement.

\section{A.6.4 Potential to Reduce $\mathrm{CO}_{2}$ Emissions by 2050}

Some of these technologies can be applied to current homes and offices; retrofits can begin immediately and take effect in 2 years. Other technologies must be applied to new construction, so full market penetration would occur after 2020 (Ref. 3).

Thus, by 2050 , the energy intensity of the existing building stock can be reduced by $50 \%$ through retrofits, and that of new construction can be reduced by $70-90 \%$ from business as usual. By 2030 , most predictions indicate a $730-1100 \mathrm{Tg} \mathrm{CO}_{2} /$ year reduction in emissions as a result of increased building energy efficiency. One projection ${ }^{4}$ estimates reductions of $1100 \mathrm{Tg} \mathrm{CO}_{2} /$ year in 2030 and $1760 \mathrm{Tg} \mathrm{CO}_{2} /$ year in 2050 .

\section{A.6.5 Potential to Reduce Oil Use by 2030}

Of the energy delivered to both commercial and residential buildings in 2006, 5.9\% (1.12 quads of 19.02 quads) was from distillate fuel oil. ${ }^{1}$ Elimination of distillate fuel oil in home and commercial use could be accomplished as a result of increased building efficiency and fuel switching. Because nearly all building petroleum use is for space heating and water heating, ${ }^{1}$ replacement with more 
efficient, demand-sensitive heat pumps, as well as maximized efficiency of the building envelope could completely eliminate this source of petroleum demand by 2030. Therefore, oil use reduction in this sector is a small but nonnegligible component of overall oil dependence reduction.

\section{A.6.6 Interactions with Other Technologies}

Both when newly designed and when retrofitted, buildings are improved with comprehensive packages of technologies, and the interactions between them are key in achieving the best possible efficiency. Achieving net zero-energy buildings will require building-integrated renewable energy sources such as PV and CHP from biofuel. The latter would benefit greatly from a vibrant biofuels industry driven by the transportation sector. For commercial and residential buildings combined, $48 \%$ of energy delivered comes from electricity, corresponding to $72 \%$ of the nation's electricity use, so electricity production is related to building energy efficiency.

\section{References}

1. Energy Information Administration (EIA), Annual Energy Outlook 2008, DOE/EIA-0383(2008), U.S. Department of Energy, Washington, DC, June 2008, http://www.eia.doe.gov/oiaf/aeo/pdf/0383(2008).pdf (accessed July 7, 2009).

2. P. Torcellini et al., Lessons Learned from Case Studies of Six High Performance Buildings (NREL/TP-55037542, National Renewable Energy Laboratory, June 2006).

3. Basic Energy Sciences Advisory Committee, Basic Research Needs to Assure a Secure Energy Future, February 2003, http://www.science.doe.gov/bes/reports/files/SEF_rpt.pdf (accessed July 7, 2009).

4. P. Kyle et al., "The Value of Advanced Technologies in the U.S. Buildings Sector in Climate Change Mitigation," presented at ACEEE Summer Study on Buildings, Pacific Grove, CA, August 17, 2008. 


\title{
A.7 ENERGY-EFFICIENT INDUSTRIAL PRACTICES
}

\author{
Moonis Raza Ally \\ Philip R. Boudreaux
}

\section{A.7.1 Technology Description}

As reported in the Annual Energy Review 2007 (Ref. 1) issued by the Energy Information Administration (EIA) of the U.S. Department of Energy (DOE), the U.S. industrial sector consumes approximately $32 \%$ of the total national energy consumption of 101.6 quadrillion Btu (quads). The primary energy sources used in the industrial sector are petroleum and natural gas, followed by electricity, renewables, and coal (in order from higher to lower consumption). The use of coal as an energy source in the industrial sector has been decreasing since at least the 1950s.

In its Annual Energy Outlook 2008 (Ref. 2), the EIA reports that the industrial sector used 25.1 quads of delivered energy in 2006 and provides projections to 2030 for reference, low economic growth, and high economic growth scenarios. In the reference scenario, industrial delivered energy consumption rises to 27.7 quads/year by 2030; in the low economic growth case, it decreases to 24.2 quads/year, and in the high economic growth case, it rises to 31.7 quads/year.

According to the Energy Technology Perspectives 2008 report produced by the International Energy Agency (IEA), in 2005, 80\% of U.S. industries' 397 million tons of oil equivalent (Mtoe) total of final energy consumption occurred in five major areas: (1) chemical and petrochemical; (2) iron and steel; (3) nonmetallic minerals; (4) paper, pulp, and print; and (5) food and tobacco. Of the $659 \mathrm{Tg}$ of $\mathrm{CO}_{2}$ emissions produced by the U.S. industrial sector, these five subsectors produced $541 \mathrm{Tg}$. Emissions in this sector can be reduced "through efficiency measures, including waste material recycling and product design changes; through fuel and feedstock substitution (such as greater use of biomass); and through $\mathrm{CO}_{2}$ capture and storage (CCS)."

\section{A.7.2 Barriers to Realizing Full Potential}

The industrial sector has a great many subsectors with different technologies, varying energy uses, and varying emissions; this overview focuses on the five major subsectors identified in Ref. 3 as responsible for $80 \%$ of U.S. industrial consumption.

\section{A.7.2.1 Chemical and Petrochemical}

The chemical and petrochemical subsector leads the industrial sector in energy intensity and emissions: in 2005, this subsector used almost half of the sector's energy and was responsible for about a third of its $\mathrm{CO}_{2}$ emissions. ${ }^{3}$ Three areas in particular have large energy requirements: (1) the production of high-value chemicals (HVCs) from ethane, steam-cracking of naphtha, and other feedstock; (2) methanol production; and (3) ammonia production. Advances in energy efficiency, new process technologies, greener feedstock such as biomass, and recycling are needed to reduce the energy intensity of this subsector.

\section{A.7.2.2 Iron and Steel}

The iron and steel subsector uses $8 \%$ of the sector's energy and emits about $14 \%$ of its $\mathrm{CO}_{2}$ (Ref. 3). The three primary steel production methods are the electric arc furnace (EAF) method, the direct reduced iron (DRI) method, and the blast furnace (BF) method. Scrap-based crude steel production via the EAF method can lower emissions but is based on scrap availability; this method has the lowest energy intensity of the three primary methods. Improvements in blast-furnace efficiency and CCS technology can improve the energy efficiency of and reduce emissions from the 
BF method. Direct casting methods and increased steel recycling can also reduce this subsector's energy intensity and emissions.

\section{A.7.2.3 Nonmetallic Minerals}

The nonmetallic mineral subsector uses $6 \%$ of the sector's energy and emits $17 \%$ of its $\mathrm{CO}_{2}$ (Ref. 3). This subsector includes the production of cement, bricks, glass, ceramics, and other materials. Cement production accounts for the majority of energy use and emissions in this subsector. Rotary dry kilns, the newest technology for making cement, can cut energy use in half compared to wet kilns, but at an increased cost. Emissions can be reduced by replacing fossil fuel with waste or biomass firing in the kilns. Rates can be anywhere from $35 \%$ to $100 \%$ for fuel substitution. ${ }^{3}$ The formation of clinker (heated limestone and chalk, the main material in cement) is the main consumer of energy in the cement making industry. Feedstock switching from clinker to volcanic ash, slag, fly ash, or glass could reduce energy use and emissions by $50 \%$ (Ref. 3 ).

\section{A.7.2.4 Paper, Pulp, and Print}

The paper and pulp subsector used $14 \%$ of the sector's energy and emitted $10 \%$ of its $\mathrm{CO}_{2}$ in 2005 (Ref. 3). The paper and pulp industry already produces about 50\% of its own energy from biomass. CCS can greatly reduce the carbon output of this industry. The efficiency of black-liquor (by-product of paper making) recovery can be increased by gasification and a gas-turbine generator. The reliability of this approach still needs research. An increase in paper recycling can also increase energy savings.

\section{A.7.2.5 Food and Tobacco}

The food and tobacco subsector uses $8 \%$ of the sector's energy and emits $9 \%$ of its $\mathrm{CO}_{2}$ (Ref. 3). Crop and livestock production account for about 7.2 quads of energy in this subsector, primarily in fertilization and mechanization. ${ }^{4}$ Better farming practices, such as reducing fertilizer use through proper timing and dosages and reducing erosion, can substantially reduce energy use. Improving the energy efficiency of food processing can reduce energy use by a predicted $10 \%$ (Ref. 4).

Co-generation methods, cold pasteurization and electron-beam sterilization, and more efficient drying technologies are just a few methods that can help save energy in this subsector. Crops that require less water and resist pests and disease can also help the food industry.

\section{A.7.3 Technological Advances Needed to Realize Full Potential}

Two strategies can be effectively applied across all of the industrial subsectors discussed in Sect. A.7.2: increased recycling and implementation of CCS technology will greatly reduce the energy intensity and emissions of the industrial sector. Also needed are wide use of co-generation and biomass for energy production and methods for recovering heat and energy from flue gases and other by-products.

Although industry is relatively efficient compared to other sectors, cost-effective techniques can improve energy efficiency by at least $20 \%$ in energy-intensive subsectors such as chemicals, paper, steel, and cement manufacturing. ${ }^{3}$ For example, in the steel industry, recovery of heat from flue gases emitted at temperatures of $\approx 1200^{\circ} \mathrm{F}\left(649^{\circ} \mathrm{C}\right)$ saves $45-60 \%$ in fuel costs, as demonstrated by the Technology Accelerated Program for High Temperature Heat Recuperation (TAPHTR) project initiated by DOE and industry in the mid-1980s (Ref. 5). A similar technology for "dirty" gases could save substantial energy in industrial subsectors. Bernstein et al., ${ }^{6}$ citing the IEA's Energy Technology Perspectives 2006, state that "the energy intensity of most industrial processes is at least $50 \%$ higher than the theoretical minimum determined by the basic laws of thermodynamics." Hence, much improvement is possible if the focus is on direct conversion of fuel to electricity, circumventing the intermediate thermal stage as is done in electrochemical devices. In Europe, much emphasis is placed 
on availability analysis, a powerful thermodynamic tool to identify opportunities for improved energy efficiency and to reduce the inefficiencies in the commercial and industrial sectors. Industrial processes can also benefit from "pinch analysis," which involves matching heat reject streams with those that require energy to reduce overall energy consumption.

\section{A.7.4 Potential to Reduce $\mathrm{CO}_{2}$ Emissions by 2050}

As noted earlier, Ref. 3 reports that U.S. industry emits $659 \mathrm{Tg} \mathrm{CO}_{2} /$ year, with $82 \%$ of the emissions coming from the five subsectors discussed above and the remaining $18 \%$ coming from a variety of smaller subsectors (machinery, textile and leather, construction, etc.).

By $2050, \mathrm{CO}_{2}$ emissions could be reduced by $20-30 \%$ below 2005 levels if the best available technologies are applied. ${ }^{3}$ Table A.7.1 provides estimates for $\mathrm{CO}_{2}$ emissions in 2005 and in 2050 with reductions of $20 \%$ and $30 \%$ across all subsectors.

Table A.7.1. Potential reductions in $\mathrm{CO}_{2}$ emissions from the U.S. industrial sector by 2050

\begin{tabular}{|c|c|c|c|}
\hline \multirow[b]{3}{*}{ Subsector } & \multicolumn{3}{|c|}{$\mathrm{CO}_{2}$ emissions, $\mathrm{Tg} /$ year } \\
\hline & & \multicolumn{2}{|c|}{2050} \\
\hline & 2005 & $\begin{array}{c}20 \% \\
\text { reduction }\end{array}$ & $\begin{array}{c}30 \% \\
\text { reduction }\end{array}$ \\
\hline Chemical and petrochemical (including feedstocks) & 209 & 167 & 146 \\
\hline Iron and steel & 91 & 73 & 64 \\
\hline Nonmetallic minerals & 115 & 92 & 81 \\
\hline Paper, pulp, and print & 66 & 53 & 46 \\
\hline Food and tobacco & 60 & 48 & 42 \\
\hline Others & 119 & 95 & 83 \\
\hline Total $\mathrm{CO}_{2}$ emissions (rounded figures) & 660 & 528 & 462 \\
\hline
\end{tabular}

U.S. industry currently uses 2.7 quads of biomass ( $58 \mathrm{Mtoe}$ ), with usage growing at a rate of $2 \%$ per year. ${ }^{7}$ Table A.7.2 provides a breakdown of $\mathrm{CO}_{2}$ emissions by fuel type for the U.S industrial sector in 2030, using the reference scenario of Ref. 1 (shown in Fig. A.7.1) and assuming that biomass is used to displace equal amounts of natural gas and oil.

\section{A.7.5 Potential to Reduce Oil Use by 2030}

Elliott et al. ${ }^{8}$ project oil savings in the industrial sector by 2020 of 0.220 million barrels of oil per day (mmbd) for a "modest" scenario, $0.344 \mathrm{mmbd}$ for a "moderate" scenario, and $0.440 \mathrm{mmbd}$ for an "aggressive" scenario.

The American Iron and Steel Institute (AISI) has set a goal of developing new steelmaking technology that, in commercial use, will reduced the amount of oil needed for steel production from 2.07 barrels/ton in 2003 to 1.2 barrels/ton in 2025. This "Saving One Barrel of Oil per Ton" (SOBOT) goal is key to an AISI roadmap for transforming the steelmaking process." 
Table A.7.2. Breakdown of energy use and $\mathrm{CO}_{2}$ emissions by fuel type for the U.S. industrial sector

\begin{tabular}{|c|c|c|c|c|c|c|c|c|}
\hline & \multicolumn{2}{|c|}{$\begin{array}{l}\text { World emissions, } \\
2005^{a}\end{array}$} & \multicolumn{2}{|c|}{$\begin{array}{l}\text { U.S. emissions, } \\
2005^{b}\end{array}$} & \multicolumn{2}{|c|}{$\begin{array}{l}\text { U.S. emissions with } \\
\text { biomass switching, } \\
2005\end{array}$} & \multicolumn{2}{|c|}{$\begin{array}{l}20 \% \text { reduction in } \\
\text { estimated annual } \\
\text { U.S. emissions, } \\
\quad 2030^{c}\end{array}$} \\
\hline & Mtoe & $\mathrm{Pg} \mathrm{CO} 2$ & Mtoe & $\mathrm{PgCO}_{2}$ & Mtoe & $\mathrm{Pg} \mathrm{CO} 2$ & Mtoe & $\mathrm{PgCO}_{2}$ \\
\hline Coal & 714 & 3.10 & 103 & 0.445 & 103 & 0.445 & 82.4 & 0.356 \\
\hline Natural gas & 561 & 1.28 & 80.6 & 0.184 & $51.6^{d}$ & 0.118 & 41.2 & 0.0944 \\
\hline $\begin{array}{l}\text { Oil and petrochemi- } \\
\text { cal feedstocks }\end{array}$ & 666 & 1.24 & 95.6 & 0.178 & $66.6^{d}$ & 0.124 & 53.2 & 0.0992 \\
\hline $\begin{array}{l}\text { Combustible renew- } \\
\text { ables and waste }\end{array}$ & 180 & $\mathrm{NA}^{e}$ & 25.8 & NA & 25.8 & NA & 20.6 & NA \\
\hline Electricity & 532 & NA & 76.4 & NA & 76.4 & NA & 61.1 & NA \\
\hline Heat & 110 & NA & 15.8 & NA & 15.8 & NA & 12.6 & NA \\
\hline Biomass $^{f}$ & NA & NA & - & - & 58 & - & - & - \\
\hline Total & 2763 & 5.62 & 397 & $0.807^{g}$ & 397 & 0.687 & 271 & 0.549 \\
\hline
\end{tabular}

${ }^{a}$ Data from Table 16.3 of Ref. 3 .

${ }^{b}$ Estimated by multiplying figures for world emissions by 0.1436 .

${ }^{c}$ Assumes efficiency improvement of $20 \%$ and continual substitution of biomass for natural gas and oil, using the reference scenario of Ref. 1.

${ }^{d}$ Biomass (58 Mtoe) displaces equal amounts of oil and natural gas (39 Mtoe).

${ }^{e} \mathrm{NA}=$ not applicable

${ }^{f}$ Assumed to be near carbon neutral.

${ }^{g}$ Exceeds value in Table A.7.1 (0.660 $\mathrm{Pg} \mathrm{CO}_{2} /$ year) presumably because U.S. industrial process efficiencies are higher than those in the developing world, so that prorating factor of 0.1436 does not apply; fraction of coal used in industrial processes (e.g., coking, steel) and for electricity generation is not easily demarcated.

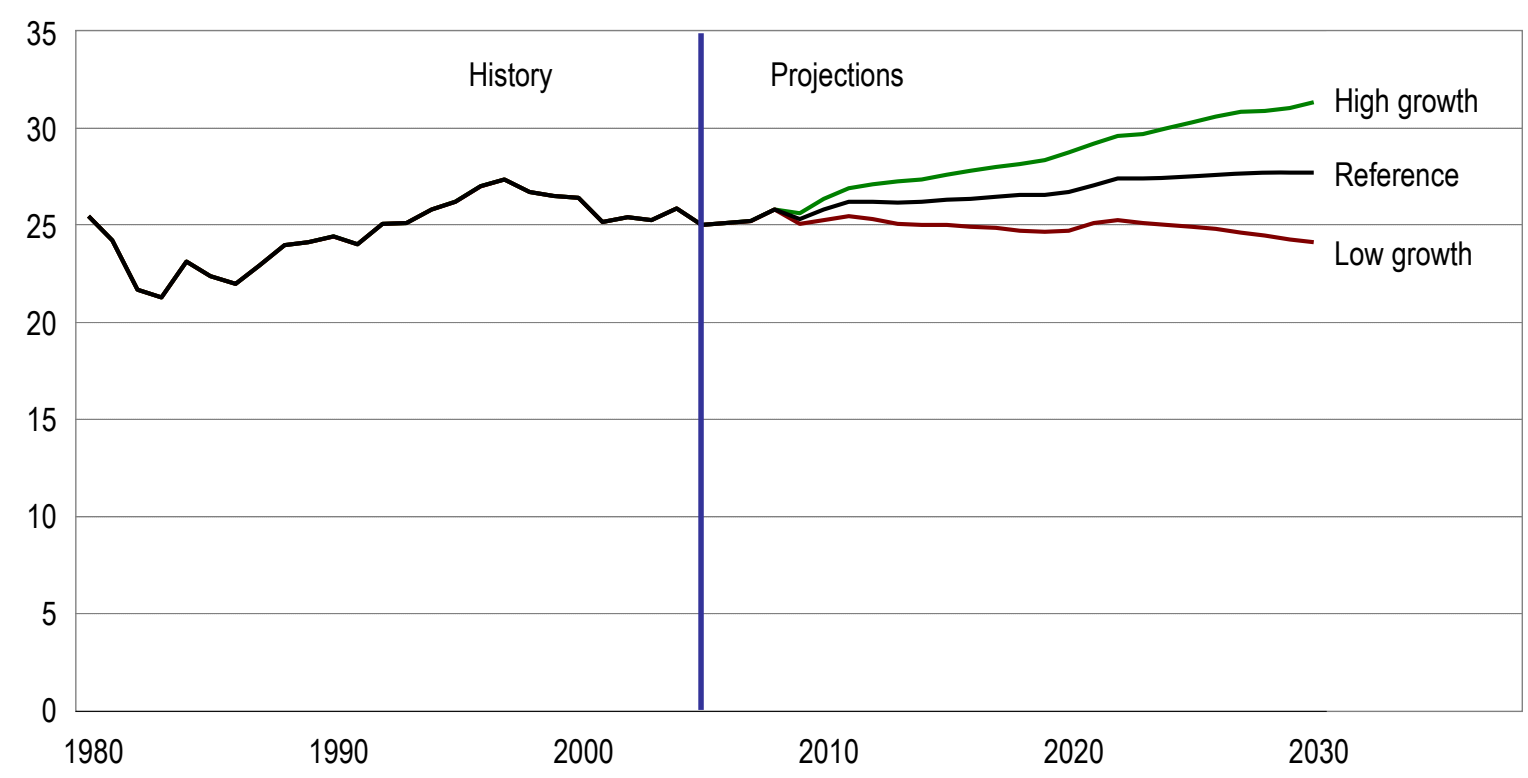

Fig. A.7.1. Industrial delivered energy consumption, 1980-2030 (quadrillion Btu). Source: Energy Information Administration, Annual Energy Outlook 2008, DOE/EIA-0383(2008), U.S. Department of Energy, Washington, DC, June 2008. 


\section{References}

1. Energy Information Administration, Annual Energy Review 2007, DOE/EIA-0384(2007), U.S. Department of Energy, June 2008, http://tonto.eia.doe.gov/FTPROOT/multifuel/038407.pdf (accessed July 8, 2009).

2. Energy Information Administration (EIA), Annual Energy Outlook 2008, DOE/EIA-0383(2008), U.S. Department of Energy, Washington, DC, June 2008, http://www.eia.doe.gov/oiaf/aeo/pdf/0383(2008).pdf (accessed July 7, 2009).

3. International Energy Agency, Energy Technology Perspectives 2008: Summaries and Strategies to 2050 (Organisation for Economic Cooperation and Development, Paris, 2008).

4. D. Pimentel et al., Environ. Dev. Sustain. 6, 279-305 (2004).

5. R. Dorazio et al., Technology Acceleration Program for the GTE Ceramic High-Temperature Recuperator: Final Report, DOE/CS/40330-T1, U.S. Department of Energy, Washington, DC, March 1983.

6. L. Bernstein et al., "Industry," pp. 447-496 in Climate Change 2007: Mitigation. Contribution of Working Group III to the Fourth Assessment Report of the Intergovernmental Panel on Climate Change, ed. B. Metz et al., Intergovernmental Panel on Climate Change, Cambridge University Press, Cambridge and New York, 2007), http://www.ipcc.ch/ipccreports/ar4-wg3.htm (accessed July 8, 2009).

7. R. Perlack et al., Biomass as Feedstock for a Bioenergy and Bioproducts Industry: The Technical Feasibility of a Billion-Ton Annual Supply, ORNL/TM-2005/66, Oak Ridge National Laboratory, Oak Ridge, TN, April 2006, http://feedstockreview.ornl.gov/pdf/billion_ton_vision.pdf (accessed July 8, 2009).

8. R. Elliott, T. Langer, S. Nadel, Reducing Oil Use Through Energy Efficiency: Opportunities Beyond Cars and Light Trucks, Rep. E061, American Council for an Energy-Efficient Economy, Washington, DC, 2006.

9. American Iron and Steel Institute, Saving One Barrel of Oil per Ton (SOBOT): A New Roadmap for Transformation of Steelmaking Process, Washington, DC, October 2005, http://www.climatevision.gov/pdfs/Saving_1005.pdf (accessed July 8, 2009). 


\title{
A.8 ENERGY-EFFICIENT TRANSPORTATION
}

\author{
David L. Greene
}

\section{A.8.1 Technology Description}

The U.S. transportation sector is more than $95 \%$ dependent on petroleum for energy. The technology briefs on biofuels (Sect. A.2) and electric drive vehicles (Sect. A.6) address the potential to introduce other forms of energy for transportation. This technology brief addresses the potential to increase the energy efficiency of all modes of transport.

Significant efficiency improvements are already included in the Frozen 2008 Technology case. Among them is the increase in light-duty vehicle (LDV) fuel economy standards from approximately 25 miles per gallon (mpg) today to $35 \mathrm{mpg}$ by 2020 , leading to a $40 \%$ increase in on-road fleet mpg by 2030 . Freight truck energy efficiency improves by $13 \%$ and commercial aircraft efficiency by $15 \%$ over the same period. In the Frozen 2008 Technology scenario, rail and shipping increase their energy efficiency by a modest $2.5 \%$ (Ref. 1). Transportation energy use in 2030 for the Frozen 2008 Technology case is shown in Fig. A.8.1.

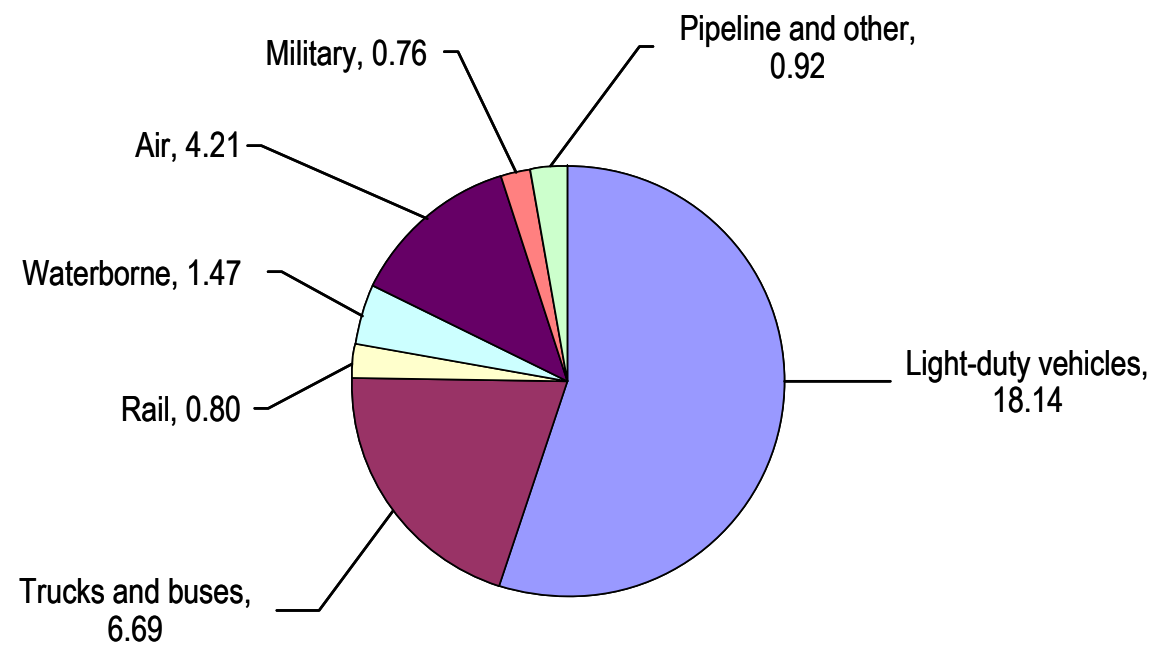

Fig. A.8.1. Transportation energy use (in quadrillion Btu) in 2030 in the Frozen 2008 Technology scenario.

\section{A.8.1.1 Light-Duty Vehicles}

Advances in the technology of internal combustion engine (ICE) LDVs could reduce fuel consumption rates by about $45 \%$ in comparison with 2005 levels (about an $80 \%$ increase in fuel economy) by 2030 (Ref. 2). Key technologies include advanced lightweight materials (20\% mass reduction), gasoline direct-injected or diesel lean-burn engines with electronically boosted turbocharging, camless valves, variable compression ratios, and continuously variable or manual-automatic transmissions. Advanced hybrid vehicles with advanced batteries and electrical components and downsized engines could double or even triple fuel economy in comparison with 2005 levels (Ref. 2). Policies will be necessary, however, to ensure that technological advances are applied to increasing energy efficiency rather than to increasing vehicle weight or power. ${ }^{3}$ 


\section{A.8.1.2 Heavy Trucks}

Key energy efficiency technologies for trucks include advanced diesel engines with a $30 \%$ improvement in efficiency, hybridization to achieve a $60 \%$ fuel economy improvement for trucks operating predominantly in stop-and-go service, advanced aerodynamics to achieve a $20 \%$ drag reduction for trucks in long-haul service, reduction of parasitic losses by $50 \%$, and advanced materials for a tare weight reduction of 15-20\% (Ref. 4). Applying all of these advanced technologies appropriately could produce a $40 \%$ reduction in energy intensity ( $67 \%$ increase in fuel economy) for heavy trucks and buses. ${ }^{5}$

\section{A.8.1.3 Aircraft}

Incremental improvements in conventional aircraft designs are expected to enable a $30-40 \%$ increase in aircraft fuel efficiency by 2050 (Ref. 6). Radical advanced designs, such as the blended wing body, the inclusion of some degree of laminar flow control, and extensive use of advanced lightweight materials could cut fuel consumption rates by $50 \%$ in comparison with 2005 levels. ${ }^{5}$ Improvement in advanced air traffic control and flight control could improve fuel economy by 10 $20 \%$ (Refs. 5 and 7).

\section{A.8.1.4 Rail and Waterborne Transport}

While they are already the most energy-efficient modes of passenger and freight transport, railroads and ships have considerable potential to reduce $\mathrm{CO}_{2}$ emissions. In the United States, perhaps the greatest potential lies in the electrification of the railroad system linked to a decarbonized electricity grid. Rail efficiency improvements are available through friction reduction, advanced lightweight materials for rolling stock, and improved aerodynamics. Opportunities for energy efficiency improvements to ships include advanced propulsion systems, improved hydrodynamics, auxiliary use of wind power, and even a switch to electric drive powered by fuel cells. ${ }^{5}$

\section{A.8.2 Barriers to Realizing Full Potential}

\section{A.8.2.1 Technical Barriers}

Control of advanced combustion systems such as homogeneous charge compression ignition under a wide range of loads and engine speeds remains an unsolved challenge that must be overcome to permit greater use of this energy-efficient combustion technology. For all lean burn engines, costeffective control of nitrogen oxide NOx) emissions continues to be a barrier to full implementation. Although camless valve systems have been built and tested, cost, energy use and control continue to be barriers to mass-market implementation. Variable compression ratio engines face similar challenges. Reductions in thermal losses and improved methods of heat recovery combined with the ability to focus thermal energy into more recoverable availability level could yield significant efficiency gains.

Weight reduction on the order of $20-30 \%$ is a key enabling technology for doubling or tripling LDV fuel economy. Key issues are reducing feedstock material costs for both aluminum and carbon fibers and developing lower-cost manufacturing methods for both materials. Low-cost carbon fiber composites could be applied across all modes of transport.

Onboard electrical storage systems with higher energy and power density and lower cost are essential for realizing the full energy efficiency potential of hybrid electric vehicles.

Advanced aircraft concepts such as the blended wing body have tremendous energy efficiency potential but are far from ready for commercial application. Questions remain about their safety, costeffectiveness, customer acceptance, and manufacturability. 


\section{A.8.2.2 Economic Barriers}

A chief economic barrier is the inefficiency of the market for fuel economy. ${ }^{8}$ Costs are a barrier for almost all advanced transport technologies, from carbon fiber composites to batteries, motors and controllers, and emissions controls for lean-burn engines.

\section{A.8.2.3 Social Barriers}

Most energy efficiency improvements are transparent to the public. However, there are continuing concerns over the safety of lightweight vehicles, and especially compatibility with trucks. Recent research has shown that lighter vehicles can be safer for their occupants, provided that all vehicles are downweighted. ${ }^{9}$ Very significant reductions in vehicle weight may require safety policies that improve vehicle compatibility.

\section{A.8.3 Technological Advances Needed to Realize Full Potential}

Key technological advances needed include:

- low-cost feedstocks and manufacturing processes for carbon fiber composites or comparable high-strength, lightweight materials,

- inexpensive battery technologies with long life and high energy density,

- methods to control combustion irreversibilities in ICEs with the essential methods for converting exhaust and rejected thermal energy to work,

- lean catalysts for NOx and reduction of the amounts of rare earth metals in catalysts, and

- development of advanced airframe concepts such as the blended wing body.

\section{A.8.4 Potential to Reduce $\mathrm{CO}_{2}$ Emissions by 2050}

With the technologies in Sect. A.8.3 and appropriate policies, it should be possible to double today's LDV fuel economy by 2030 , with a tripling achievable by 2050 . The lag in stock turnover implies only a $25 \%$ gain vs the Frozen 2008 Technology case by 2030 and a $75 \%$ gain by 2050 . Taking into account the 40\% fuel economy improvement over 2005 in the Frozen 2008 Technology scenario, this additional increase implies a $75 \%$ improvement over 2005 by 2030 and a nearly $150 \%$ improvement by 2050 . This improvement compares well with the estimates of a $60-70 \%$ reduction in new LDV fuel consumption rates by 2050 in the advanced technology scenarios proposed by the International Energy Agency (IEA). ${ }^{5}$ Through a combination of hybridization of locally operating heavy trucks and thermodynamic, aerodynamic, and other improvements to over-the-road trucks, an additional 50\% improvement in heavy truck fuel economy beyond the Frozen 2008 Technology scenario should be possible. Aircraft efficiency is assumed to improve by an additional $20 \%$ beyond the 15\% improvement in the Frozen 2008 Technology scenario through accelerated implementation of air traffic and flight controls and additional improvements in propulsion, aerodynamics, and lightweight materials. By 2050, it is assumed that advanced technologies enable a 50\% improvement over the Frozen 2008 Technology scenario.

Diffusion of technology into the on-road stock of new vehicles is delayed by a redesign cycle of 5-8 years for new automobiles and 15-20 years for new aircraft. Rates of stock turnover further delay the impact on the operating vehicle stock, by 10-15 years for automobiles, 25-30 years for aircraft, and longer periods for the largest transportation vehicles.

\section{A.8.4.1 Total Potential by 2050}

With the above advanced technologies, it should be possible to increase energy efficiency by more than $20 \%$ in 2030 and by almost $60 \%$ in 2050 in comparison with the Frozen 2008 Technology scenario. Estimated impacts on energy use in the Frozen 2008 Technology scenario are shown in Table A.8.1. The total savings potential in 2050 for the transportation industry is 13.94 quads. If 
1 quad emits about $69.7 \mathrm{Tg}$ of $\mathrm{CO}_{2}$, as calculated from 2007 Energy Information Administration transportation sector data, ${ }^{10}$ then $\mathrm{CO}_{2}$ emissions may be reduced by about $970 \mathrm{Tg} \mathrm{CO}_{2}$ per year.

Table A.8.1. Potential to increase transportation energy and energy savings

\begin{tabular}{|c|c|c|c|c|c|c|}
\hline & \multicolumn{3}{|c|}{2030} & \multicolumn{3}{|c|}{2050} \\
\hline & $\begin{array}{c}\text { Energy use, } \\
\text { quads }\end{array}$ & $\begin{array}{l}\text { Efficiency } \\
\text { gain, } \%\end{array}$ & $\begin{array}{l}\text { Savings, } \\
\text { quads }\end{array}$ & $\begin{array}{c}\text { Energy use, } \\
\text { quads }\end{array}$ & $\begin{array}{c}\text { Efficiency } \\
\text { gain, } \%\end{array}$ & $\begin{array}{c}\text { Savings, } \\
\text { quads }\end{array}$ \\
\hline Light-duty vehicles & 18.14 & 25 & 3.63 & 19.86 & 75 & 8.51 \\
\hline Heavy-duty vehicles & 6.69 & 20 & 1.11 & 8.09 & 50 & 2.70 \\
\hline Rail & 0.80 & 10 & 0.07 & 0.97 & 20 & 0.16 \\
\hline Waterborne & 1.47 & 15 & 0.19 & 1.56 & 33 & 0.39 \\
\hline Aircraft & 4.21 & 20 & 0.70 & 5.65 & 50 & 1.88 \\
\hline Other & 1.69 & 10 & 0.15 & 1.82 & 20 & 0.30 \\
\hline Total & 33.00 & 22 & 5.86 & 37.96 & 58 & 13.94 \\
\hline
\end{tabular}

\section{A.8.5 Potential to Reduce Oil Use by 2030}

In the Frozen 2008 Technology scenario, approximately 10\% of LDV energy use is biofuel (ethanol) by 2010. The energy savings in Table A.8.1 for LDVs are therefore reduced by $10 \%$ to obtain petroleum savings. Oil use reductions by 2030 are more limited because of the inclusion of a 40\% increase in LDV fuel economy in the Frozen 2008 Technology scenario and the shorter lead time for implementation. Average in-use efficiency improvements relative to the Frozen 2008 Technology scenario are shown in Table A.8.1. A National Research Council study ${ }^{11}$ estimated potential reductions in LDV gasoline use of 2.2 billion gallons in 2020 and 35 billion gallons in 2035 resulting from advanced ICE efficiency improvements beyond the existing fuel economy standards. Linear interpolation of a 2030 value and conversion to quads implies a reduction of 3.1 quads, which compares favorably to the energy savings of 3.6 quads shown in Table A.8.1.

\section{A.8.6 Interactions with Other Technologies}

Transportation energy efficiency improvements will not have significant interactions with other technologies that are not accounted for in the essential energy technologies model.

\section{References}

1. Energy Information Administration (EIA), Annual Energy Outlook 2008, DOE/EIA-0383(2008), U.S. Department of Energy, Washington, DC, June 2008, http://www.eia.doe.gov/oiaf/aeo/pdf/0383(2008).pdf (accessed July 7, 2009).

2. E. Kasseris, J. Heywood. "Comparative Analysis of Automotive Powertrain Choices for the Next 25 Years,” SAE Technical Paper Series 2007-01-1605, SAE International, Warrendale, PA, 2007.

3. L. Cheah, C. Evans, A. Bandivadekar, J. Heywood. "Factor of Two: Halving the Fuel Consumption of New U.S. Automobiles by 2035," LFEE 2007-04 RP, Laboratory for Energy and the Environment, Massachusetts Institute of Technology, Cambridge, MA, 2007.

4. Office of Energy Efficiency and Renewable Energy, 21st Century Truck Partnership: Roadmap and Technical White Papers, 21CTP-0003, U.S. Department of Energy, Washington, DC, 2006, http://www1.eere.energy.gov/vehiclesandfuels/pdfs/program/21ctp_roadmap_2007.pdf (accessed July 9, 2009).

5. International Energy Agency, Energy Technology Perspectives 2008: Summaries and Strategies to 2050 (Organisation for Economic Cooperation and Development, Paris, 2008).

6. IPCC Special Report on Aviation and the Global Atmosphere, ed. J. E. Penner et al., Intergovernmental Panel on Climate Change, Cambridge University Press, Cambridge, 1999, http://www.ipcc.ch/ipccreports/sres/aviation/index.htm (accessed July 9, 2009). 
7. Japan International Transport Institute, Issues Concerning the Reduction of Carbon Dioxide in International Aviation, The Nippon Foundation, Tokyo, Japan, August 2007, http://www.japantransport.com/publications/pub_2007.pdf (accessed July 9, 2009).

8. D. Greene, J. German, M. Delucchi, "Fuel Economy: The Case for Market Failure," pp. 181-205 in Reducing Climate Impacts in the Transportation Sector, ed. D. Sperling, J. Cannon, Springer Science, Berkeley, California, 2008).

9. R. Van Auken, J. Zellner. "An Assessment of the Effects of Vehicle Weight and Size on Fatality Risk in 1985 to 1998 Model Year Passenger Cars and 1985 to 1997 Model Year Light Trucks and Vans," SAE Technical Paper 05B-244, SAE International, Warrendale, PA, 2004.

10. Energy Information Administration, Annual Energy Review 2007, DOE/EIA-0384(2007), U.S. Department of Energy, June 2008, http://tonto.eia.doe.gov/FTPROOT/multifuel/038407.pdf (accessed July 7, 2009).

11. National Research Council, Transitions to Alternative Transportation Technologies-A Focus on Hydrogen, National Academies Press, Washington, DC, 2008. 


\title{
A.9 NUCLEAR ENERGY
}

\author{
Alexander Zucker
}

\section{A.9.1 Technology Description}

Currently, $20 \%$ of electricity generated in the United States derives from nuclear power. Energy Information Administration (EIA) forecasts (e.g., Ref. 1) predict that most new electric generation will come from coal combustion. However, fossil-based electric generating plants are a major source of anthropogenic $\mathrm{CO}_{2}$ emissions in the United States, accounting for $40 \%$ of the total and $60 \%$ of the stationary-source (nontransportation) total. Increased use of nuclear power from its current share of $20 \%$ of electricity production to $35 \%$ by 2050 , and growing thereafter to keep pace with demand, would have a major impact on carbon emissions while delivering reliable power.

\section{A.9.2 Barriers to Realizing Full Potential}

The future of nuclear power faces two challenges: one is revitalization of an industry that, in spite of its crucial role in the economy, has stagnated technically; the other is to overcome societal issues that have constrained the natural growth of the industry.

\section{A.9.2.1 Technical Barriers}

Nuclear power production is a proven technology. Nonetheless, technological improvements will spur expansion of nuclear generating capacity and will be necessary for continued large-scale use beyond 2050. Key priorities for research and development (R\&D) include the following.

\section{Waste disposal}

Radioactive waste disposal in geological formations is generally considered to be the best currently available option. Problems arise because (1) fission fragment waste must be cooled over a period of hundreds of years and (2) for the long-lived actinides, waste storage must be safe over periods of thousands of years, a time scale that greatly exceeds the lifespan of any engineering project or nation in human experience. The availability of materials that do not corrode in what could be chemically active environments and that can tolerate high temperatures and irradiation over long periods is an important area where R\&D is needed.

Existing technologies include vitrification for fission fragment sequestration, currently used in France, or storage in copper-clad containers, proposed by Sweden for both fission fragments and actinides. ${ }^{2}$ Fundamental to long-term waste disposal is a good understanding of the geology of candidate repositories, including especially the possibility of water incursion and the effect of earthquakes. The technology also faces the ethical question: to what extent is the current generation responsible to protect generations of humans and the environment in the far distant future?

Another technological challenge is transforming the waste into elements with far shorter halflives that pose less serious risks to the environment or society. A very small fraction of nuclear waste, the minor actinides, contribute overwhelmingly to the heat load and to the transportable, highly biologically toxic component of the waste. After reprocessing to remove the plutonium and uranium, an accelerator-based "burner" can transmute the remaining minor actinides to shorter lived and therefore more manageable waste streams - with a half-life measured in a few hundred years - that do not require long-term storage. Prospects for transmutation of the long-lived minor actinides in radioactive waste by proton beams supplied by high-power particle accelerators are being actively examined by Japan, Korea, and the European Union. Further, burning of the weapons-grade plutonium also benefits nonproliferation efforts. 
A 2008 assessment by the International Energy Agency ${ }^{3}$ led to the following conclusion: "Transmutation of the minor actinides to shorter-lived isotopes will probably involve either fast reactor or accelerator technologies - thermal reactors cannot practically do this for all the necessary isotopes. Progress is likely only with substantial international co-operation. There are significant problems associated with handling large quantities of pure americium and curium, however, and in creating fuel for fast-reactor transmutation, or targets for accelerator transmutation. Commercial application of these technologies is still a considerable way off." The time scale for implementation if sufficient research is done appears to be 2-3 decades.

\section{Fuel cycle}

Fuel and enrichment capacity in the United States are sufficient to satisfy the requirements to 2050 (Ref. 4). Beyond that date, a growing nuclear energy enterprise will have to address enrichment, spent fuel storage, recycle of spent fuel, and the many chemical, materials, and environmental questions connected to them. It will therefore be necessary to begin planning, serious technical investigations, and R\&D within the next ten years. A long-term commitment to nuclear energy implies serious investigations of new fuels, fast reactor development for breeders, and fuel reprocessing and re-enrichment.

\section{New reactors}

The United States currently has 104 operating power reactors. If these reactors are replaced at 60 years of age, and nuclear power generation expands to $35 \%$ of supply by 2050 , the equivalent of about 300 plants, each with a capacity of $1 \mathrm{GWe}$, will need to be built. These reactors will incorporate a number of technological advances to increase safety and efficiency while reducing cost and simplifying construction. About two-thirds of the current reactors are pressurized water reactors (PWRs), and the rest are boiling water reactors (BWRs). Currently contemplated technology related to reactor safety includes integral design, where pumps and steam generators are inside the shield structure, with essentially no penetrations for pipes. Generation III+ reactors, such as the Westinghouse AP1000 PWR and the GE ESBWR (Economic Simplified BWR), employ passive safety systems to shut down the reactor and dissipate heat without operator intervention or need for electric power. New technology for the next generation of safe power reactors may include the following advances.

1. Smaller reactors, between 300 and $600 \mathrm{MWe}$, represent smaller risks. In safety parlance, small is beautiful. These reactors may be gas cooled, eliminating many corrosion problems, and make siting independent of large bodies of water.

2. Design studies are now under way to develop modular reactors, with individual self-contained modules of $30 \mathrm{MWe}$, employing factory construction of pressure vessels and component installation. This new technology makes safety-related inspection simpler and more reliable, and incidentally could lead to an export item for smaller countries that are looking for small, safe, and easy-to-operate electric power sources. Unless substantial economies of scale can be realized in production these small reactors are likely to be much more expensive in dollars per $\mathrm{kW}$.

3. Work on controls represents another area where technical progress will make reactors safer. Digital controls are currently the state of the art, but there is room for development of safetyrelated diagnostic and control systems with faster response times that incorporate better displays, artificial intelligence, and robotic controls. Retrofitting existing reactors with digital controls will add safety to reactors to be relicensed.

4. Every technology can benefit from new and improved materials. Safe, high-temperature reactors, with improved efficiency, require high-temperature materials: ceramics, composites, and alloys. Technical advances in this area will require both new basic research and the application of new technologies. The expected result is the development of reactors with efficiencies in the $45 \%$ range, compared to the current generation of reactors with efficiencies of about $33 \%$ (Ref. 5). 


\section{Nuclear proliferation}

Nuclear proliferation is a major impediment to the globalization of nuclear power, and it remains a serious issue for domestic nuclear power, as well. Enriched uranium fuel is one concern, but power plant fuel must be further enriched for weapons. Of more concern is waste, which can be used in dirty bombs and from which plutonium can be extracted to make hydrogen bombs. Expansion of nuclear power will create more waste at more sites, creating more opportunity for theft and diversion. Several technical areas could benefit from renewed attention and new ideas:

- Large information systems are needed to keep track of fissionable materials. Interrogation systems based on neutron or X-ray sources and employing large-area detectors may be of use.

- Small accelerators or perhaps even small, pulsed reactors may be useful in detecting fissionable materials transported in ships or airplanes.

- Development of a thorium-based breeder reactor would make the theft of fuel much more difficult since it inevitably contains uranium-232, a strong gamma emitter that is hard to handle and easy to detect. A thorium-based nuclear breeder may be advantageous in its own right, since thorium is more plentiful in the earth's crust than uranium, but in this case the relatively short life and the strong gamma radiation are impediments to the technology.

\section{A.9.2.2 Economic Barriers}

Nuclear power plants have high and rapidly rising capital costs. Recent projects have overnight capital costs of about $\$ 4,500 / \mathrm{kW}(\mathrm{e})$. High finance costs, reflecting project risk and long construction timetables, lead to total project costs (including interest and escalation for materials and labor) approaching $\$ 7,000 / \mathrm{kW}(\mathrm{e})$ (Ref. 6). These costs are more than double the estimates of a just a few years ago (e.g., the overnight cost of $\$ 2,000 / \mathrm{kW}(\mathrm{e})$ advanced in a 2003 study by the Massachusetts Institute of Technology $\left.{ }^{7}\right)$. The recent cost escalations reflect a combination of factors, including commodity cost increases, shortage of skilled labor, and insufficient production capacity or number of suppliers for critical parts. ${ }^{8}$

In contrast to fossil generating plants, nuclear plants have low costs for fuel, and they do not emit $\mathrm{CO}_{2}$. These two factors will weigh heavily on plant economics, particularly if $\mathrm{CO}_{2}$ emissions are taxed or capped. The more expensive fossil fuel and carbon emissions become, the better nuclear looks. The other factor that will weigh heavily is policy. For nuclear, key issues include tax incentives, loan guarantees, carbon credits, long-term waste disposal, and regulatory relief to accelerate construction times.

\section{A.9.2.3 Social Barriers}

The major societal barriers largely mirror the technical barriers discussed above. Expansion of nuclear energy still faces significant resistance due to public fears about safety and concerns about waste disposal. Two high-profile accidents (at Three Mile Island in the United States in 1979 and Chernobyl in the Soviet Union in 1986) dampened public enthusiasm for nuclear power. Since that time, the U.S. nuclear power industry, under the supervision of the Nuclear Regulatory Commission, has maintained an excellent safety record. Recent polls suggest softening in the opposition to nuclear power plants, particularly when support is framed in terms of a benefit. For example, a 2006 Bloomberg-Los Angeles Times poll found that $61 \%$ of Americans would support "increased use of nuclear power as a source of energy in order to prevent global warming." (Ref. 9).

\section{A.9.3 Technological Advances Needed to Realize Full Potential}

Nuclear power generation has been used in the United States for more than 50 years, and there are no major technical barriers preventing the deployment of 300 new reactors by 2050. In this time frame, several key technological challenges can remain unsolved, including long-term waste disposal, 
fuel reprocessing, and advanced fuel cycles. The barriers that exist are technological, social, and economic.

\section{A.9.4 Potential to Reduce $\mathrm{CO}_{2}$ Emissions by 2050.}

Nuclear power is potentially a large source of low- $\mathrm{CO}_{2}$ electricity. The exact carbon footprint of nuclear power generation is the subject of some debate. Although the plants release no $\mathrm{CO}_{2}$ in the course of operation, substantial indirect emissions occur in their construction, operation, and shutdown, as well as in the mining and processing of uranium. A recent survey of 103 lifecycle analyses ${ }^{10}$ found $\mathrm{CO}_{2}$ emission estimates ranging from 1.4 to $288 \mathrm{~g} \mathrm{CO}_{2} / \mathrm{kWh}$. Considering the mean value of $66 \mathrm{~g} \mathrm{CO}_{2} / \mathrm{kWh}$, nuclear does not do as well as some of the renewables, but it fairs far better than fossil fuels. In 1998, $\mathrm{CO}_{2}$ emissions in electric generation were estimated at $950 \mathrm{~g} / \mathrm{kWh}$ for coal, $893 \mathrm{~g} / \mathrm{kWh}$ for petroleum, and $599 \mathrm{~g} / \mathrm{kWh}$ for gas. ${ }^{11}$ Even with CCS on the fossil generation, nuclear will be at least competitive and likely superior. Table A.9.1 estimates the emissions reduction obtainable in 2050 by increasing the percentage of nuclear-based electricity from today's level of $19 \%$ to $35 \%$ and using it to replace coal-based electricity. Total electricity generation in 2050 is estimated at $6,918 \mathrm{kWh}$ in 2050 by linearly extrapolating from the high economic growth case of Ref. 1.

Table A.9.1. Emissions reduction obtainable by increasing nuclear-based energy generation from $19 \%$ to $25 \%$ of total electricity generation $(6,918 \mathrm{kWh})$ in 2050

\begin{tabular}{|c|c|c|c|c|c|c|}
\hline & \multicolumn{3}{|c|}{$19 \%$ nuclear } & \multicolumn{3}{|c|}{$35 \%$ nuclear } \\
\hline & $\begin{array}{c}\text { Share } \\
\text { of total } \\
\text { generation }\end{array}$ & $\begin{array}{l}\text { Electricity } \\
\text { generated, } \\
\text { billion } \mathrm{kWh}\end{array}$ & $\begin{array}{c}\text { Emissions, } \\
\mathrm{Tg} \mathrm{CO}_{2}\end{array}$ & $\begin{array}{c}\text { Share } \\
\text { of total } \\
\text { generation }\end{array}$ & $\begin{array}{l}\text { Electricity } \\
\text { generated, } \\
\text { billion } \mathrm{kWh}\end{array}$ & $\begin{array}{c}\text { Emissions, } \\
\mathrm{Tg} \mathrm{CO}_{2}\end{array}$ \\
\hline Coal & $49 \%$ & 3390 & 3220 & $33 \%$ & 2283 & 2169 \\
\hline Nuclear & $19 \%$ & 1314 & 87 & $35 \%$ & 2421 & 160 \\
\hline $\begin{array}{l}\text { Total emission, } \\
\mathrm{Tg} \mathrm{CO}_{2}\end{array}$ & & & 3307 & & & 2329 \\
\hline $\begin{array}{l}\text { reduction, } \\
\mathrm{Tg} \mathrm{CO}_{2}\end{array}$ & & & & & & 978 \\
\hline
\end{tabular}

\section{A.9.5 Potential to Reduce Oil Use by 2030}

Only a small, steadily decreasing fraction of electricity $(1.2 \%)$ is generated from petroleum, and most of the petroleum burned for electric generation is residual fuel oil and petroleum coke, which are not suitable for transportation. Competition for transportation fuel amounts to approximately 43,000 barrels per day of distillate oil. ${ }^{12}$ Transportation use amounts to 14 million barrels per day (mmbd), projected to increase to $16.6 \mathrm{mmbd}$ in 2030 (Ref. 1). Electric generation therefore competes for just $0.3 \%$ of transportation fuel. Given that the distillate oil used is primarily diesel fuel for remote, supplemental, and backup generation, it is unlikely that expanded use of nuclear power will directly displace a significant amount of oil consumption.

Indirect displacement could occur in three major ways. First, electrification of the transportation sector would displace a shift a significant amount of petroleum consumption to electric energy consumption. Second, replacement of petroleum used for space heating with electricity could have a significant impact. In 2006, 1.12 quads of energy from distillate fuel oil was used for residential and commercial space and water heating. ${ }^{1}$ If nuclear-based electricity were used instead of the fuel oil, this would save 1.12 quads of petroleum. Third, nuclear power could in principle be used to generate hydrogen to replace petroleum fuels in transportation. 


\section{A.9.6. Interactions with Other Technologies}

Nuclear will need to compete with other electric technologies on the basis of safety, reliability, and cost. To the extent that wind, solar, and advanced fossil fuel generating technologies (with or without CCS) succeed, nuclear will become less important. To the extent that they fail, nuclear will become more important.

\section{References}

1. Energy Information Administration (EIA), Annual Energy Outlook 2008, DOE/EIA-0383(2008), U.S. Department of Energy, Washington, DC, June 2008, http://www.eia.doe.gov/oiaf/aeo/pdf/0383(2008).pdf (accessed July 7, 2009).

2. V. Petitjean, C. Fillet, R. Boen, C. Veyer, T. Flament, "Development of Vitrification Process and Glass Formulation for Nuclear Waste Conditioning," presented at the 2002 Waste Management Conference (WM02), Tucson, AZ, February 24-28, 2002.

3. International Energy Agency, Energy Technology Perspectives 2008: Summaries and Strategies to 2050 (Organisation for Economic Cooperation and Development, Paris, 2008), p. 298.

4. Basic Energy Sciences Advisory Committee, Basic Research Needs to Assure a Secure Energy Future, February 2003, http://www.science.doe.gov/bes/reports/files/SEF_rpt.pdf (accessed July 7, 2009).

5. J. Buongiorno, P. MacDonald, Supercritical Water Reactor (SCWR): Progress Report for the FY-03 Generation-IV R\&D Activities for the Development of SCWR in the U.S., INEEL/EXT-03-01210, Idaho National Energy and Engineering Laboratory, Idaho Falls, ID, September 2003, http://nuclear.inl.gov/gen4/docs/scwr_annual_progress_report_gen-iv_fy-03.pdf (accessed July 8, 2009).

6. Nuclear Energy Institute, The Cost of New Generating Capacity in Perspective, white paper, 2008, http://www.nei.org/filefolder/The_Cost_of_New_Generating_Capacity_in_Perspective.pdf)

7. Massachusetts Institute of Technology, The Future of Nuclear Power, Cambridge, MA, 2003, http://web.mit.edu/nuclearpower/pdf/nuclearpower-full.pdf (accessed July 8, 2009).

8. S. Kidd, "Escalating Costs of New Build: What Does It Mean?" Nuclear Engineering International, August 22, 2008, http://www.neimagazine.com/story.asp?storyCode=2050690 (accessed July 8, 2009).

9. T. Bolsen, F. L. Cook, Public Opin. Quart. 72, 364-388 (2008).

10. B. K. Sovacool, Energ. Policy 36, 2950-2963 (2008).

11. Department of Energy, Environmental Protection Agency, Carbon Dioxide Emissions from the Generation of Electric Power in the United States, Washington, DC, 2000, http://www.eia.doe.gov/cneaf/electricity/page/co2_report/co2emiss.pdf (accessed July 8, 2009).

12. Energy Information Agency, Sales of Distillate Fuel Oil by End Use, U.S. Department of Energy, Washington, DC, http://tonto.eia.doe.gov/dnav/pet/pet_cons_821dst_dcu_nus_a.htm (accessed July 8 , 2009). 


\title{
A.10 SOLAR ENERGY
}

\author{
Philip R. Boudreaux
}

\section{A.10.1 Technology Description}

The sun delivers a massive amount of power to the Earth's surface, over 10,000 times the annual global energy use. ${ }^{1}$ This solar energy can presently be converted to electricity at an average efficiency of $15 \%$. Technologies used to convert sunlight to electricity can be categorized into two areas: solar thermal power or concentrating solar power (CSP) and photovoltaics (PV). CSP harnesses the heat from the sun and converts the heat to electricity, while PV uses semiconductor devices to convert the solar radiation directly to electricity. The three main types of CSP technologies are trough-based power plants, power tower plants, and dish/engine-based systems. CSP technologies are appropriate for utility-scale power generation but are of practical value primarily in arid climates at low latitudes. PV technologies are applicable to both utility-scale and distributed power generation installations. The highest efficiency PV systems are based on single-crystal silicon, with multi-crystal silicon following closely behind in efficiency. Thin-film technologies for PV offer the potential for low-cost (per area) systems but are much less efficient. Emerging technologies in thin-film PV that may revolutionize the PV market are CIGS (copper indium gallium di-selenide) and cadmium telluride (CdTe). A subset of PV technology, concentrator PV (CPV), uses concentrating optics to focus sunlight on relatively small PV cells, enabling the use of more exotic, multi-layer PV components. CPV is applicable both for utility and distributed power generation but, like CSP, is limited in practical application to low-latitude arid environments. Solar water heating at individual facilities is a very efficient use of solar energy to displace energy from conventional (electric or gas) water heating systems, but it is limited to distributed generation installations.

\section{A.10.2 Barriers to Realizing Full Potential}

\section{A.10.2.1 Technical Barriers}

Solar energy in general has similar issues across all technologies. Performance depends on the quality of the solar resource available in the area. For large grid-tied solar-based power plants that rely on solar concentration, this limits the technology to arid low-latitude areas. For these systems, thermal storage technologies are an enabling and emerging technology area that significantly increases the practicality of the systems. Thermal storage enables the deployment of CSP energy at optimum intervals to offset peak grid loads and also enables CSP systems to remain viable energy sources during the temporary absence (up to 1-2 days) of significant sun exposure. The efficiency of all solar technologies needs to be increased to make them competitive with conventional power generation methods.

\section{A.10.2.2 Economic Barriers}

Solar power is more expensive, in terms of dollars per kilowatthour, than coal, natural gas, and nuclear power. Current costs are $\$ 0.21-0.38 / \mathrm{kWh}$ for PV-based electricity ${ }^{2}$ and $\$ 0.10-0.12 / \mathrm{kWh}$ for trough-based CSP, ${ }^{3}$ compared with $\$ 0.014-0.028 / \mathrm{kWh}$ for coal-based electricity ${ }^{4}$ (for natural gas, the power generation cost is similar but the fuel is more expensive). Solar technology will not become competitive until its costs come down to the same level as coal and natural gas, or conversely until the costs of conventional electricity production rise to the same level as solar power (for example, implementation of a carbon tax of $\$ 50 / \mathrm{Mg}$ of $\mathrm{CO}_{2}$ could raise the price for coal-based electricity by about $\$ 0.05 / \mathrm{kWh})$. 
The cost of solar power can be reduced both by increasing the efficiency of the technologies through research and development (R\&D) and by moving to larger scale production of components and guaranteed material stocks. According to one report, ${ }^{3}$ trough-based systems are expected to produce electricity at a cost of $\$ 0.035-0.062 / \mathrm{kWh}$ by 2020 , and the International Energy Agency predicts a decrease in the cost of PV to $\$ 0.05-0.07 / \mathrm{kWh}$ by 2050 for installations producing more than $1600 \mathrm{kWh} / \mathrm{kWp}$-year in the "sunbelt" region if significant technological advances are achieved. ${ }^{4}$ In the meantime, federal and state incentives can help bring down end-user cost and spur acceptance of solar technologies.

\section{A.10.2.3 Social Barriers}

Social factors that affect the adoption of large-scale solar generation facilities fall into two categories: generation and distribution. Large-scale facilities require large landmass areas and may invoke a host of environmental and aesthetic concerns. Ideal locations for large-scale systems are often located at significant geographical distances from population centers and thus may require construction of new transmission lines (with attendant environmental and right of way issues) and contribute to overloading of existing grid infrastructure.

\section{A.10.3 Technological Advances Needed to Realize Full Potential}

\section{All solar technologies need increases in solar-to-electric efficiency and a decrease in cost.} Of the CSP technologies, trough-based power is the most mature. Development of a direct steam generation technique that replaces the oil used in the receiver tubes with water would allow cost reductions. ${ }^{5}$ It may also be possible to use larger turbines to increase efficiency. Power tower and dish/engine technology still needs to be demonstrated at a large grid-tied megawatt scale.

Single-crystal silicon remains preeminent in PV efficiency, and improved feedstock infrastructures will continue to lower costs. Emerging technologies for high-efficiency thin-film devices (e.g., CIGS and CdTe) may provide effective building-integrated PV solutions for large-area arrays in locations that are not suited to higher efficiency PV technologies. A technical focus on methods for effectively integrating those technologies into building structures will facilitate the acceptance and integration of these emerging technologies.

\section{A.10.4 Potential to Reduce $\mathrm{CO}_{2}$ Emissions by 2050}

Predictions of solar energy's impacts on greenhouse gas (GHG) emissions span a wide range. The estimates presented here have been gathered from the available literature and range from conservative to extremely generous.

A report produced by the American Solar Energy Society ${ }^{6}$ projects that CSP could provide 30 $80 \mathrm{GW}$ by 2030 . For a capacity factor of 0.427 and a conversion rate of $770 \mathrm{Mg} \mathrm{CO} / / \mathrm{GWh}$ displaced, this amount of CSP would reduce carbon emissions by $230 \mathrm{Tg} \mathrm{CO}_{2} /$ year. This report also claims that $200 \mathrm{GW}$ of PV could be installed in the United States by 2030. For a capacity factor of 0.427 and a conversion rate of $770 \mathrm{Mg} \mathrm{CO}_{2} / \mathrm{GWh}$ displaced, $200 \mathrm{GW}$ of PV could reduce $\mathrm{CO}_{2}$ emissions by an additional $230 \mathrm{Tg} \mathrm{CO}_{2} /$ year. Thus, solar energy could produce a carbon reduction of $460 \mathrm{Tg} \mathrm{CO} /$ year by 2030 .

The "Blue" scenario proposed in the International Energy Agency (IEA) Energy Technology Perspectives 2008 (Ref. 4) calls for a 50\% reduction in emissions (compared with 2005 levels) by 2050; it includes $650 \mathrm{TWh}$ of PV power generation and $300 \mathrm{TWh}$ of CSP generation in North America by this date. This would require $436 \mathrm{GW}$ of PV (assuming a 17\% capacity factor) and $80 \mathrm{GW}$ of CSP (assuming a 0.427 capacity factor). Although the Organisation for Economic and Community Development (OECD) definition of North America includes Mexico, which has a significant solar resource, for the sake of argument it is assumed that the United States will install the solar power required by the "Blue" scenario. If the stated amounts of power are achieved, then a 
reduction of $734 \mathrm{Tg} \mathrm{CO}_{2} /$ year could be achieved by 2050 (assuming $770 \mathrm{Mg} \mathrm{C} / \mathrm{GWh}$ and the replacement of $950 \mathrm{TWh}$ of conventional power generation with solar power).

Zweibel et al. ${ }^{7}$ describe a series of steps that would make it possible for solar power to provide $69 \%$ of the U.S. electricity demand and $35 \%$ of the total energy demand in 2050 . This plan reduces $\mathrm{CO}_{2}$ by $3.6 \mathrm{Pg} /$ year $(1.7 \mathrm{Pg} /$ year from power plants and $1.9 \mathrm{Pg} /$ year from replacement of gasolinepowered cars with plug-in hybrid electric vehicles); it also calls for a DC transmission infrastructure and compressed air and hot salt energy storage for the solar plants. If this plan were fully implemented, $\mathrm{CO}_{2}$ emissions levels in 2050 would be $62 \%$ lower than in 2005; however, success requires that the United States be fully invested in solar power.

\section{A.10.5 Potential to Reduce Oil Use by 2030}

As petroleum accounts for less than $2 \%$ of the electricity fuels, the use of solar power to generate electricity will not significantly reduce oil use by 2030 . If solar does replace the petroleum used in the electricity generation sector, then it would save about 0.224 quads, assuming that petroleum-based electricity accounted for $65.7 \mathrm{TWh}$ in 2007 (Ref. 8). The use of solar power to replace coal and natural gas may indirectly reduce oil use if there is a decrease in coal mining and natural gas drilling, which are dependent on diesel and gas. The savings, however, are very difficult to calculate. Also, if plug-in hybrid electric vehicles succeed and the electricity needed for the vehicles is supplied by solar power, then solar power has the opportunity to reduce oil use in the transportation industry.

\section{A.10.6 Interactions with Other Technologies}

Solar energy can replace other power-generating technologies, such as coal and natural gas, and effectively decrease GHG emissions. The use of solar technology use in residential and commercial off-grid applications, such as PV and solar hot water heating, can reduce energy needs from the grid. If plug-in hybrid electric vehicles are successful, then clean sources of electricity will become more crucial; in this scenario, solar energy is very attractive.

\section{References}

1. Climate Change 2007: Mitigation. Contribution of Working Group III to the Fourth Assessment Report of the Intergovernmental Panel on Climate Change, ed. B. Metz et al., Intergovernmental Panel on Climate Change, Cambridge University Press, Cambridge and New York, 2007), http://www.ipcc.ch/ipccreports/ar4-wg3.htm (accessed July 8, 2009).

2. Solarbuzz, "Solar Electricity Global Benchmark Price Indices," http://www.solarbuzz.com/SolarIndices.htm (accessed August 25, 2008).

3. H. Price, Executive Summary: Assessment of Parabolic Trough and Power Tower Solar Technology Cost and Performance Forecasts, NREL/SR-550-35060, National Renewable Energy Laboratory, Golden, CO, October 2003.

4. International Energy Agency, Energy Technology Perspectives 2008: Summaries and Strategies to 2050 (Organisation for Economic Cooperation and Development, Paris, 2008).

5. M. Eck, W. Steinmann, J. Solar Energy Eng. 124, 134-139 (May 2002).

6. Tackling Climate Change in the US-Potential Carbon Emissions Reductions from Energy Efficiency and Renewable Energy by 2030, ed. C. Kutscher, American Solar Energy Society, 2007.

7. K. Zweibel, J. Mason, V. Fthenakis, “A Solar Grand Plan,” Scientific American 298, 64-73 (2008), http://www.sciam.com/article.cfm?id=a-solar-grand-plan\&page=5 (accessed July 8, 2009).

8. Energy Information Administration, Annual Energy Review 2007, DOE/EIA-0384(2007), U.S. Department of Energy, June 2008, http://tonto.eia.doe.gov/FTPROOT/multifuel/038407.pdf (accessed July 7, 2009). 


\section{A.11 WIND ENERGY}

Philip R. Boudreaux

Alexander Zucker

\section{A.11.1 Technology Description}

Since the early 1980s, turbines have been used to harness the power of wind for utility-scale electricity generation. Today, turbines typically have a power capacity of $0.5-5.0 \mathrm{MW}$ and blade lengths of 20-40 m, are 60-90 m tall, and turn at 10-22 revolutions per minute. These turbines perform best in winds above 10 miles/hour that are fairly constant, making site location a critical component in the performance of the turbines. For a commercial utility-scale installation, thousands of turbines might be installed.

This method of energy generation stagnated in the late 1980s and early 1990s. However, in the past few years, high energy costs, a heightened awareness of environmental pollution, and the desire for energy independence have contributed to a rapid increase in U.S. wind capacity. The American Wind Energy Association (AWEA) estimated that at the end of 2008, the United States had $24,000 \mathrm{MW}$ of total wind power capacity. ${ }^{1}$ Figure A.11.1 shows the growth of U.S. wind power capacity from 1999 through 2008 (Refs. 1 and 2). In 2007, wind energy accounted for 35\% of all new U.S. electric generating capacity, with more than 5,000 MW installed. This was second only to natural gas (7,500 MW installed) and well ahead of coal-fired generation (1,400 MW installed). ${ }^{3}$

With a total installed wind electric generating capacity of $24 \mathrm{GW}$ generating almost $70 \mathrm{TWh}$ in a year (assuming a 33\% capacity factor), the United States now leads the world in wind-powered electrical energy. However impressive this might sound, wind energy still only provides around $1 \%$ of the nation's energy use. Also, increases in the cost of wind turbines could slow growth in this sector; since 2004, costs have increased by $20 \%$ (Ref. 4).

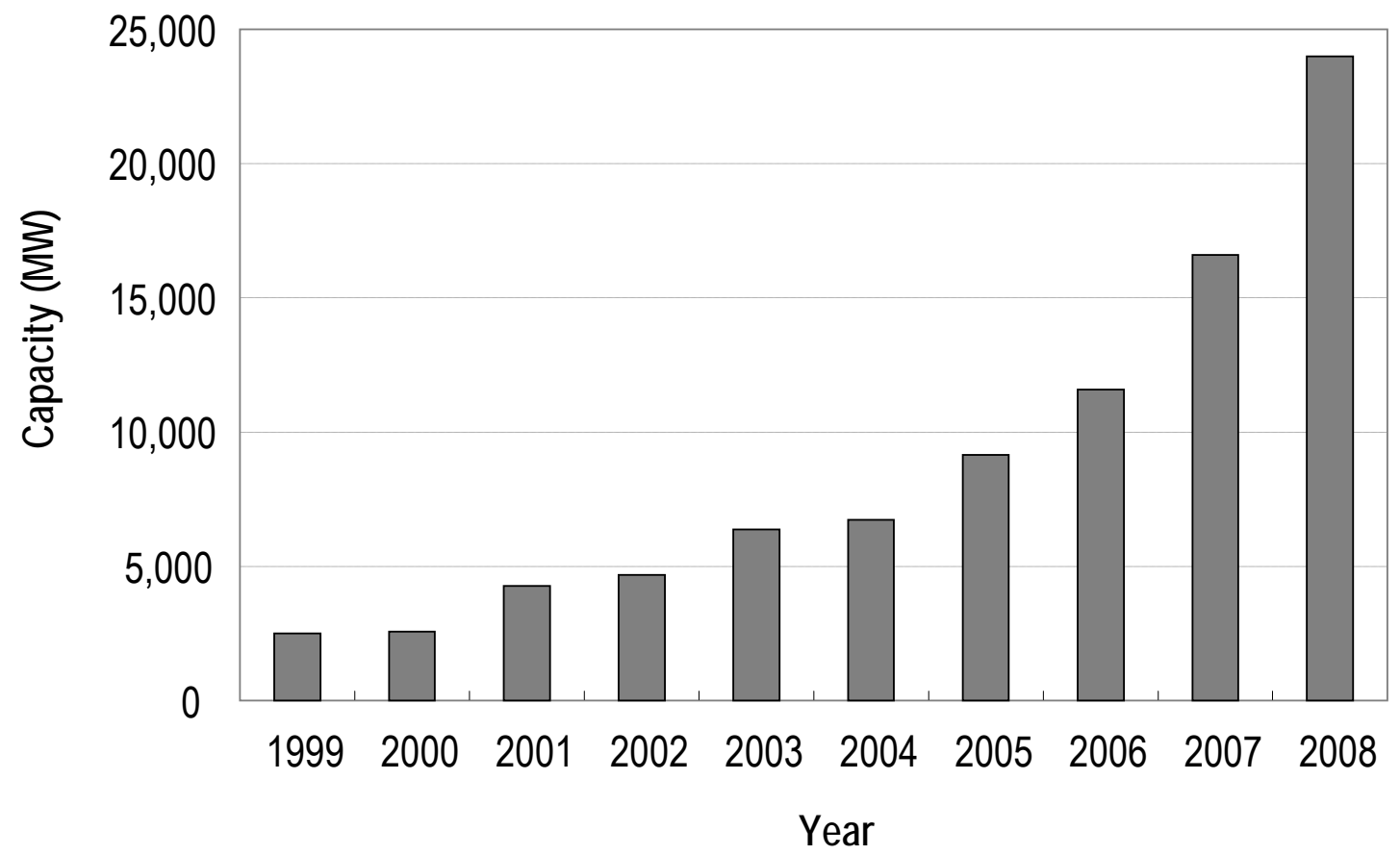

Fig. A.11.1. Total U.S. wind capacity. Data compiled from the National Renewable Energy Laboratory and the American Wind Energy Association. 
A 2008 report $^{5}$ issued by the U.S. Department of Energy (DOE) states that $20 \%$ of U.S. electricity could be generated by wind power by 2030 with no new technological breakthroughs, just advances in the current technology. This would greatly decrease greenhouse gas (GHG) emissions if wind power replaces electricity generated by burning coal or natural gas.

\section{A.11.2 Barriers to Realizing Full Potential}

\section{A.11.2.1 Technical Barriers}

In discussing wind power it is useful to divide the industry into two sectors: onshore and offshore. Currently, all U.S. wind energy is onshore.

The efficiency of onshore wind turbines has increased by $2-3 \%$ each year over the last 15 years (Ref. 4) as the result of greater elevation of blades and turbines, more efficient generators, and improved siting. Further increases in performance can be obtained through continued effort in these areas, although difficulties in transportation of extremely large components will ultimately limit turbine size and height.

Offshore wind turbines are typically larger than onshore; most have outputs of 3-3.5 MW, with some reaching 5-6 MW. Denmark and the United Kingdom are leading the world in offshore wind energy capacity. Although offshore wind costs are 50\% higher than onshore installations, the turbines can produce $50 \%$ more power because of better wind conditions. ${ }^{4}$ The most challenging aspects of offshore wind farms are grid connection and dealing with harsh environments. Offshore installations are limited to areas where water depth is less than $50 \mathrm{~m}$. Floating platforms are getting some attention as means of placing wind farms in deeper water. This idea would also be useful in a hybrid-type power plant using both wave motion and wind turbines to generate electricity. The International Energy Agency (IEA) cites four specific priorities for research and design efforts in offshore wind power: substructure research, improved reliability, better transport and logistics, and high-voltage DC technology for connecting offshore farms to the grid. ${ }^{4}$

Other technical issues affecting all wind technologies include energy storage methods, cost reductions, improvements to power quality, and wind forecasting. More efficient superconducting generators, smart rotors, and kite concepts are more novel ideas that might one day increase the quality of wind power.

\section{A.11.2.2 Economic Barriers}

The AWEA estimates that wind power costs about $\$ 0.05 / \mathrm{kWh}$ with current tax credits, ${ }^{6}$ making it competitive with coal and natural gas. Capital costs are $\$ 1,200-1,700 / \mathrm{kW}$ for onshore installations and $\$ 2,225-3,000 / \mathrm{kW}$ for offshore installations. ${ }^{4}$ Vestas Wind Systems (one of the largest wind turbine manufacturers) has located substantial manufacturing capacity in Colorado; a blade manufacturing plant in Windsor produces 1,800 blades per year, and a tower factory in Pueblo will construct 900 towers per year. The company is also constructing a nacelle assembly factory and blade factory in Brighton, with expected annual production capacity of 1,400 nacelles and 1,800-2,000 blades. ${ }^{7}$

As indicated in Fig. A.11.2, the potential for wind power is not equally distributed over the continental United States. The densest areas of good wind resources for onshore installations are in the central portion of the nation, far from the large cities on the east and west coasts. In addition, wind intensity varies not only geographically, but also daily and seasonally; in general, winter and spring are high wind seasons, and summer and autumn are low seasons. This is not universally true: for example, Washington and Oregon have high winds in the summer, and other regions do not follow the general rule. Nevertheless, the variability over days and months means that in the absence of improved energy storage technology, wind power - unlike coal, natural gas, or nuclear energy —is not yet a dependable source of baseload power. 


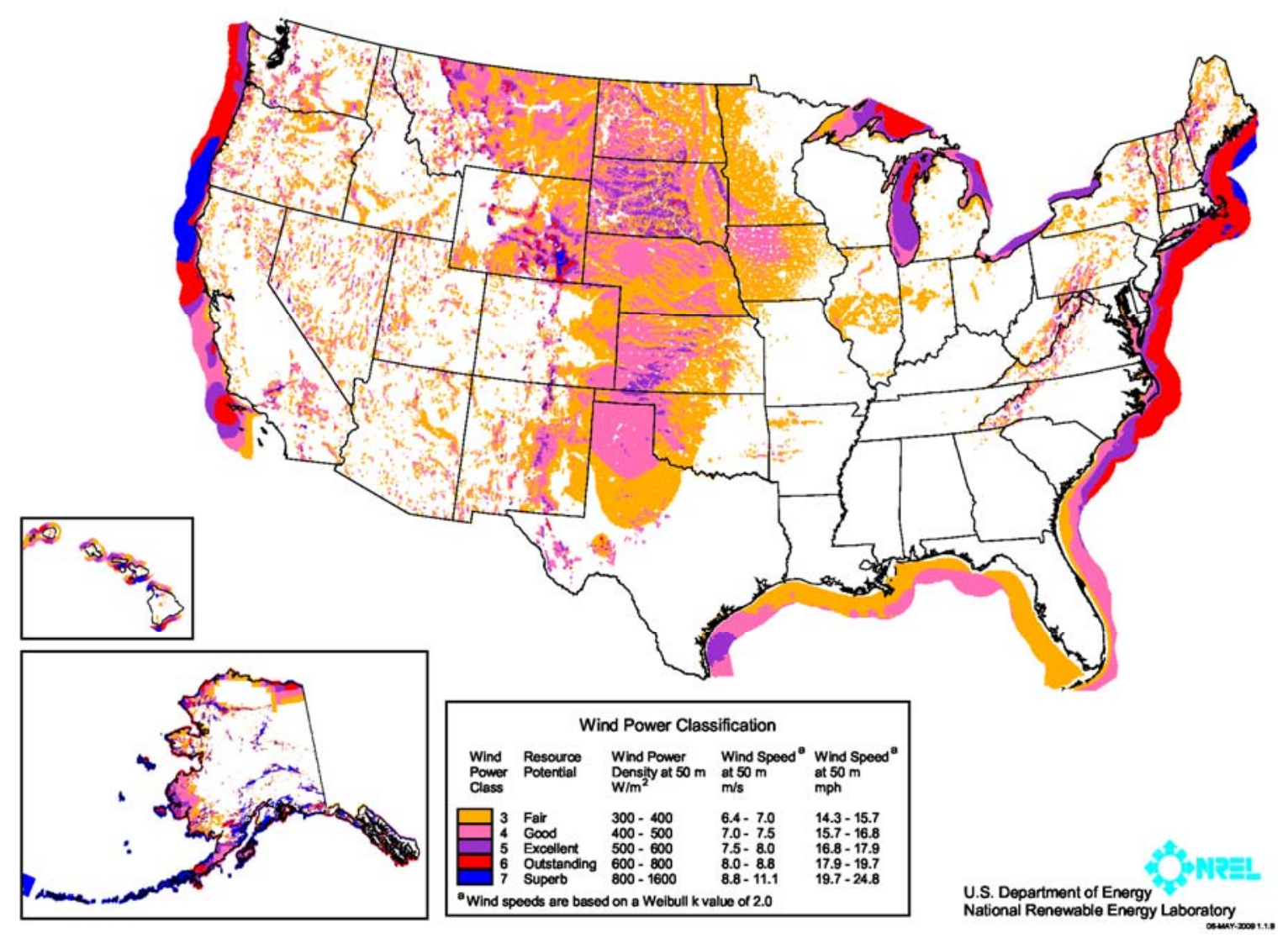

Fig. A.11.2. U.S. wind resource map, showing annual average wind power estimates at a height of $50 \mathbf{~ m}$. The map combines high-resolution and low-resolution data sets produced by the National Renewable Energy Laboratory and other organizations; data was screened to eliminate areas unlikely to be developed onshore due to land use or environmental issues. In many states, the wind resource on this map is visually enhanced to better show the distribution on ridge crests and other features. Source: National Renewable Energy Laboratory.

\section{A.11.2.3 Social Barriers}

Wind power has four main social impacts: aesthetics, noise, potential interactions with weather and climate patterns, and impacts on bird and bats.

The visual impact of wind turbines is a key factor in public acceptance; some people see them as detracting from the beauty of scenery and landscapes. Wind turbine manufacturers are making efforts to paint turbines in colors that will blend in with clouds. Design tools, such as photomontage and animation, are making it easier for designers and developers to visualize the aesthetic impact that wind turbines will have on the surrounding landscape. ${ }^{4}$

Noise is generated both by the mechanics in the generator/transmission assembly and by the blades themselves as they slice through the air. Both sources of noise can be minimized with careful engineering and design.

Although wind turbines produce no $\mathrm{CO}_{2}$ when operating, little is known about how widespread tapping of the world's wind resource might affect climate and weather patterns. Keith et al. ${ }^{8}$ have performed climate simulations showing that very large amounts of wind power can produce nonnegligible climatic change at continental scales, and Brostom ${ }^{9}$ has studied the influence of large wind farms on the upper ocean circulation. Additional research on this topic is needed. 
Impacts on birds and bats represent another environmental aspect of wind turbines. It may be that as turbines increase in size and turn more slowly, fewer birds are harmed. Blade tip speeds, however, do not appear to be slowing. According to a study by WEST, Inc., the wind farm at Altamont Pass in California kills some 540 raptors a year. ${ }^{10}$ This wind farm has 5,400 turbines, and the high raptor mortality rate is attributed to the type of turbine (small and fast rotating), layout of the wind farm (turbines close together), and location (high raptor presence because of prey in area). New wind turbines are estimated to have raptor mortality rates of 0-0.04 /year, compared to the per-turbine rate of 0.05-0.1/year at Altamont Pass. ${ }^{10}$ The Bats and Wind Energy Cooperative, an alliance of state and federal agencies, private industry, academic institutions, and nongovernmental organizations, is engaged in developing solutions to minimize or, where possible, prevent mortality of bats at wind power turbines.

\section{A.11.3 Technological Advances Needed to Realize Full Potential}

Wind power is a relatively mature industry; however, improvements in efficiency can be made by increasing the height of towers and the blade length of the turbines, designing more efficient generators, and focusing on site research so that sites with the best wind resources are tapped. Other areas for potentially fruitful research include connecting wind power to the grid and optimizing the use of an intermittent power source. Research in this area should be focused on power storage, robust electrical networks (including superconducting transmission lines), and power conditioning. The National Renewable Energy Laboratory (NREL) and Sandia National Laboratories are collaborating in research on low wind speed technologies and on the WindPACT program to help industry increase the efficiency of the mechanics and parts of the wind turbine. NREL also collaborates in research on utility grid integration.

Storage of the electrical energy from wind turbines is important because of wind power's intermittent nature. One promising way to store the energy is to produce and store hydrogen. Wind turbines can produce hydrogen through electrolysis, and hydrogen can be stored and used at any time to power homes, industry, or transportation. Although this possibility is still in the research and design stage, work on the idea is under way at NREL, which has a research focus called Wind-toHydrogen and has launched a demonstration project in partnership with industry. ${ }^{11}$

\section{A.11.4 Potential to Reduce $\mathrm{CO}_{2}$ Emissions by 2050}

A roadmap 5 prepared by DOE's Office of Energy Efficiency and Renewable Energy (EERE) outlines a plan for achieving $300 \mathrm{GW}$ of wind power capacity by 2030 (with an average $50 \%$ capacity factor), which will supply the nation with $20 \%$ of its electricity needs. Three areas are identified as critical to ensuring the success of this plan: improvements in turbine technology for more efficient wind-to-electricity conversion, improvements in transmission systems for connecting wind farms to the electric grid, and expanded markets for wind power. With these targets met, the plan projects cumulative emission reductions of 7,600 $\mathrm{Tg}$ of $\mathrm{CO}_{2}$ by 2030 (with a reduction of $825 \mathrm{Tg}$ of $\mathrm{CO}_{2}$ in 2030 alone) and $15,000 \mathrm{Tg}$ of $\mathrm{CO}_{2}$ by 2050 . Wind power is assumed to replace $50 \%$ of the nation's natural gas-based electricity and $18 \%$ of its coal-based electricity.

The EERE Wind Technologies Program projects that $240 \mathrm{GW}$ of wind capacity will be available by 2050 if program goals are met. ${ }^{12}$ This program is focused on increasing turbine capacity factors and lowering costs through increased technical viability and wind energy deployment in the marketplace. Assuming a 50\% capacity factor and $631 \mathrm{Mg} \mathrm{CO}_{2} / \mathrm{GWh}$ reduction in GHG for fossil fuel based electric generation that is replaced, $240 \mathrm{GW}$ of wind capacity can reduce emissions by $663 \mathrm{Tg} \mathrm{CO}_{2} /$ year by 2050 . 


\section{A.11.5 Potential to Reduce Oil Use by 2030}

Oil has an insignificant role in the electricity generation sector; thus, the use of wind power to generate electricity will not displace a significant amount of oil. ${ }^{12}$ However, if wind-based electricity is used for electric vehicles, then there is some potential for wind power to reduce the amount of oil used in transportation fuels.

\section{A.11.6 Interactions with Other Technologies}

Wind power has the potential to reduce the use of electricity generated using fossil fuel. Depending on what this "green" source of electricity is used for, wind power also has the potential to decrease transportation fuel use if the electric drive vehicle succeeds.

\section{References}

1. American Wind Energy Association, 3rd Quarter 2008 Market Report, October 2008, http://www.awea.org/newsroom/releases/solar_and_wind_09Jan09.html.

2. Office of Energy Efficiency and Renewable Energy, "Installed U.S. Wind Capacity and Wind Project Locations," U.S. Department of Energy, Washington, DC, http://www.windpoweringamerica.gov/wind_installed_capacity.asp (accessed July 10, 2009).

3. Office of Energy Efficiency and Renewable Energy, Annual Report on U.S. Wind Power Installations, Cost, and Performance Trends for 2007, U.S. Department of Energy, Washington, DC, May 2008, http://www1.eere.energy.gov/windandhydro/pdfs/43025.pdf).

4. International Energy Agency, Energy Technology Perspectives 2008: Summaries and Strategies to 2050 (Organisation for Economic Cooperation and Development, Paris, 2008).

5. Office of Energy Efficiency and Renewable Energy, 20\% Wind Energy by 2030, DOE/GO-102008-2567, U.S. Department of Energy, Washington, DC, July 2008, http://www.windpoweringamerica.gov/pdfs/20_percent_wind_2.pdf (accessed July 10, 2009).

6. American Wind Energy Association (AWEA), "Wind Energy Costs," http://www.awea.org/faq/wwt_costs.html (accessed July 10, 2009).

7. Wind Powering America, "Economic Impacts in Colorado from Four Vestas Manufacturing Facilities," Wind Powering America Fact Sheet Series, DOE/GO-102009-2717, U.S. Department of Energy, Washington, DC, April 2009, http://www.windpoweringamerica.gov/pdfs/economic_development/2009/ vestas_manufacturing_facilities.pdf (accessed July 9, 2009).

8. D. W. Keith et al., Proc. Natl. Acad. Sci. 101, 16115-16120 (2004).

9. G. Brostrom, J. Marine Sys. 74, 585-591 (2008)

10. W. Erickson et al., Synthesis and Comparison of Baseline Avian and Bat Use, Raptor Nesting and Mortality Information from Proposed and Existing Wind Developments, West, Inc., Cheyenne, WY, December 2002.

11. National Renewable Energy Laboratory, "Wind-to-Hydrogen Project," (accessed July 10, 2009).

12. Projected Benefits of Federal Energy Efficiency and Renewable Energy Programs: FY 2008 Budget Request, NREL/TP-640-41347, National Renewable Energy Laboratory, Golden, CO, March 2007, http://www.nrel.gov/docs/fy07osti/41347.pdf (accessed July 10, 2009). 
APPENDIX B. TECHNOLOGY IMPACT MATRICES 


\section{B.1 ELECTRICITY}

Table B.1.1 provides the 2050 reference projections for the electricity sector that were used to assess the impacts of the 11 essential energy technologies on $\mathrm{CO}_{2}$ emissions from each fuel source for this sector, as documented in Table B.1.2.

Table B.1.3 documents the impacts of the 11 essential energy technologies on the U.S. petroleum supply/demand balance in the electricity sector in 2030 .

Table B.1.1 Electricity sector: 2050 reference projections

\begin{tabular}{lrrrr}
\hline \multicolumn{1}{c}{ Energy source } & $\begin{array}{c}\text { Energy, } \\
\text { quads }\end{array}$ & $\begin{array}{c}\text { Energy } \\
\text { share }\end{array}$ & $\begin{array}{c}\text { Carbon } \\
\text { intensity, } \\
\mathrm{Tg} \mathrm{CO}_{2} / \text { quad }\end{array}$ & $\begin{array}{c}\text { Total } \mathrm{CO}_{2} \\
\text { emissions, } \\
\mathrm{Tg}\end{array}$ \\
\hline Coal & 47.0 & $73.2 \%$ & 94.9 & 4462.1 \\
Natural gas & 3.7 & $5.7 \%$ & 53.1 & 197.8 \\
Petroleum & 0.9 & $1.3 \%$ & 75.9 & 65.6 \\
Biofuel/renewable & 7.4 & $11.4 \%$ & 0.0 & 0.0 \\
Electricity/nuclear/electricity imports & 6.0 & $9.2 \%$ & 0.8 & 4.9 \\
\hline
\end{tabular}


Table B.1.2. Technology impacts on $\mathrm{CO}_{2}$ emissions in the electricity sector

\begin{tabular}{|c|c|c|c|c|c|c|c|c|c|c|c|}
\hline & $\mathrm{CCS}$ & Nuclear & Wind & Solar & Biomass & $\mathrm{EV}$ & TRAN & BLDG & IND & EEGD & AFL \\
\hline \multicolumn{12}{|l|}{ Coal } \\
\hline Carbon intensity & $-90 \%$ & $0 \%$ & $0 \%$ & $0 \%$ & $0 \%$ & $0 \%$ & $0 \%$ & $0 \%$ & $0 \%$ & $0 \%$ & $0 \%$ \\
\hline Energy intensity & $10 \%$ & $0 \%$ & $0 \%$ & $0 \%$ & $0 \%$ & $0 \%$ & $0 \%$ & $0 \%$ & $0 \%$ & $-30 \%$ & $0 \%$ \\
\hline Energy share, quads & 0.0 & -11.6 & -8.5 & -8.0 & -3.0 & 0.0 & 0.0 & 0.0 & 0.0 & 0.0 & 0.0 \\
\hline \multicolumn{12}{|l|}{ Natural gas } \\
\hline Carbon intensity & $-90 \%$ & $0 \%$ & $0 \%$ & $0 \%$ & $0 \%$ & $0 \%$ & $0 \%$ & $0 \%$ & $0 \%$ & $0 \%$ & $0 \%$ \\
\hline Energy share, quads & 0.0 & -0.9 & -1.9 & -0.6 & -0.2 & 0.0 & 0.0 & 0.0 & 0.0 & 0.0 & 0.0 \\
\hline \multicolumn{12}{|l|}{ Petroleum } \\
\hline Carbon intensity & $0 \%$ & $0 \%$ & $0 \%$ & $0 \%$ & $0 \%$ & $0 \%$ & $0 \%$ & $0 \%$ & $0 \%$ & $0 \%$ & $0 \%$ \\
\hline Energy intensity & $0 \%$ & $0 \%$ & $0 \%$ & $0 \%$ & $0 \%$ & $0 \%$ & $0 \%$ & $0 \%$ & $0 \%$ & $-30 \%$ & $0 \%$ \\
\hline Energy share, quads & 0.0 & -0.2 & 0.0 & -0.1 & -0.1 & 0.0 & 0.0 & 0.0 & 0.0 & 0.0 & 0.0 \\
\hline \multicolumn{12}{|l|}{$\begin{array}{l}\text { Biofuel/renewable } \\
\text { energy }\end{array}$} \\
\hline Carbon intensity & $0 \%$ & $0 \%$ & $0 \%$ & $0 \%$ & $0 \%$ & $0 \%$ & $0 \%$ & $0 \%$ & $0 \%$ & $0 \%$ & $0 \%$ \\
\hline Energy intensity & $0 \%$ & $0 \%$ & $0 \%$ & $0 \%$ & $0 \%$ & $0 \%$ & $0 \%$ & $0 \%$ & $0 \%$ & $-30 \%$ & $0 \%$ \\
\hline Energy share, quads & 0.0 & -1.8 & 10.3 & 9.7 & 3.7 & 0.0 & 0.0 & 0.0 & 0.0 & 0.0 & 0.0 \\
\hline \multicolumn{12}{|l|}{$\begin{array}{l}\text { Electricity/nuclear/ } \\
\text { electricity imports }\end{array}$} \\
\hline Carbon intensity & $0 \%$ & $0 \%$ & $0 \%$ & $0 \%$ & $0 \%$ & $0 \%$ & $0 \%$ & $0 \%$ & $0 \%$ & $0 \%$ & $0 \%$ \\
\hline Energy intensity & $0 \%$ & $0 \%$ & $0 \%$ & $0 \%$ & $0 \%$ & $0 \%$ & $0 \%$ & $0 \%$ & $0 \%$ & $-30 \%$ & $0 \%$ \\
\hline Energy share, quads & 0.0 & 14.5 & 0.0 & -1.0 & -0.4 & 0.0 & 0.0 & 0.0 & 0.0 & 0.0 & 0.0 \\
\hline
\end{tabular}


Table B.1.3. Technology impacts on petroleum in the electricity sector

2030 reference projection: Petroleum provides 0.68 quads of energy ( $1.3 \%$ of total for sector) with an impact factor of 75.9

\begin{tabular}{|l|c|c|c|c|c|c|c|c|c|c|c|}
\hline & CCS & Nuclear & Wind & Solar & Biomass & EV & TRAN & BLDG & IND & EEGD & AFL \\
\hline Petroleum intensity & $0 \%$ & $0 \%$ & $0 \%$ & $0 \%$ & $0 \%$ & $0 \%$ & $0 \%$ & $0 \%$ & $0 \%$ & $0 \%$ & $0 \%$ \\
\hline Energy intensity & $0 \%$ & $0 \%$ & $0 \%$ & $0 \%$ & $0 \%$ & $0 \%$ & $0 \%$ & $0 \%$ & $0 \%$ & $\mathbf{- 3 0 . 0} \%$ & $0 \%$ \\
\hline Energy share, quads & 0.0 & 0.0 & 0.0 & 0.0 & 0.0 & 0.0 & 0.0 & 0.0 & 0.0 & $\mathbf{- 0 . 9}$ & 0.0 \\
\hline
\end{tabular}





\section{B.2 INDUSTRY}

Table B.2.1 provides the 2050 reference projections for the industry sector that were used to assess the impacts of the 11 essential energy technologies on $\mathrm{CO}_{2}$ emissions from each fuel source for this sector, as documented in Table B.2.2.

Table B.2.3 documents the impacts of the 11 essential energy technologies on the U.S. petroleum supply/demand balance in the industry sector in 2030 .

Table B.2.1 Industry sector: 2050 reference projections

\begin{tabular}{|c|c|c|c|c|}
\hline Energy source & $\begin{array}{c}\text { Energy, } \\
\text { quads }\end{array}$ & $\begin{array}{c}\text { Energy } \\
\text { share }\end{array}$ & $\begin{array}{c}\text { Carbon } \\
\text { intensity, } \\
\mathrm{Tg} \mathrm{CO}_{2} / \text { quad } \\
\end{array}$ & $\begin{array}{c}\text { Total } \mathrm{CO}_{2} \\
\text { emissions, } \\
\mathrm{Tg} \\
\end{array}$ \\
\hline Coal & 2.7 & $8.5 \%$ & 90.2 & 240.7 \\
\hline Natural gas & 9.2 & $29.5 \%$ & 52.2 & 481.4 \\
\hline Petroleum & 10.9 & $35.0 \%$ & 47.3 & 515.9 \\
\hline Biofuel/renewable & 4.5 & $14.4 \%$ & 0.0 & 0.0 \\
\hline Electricity/nuclear/electricity imports & 3.9 & 12.5 & 0.0 & 0.0 \\
\hline
\end{tabular}


Table B.2.2. Technology impacts on $\mathrm{CO}_{2}$ emissions in the industry sector

\begin{tabular}{|c|c|c|c|c|c|c|c|c|c|c|c|}
\hline & $\mathrm{CCS}$ & Nuclear & Wind & Solar & Biomass & EV & TRAN & BLDG & IND & EEGD & AFL \\
\hline \multicolumn{12}{|l|}{ Coal } \\
\hline Carbon intensity & $-50 \%$ & $0 \%$ & $0 \%$ & $0 \%$ & $0 \%$ & $0 \%$ & $0 \%$ & $0 \%$ & $0 \%$ & $0 \%$ & $0 \%$ \\
\hline Energy intensity & $5 \%$ & $0 \%$ & $0 \%$ & $0 \%$ & $0 \%$ & $0 \%$ & $0 \%$ & $0 \%$ & $-25 \%$ & $0 \%$ & $0 \%$ \\
\hline Energy share, quads & 0.0 & 0.0 & 0.0 & 0.0 & 0.0 & 0.0 & 0.0 & 0.0 & 0.0 & 0.0 & 0.0 \\
\hline \multicolumn{12}{|l|}{ Natural gas } \\
\hline Carbon intensity & $-50 \%$ & $0 \%$ & $0 \%$ & $0 \%$ & $0 \%$ & $0 \%$ & $0 \%$ & $0 \%$ & $0 \%$ & $0 \%$ & $0 \%$ \\
\hline Energy share, quads & 0.0 & 0.0 & 0.0 & 0.0 & -0.1 & 0.0 & 0.0 & 0.0 & 0.0 & 0.0 & 0.0 \\
\hline \multicolumn{12}{|l|}{ Petroleum } \\
\hline Carbon intensity & $0 \%$ & $0 \%$ & $0 \%$ & $0 \%$ & $0 \%$ & $0 \%$ & $0 \%$ & $0 \%$ & $0 \%$ & $0 \%$ & $0 \%$ \\
\hline Energy intensity & $0 \%$ & $0 \%$ & $0 \%$ & $0 \%$ & $0 \%$ & $0 \%$ & $0 \%$ & $0 \%$ & $-25 \%$ & $0 \%$ & $0 \%$ \\
\hline Energy share, quads & 0.0 & 0.0 & 0.0 & 0.0 & -0.1 & 0.0 & 0.0 & 0.0 & 0.0 & 0.0 & 2.0 \\
\hline \multicolumn{12}{|l|}{$\begin{array}{l}\text { Biofuel/renewable } \\
\text { energy }\end{array}$} \\
\hline Carbon intensity & $-50 \%$ & $0 \%$ & $0 \%$ & $0 \%$ & $0 \%$ & $0 \%$ & $0 \%$ & $0 \%$ & $0 \%$ & $0 \%$ & $0 \%$ \\
\hline Energy intensity & $5.0 \%$ & $0 \%$ & $0 \%$ & $0 \%$ & $0 \%$ & $0 \%$ & $0 \%$ & $0 \%$ & $-25 \%$ & $0 \%$ & $0 \%$ \\
\hline Energy share, quads & 0.0 & 0.0 & 0.0 & 0.0 & 0.3 & 0.0 & 0.0 & 0.0 & 0.0 & 0.0 & 0.0 \\
\hline \multicolumn{12}{|l|}{$\begin{array}{l}\text { Electricity/nuclear/ } \\
\text { electricity imports }\end{array}$} \\
\hline Carbon intensity & $0 \%$ & $0 \%$ & $0 \%$ & $0 \%$ & $0 \%$ & $0 \%$ & $0 \%$ & $0 \%$ & $0 \%$ & $0 \%$ & $0 \%$ \\
\hline Energy intensity & $0 \%$ & $0 \%$ & $0 \%$ & $0 \%$ & $0 \%$ & $0 \%$ & $0 \%$ & $0 \%$ & $-25 \%$ & $0 \%$ & $0 \%$ \\
\hline Energy share, quads & 0.0 & 0.0 & 0.0 & 0.0 & 0.0 & 0.0 & 0.0 & 0.0 & 0.0 & 0.0 & 0.0 \\
\hline
\end{tabular}

Notes: The impact of advanced fossil fuel liquids on the carbon intensity of petroleum use is dependent on the success of carbon capture and storage (CCS). With CCS, there is assumed to be no impact. Without CCS, the impact is an energy share-weighted average of the different sources of advanced fossil fuels. For coal-to-liquids, the multiplier is 2.0; for enhanced oil recovery, it is 0.7 ; and for oil produced from sensitive environments, it is 1.0 . 
Table B.2.3. Technology impacts on petroleum in the industry sector

2030 reference projection: Petroleum provides 10.33 quads of energy (34.3\% of total for sector) with an impact factor of 47.3

\begin{tabular}{|l|c|c|c|c|c|c|c|c|c|c|c|}
\hline & CCS & Nuclear & Wind & Solar & Biomass & EV & TRAN & BLDG & IND & EEGD & AFL \\
\hline Petroleum intensity & $0 \%$ & $0 \%$ & $0 \%$ & $0 \%$ & $0 \%$ & $0 \%$ & $0 \%$ & $0 \%$ & $0 \%$ & $0 \%$ & $0 \%$ \\
\hline Energy intensity & $0 \%$ & $0 \%$ & $0 \%$ & $0 \%$ & $0 \%$ & $0 \%$ & $0 \%$ & $0 \%$ & $\mathbf{- 1 0} \%$ & $0 \%$ & $0 \%$ \\
\hline Energy share, quads & 0.0 & 0.0 & 0.0 & 0.0 & $-\mathbf{0 . 7}$ & $\mathbf{- 0 . 2}$ & $\mathbf{- 0 . 3}$ & 0.0 & 0.0 & 0.0 & 0.0 \\
\hline
\end{tabular}





\section{B.3 TRANSPORTATION}

Table B.3.1 provides the 2050 reference projections for the transportation sector that were used to assess the impacts of the 11 essential energy technologies on $\mathrm{CO}_{2}$ emissions from each fuel source for this sector, as documented in Table B.3.2.

Table B.3.3 documents the impacts of the 11 essential energy technologies on the U.S. petroleum supply/demand balance in the transportation sector in 2030 .

Table B.3.1 Transportation sector: 2050 reference projections

\begin{tabular}{lrrrr}
\hline \multicolumn{1}{c}{ Energy source } & $\begin{array}{c}\text { Energy, } \\
\text { quads }\end{array}$ & $\begin{array}{c}\text { Energy } \\
\text { share }\end{array}$ & $\begin{array}{c}\text { Carbon } \\
\text { intensity, } \\
\mathrm{Tg} \mathrm{CO}_{2} / \text { quad }\end{array}$ & $\begin{array}{c}\text { Total } \mathrm{CO}_{2} \\
\text { emissions, } \\
\mathrm{Tg}\end{array}$ \\
\hline Coal & 0.0 & $0.0 \%$ & 95.0 & 0.0 \\
Natural gas & 0.9 & $2.4 \%$ & 53.7 & 49.9 \\
Petroleum & 35.4 & $92.2 \%$ & 66.7 & 2360.1 \\
Biofuel/renewable & 2.0 & $5.3 \%$ & 20.0 & 41.0 \\
Electricity/nuclear/electricity imports & 0.0 & $0.1 \%$ & 0.0 & 0.0 \\
\hline
\end{tabular}


Table B.3.2. Technology impacts on $\mathrm{CO}_{2}$ emissions in the transportation sector

\begin{tabular}{|c|c|c|c|c|c|c|c|c|c|c|c|}
\hline & $\mathrm{CCS}$ & Nuclear & Wind & Solar & Biomass & EV & TRAN & BLDG & IND & EEGD & AFL \\
\hline \multicolumn{12}{|l|}{ Coal } \\
\hline Carbon intensity & $0 \%$ & $0 \%$ & $0 \%$ & $0 \%$ & $0 \%$ & $0 \%$ & $0 \%$ & $0 \%$ & $0 \%$ & $0 \%$ & $0 \%$ \\
\hline Energy intensity & $0 \%$ & $0 \%$ & $0 \%$ & $0 \%$ & $0 \%$ & $0 \%$ & $-35.0 \%$ & $0 \%$ & $0 \%$ & $0 \%$ & $0 \%$ \\
\hline Energy share, quads & 0.0 & 0.0 & 0.0 & 0.0 & 0.0 & 0.0 & 0.0 & 0.0 & 0.0 & 0.0 & 0.0 \\
\hline \multicolumn{12}{|l|}{ Natural gas } \\
\hline Carbon intensity & $0 \%$ & $0 \%$ & $0 \%$ & $0 \%$ & $0 \%$ & $0 \%$ & $0 \%$ & $0 \%$ & $0 \%$ & $0 \%$ & $0 \%$ \\
\hline Energy intensity & $0 \%$ & $0 \%$ & $0 \%$ & $0 \%$ & $0 \%$ & $0 \%$ & $-35.0 \%$ & $0 \%$ & $0 \%$ & $0 \%$ & $0 \%$ \\
\hline Energy share, quads & 0.0 & 0.0 & 0.0 & 0.0 & 0.0 & 0.0 & 0.0 & 0.0 & 0.0 & 0.0 & 0.0 \\
\hline \multicolumn{12}{|l|}{ Petroleum } \\
\hline Carbon intensity & $0 \%$ & $0 \%$ & $0 \%$ & $0 \%$ & $0 \%$ & $0 \%$ & $0 \%$ & $0 \%$ & $0 \%$ & $0 \%$ & $0 \% / 14.7 \%$ \\
\hline Energy intensity & $0 \%$ & $0 \%$ & $0 \%$ & $0 \%$ & $0 \%$ & $0 \%$ & $-35.0 \%$ & $0 \%$ & $0 \%$ & $0 \%$ & $0 \%$ \\
\hline Energy share, quads & 0.0 & 0.0 & 0.0 & 0.0 & -6.7 & -13.2 & 0.0 & 0.0 & 0.0 & 0.0 & 0.0 \\
\hline \multicolumn{12}{|l|}{$\begin{array}{l}\text { Biofuel/renewable } \\
\text { energy }\end{array}$} \\
\hline Carbon intensity & $0 \%$ & $0 \%$ & $0 \%$ & $0 \%$ & $0 \%$ & $0 \%$ & $0 \%$ & $0 \%$ & $0 \%$ & $0 \%$ & $0 \%$ \\
\hline Energy intensity & $0 \%$ & $0 \%$ & $0 \%$ & $0 \%$ & $0 \%$ & $0 \%$ & $-35.0 \%$ & $0 \%$ & $0 \%$ & $0 \%$ & $0 \%$ \\
\hline Energy share, quads & 0.0 & 0.0 & 0.0 & 0.0 & 6.7 & 0.0 & 0.0 & 0.0 & 0.0 & 0.0 & 0.0 \\
\hline \multicolumn{12}{|l|}{$\begin{array}{l}\text { Electricity/nuclear/ } \\
\text { electricity imports }\end{array}$} \\
\hline Carbon intensity & $-85 \%$ & $0 \%$ & $0 \%$ & $0 \%$ & $0 \%$ & $0 \%$ & $0 \%$ & $0 \%$ & $0 \%$ & $0 \%$ & $0 \%$ \\
\hline Energy intensity & $0 \%$ & $0 \%$ & $0 \%$ & $0 \%$ & $0 \%$ & $0 \%$ & $-35.0 \%$ & $0 \%$ & $0 \%$ & $0 \%$ & $0 \%$ \\
\hline Energy share, quads & 0.0 & 0.0 & 0.0 & 0.0 & 0.0 & 6.6 & 0.0 & 0.0 & 0.0 & 0.0 & 0.0 \\
\hline
\end{tabular}

Notes: The impact of advanced fossil fuel liquids on the carbon intensity of petroleum use is dependent on the success of carbon capture and storage (CCS). With CCS, there is assumed to be no impact. Without CCS, the impact is an energy share-weighted average of the different sources of advanced fossil fuels. For coal-to-liquids, the multiplier is 2.0; for enhanced oil recovery, it is 0.7 ; and for oil produced from sensitive environments, it is 1.0 . 
Table B.3.3. Technology impacts on petroleum in the transportation sector

2030 reference projection: Petroleum provides 29.93 quads of energy ( $90.7 \%$ of total for sector) with an impact factor of 71.6

\begin{tabular}{|l|c|c|c|c|c|c|c|c|c|c|c|}
\hline & CCS & Nuclear & Wind & Solar & Biomass & EV & TRAN & BLDG & IND & EEGD & AFL \\
\hline Petroleum intensity & $0 \%$ & $0 \%$ & $0 \%$ & $0 \%$ & $0 \%$ & $0 \%$ & $0 \%$ & $0 \%$ & $0 \%$ & $0 \%$ & $0 \%$ \\
\hline Energy intensity & $0 \%$ & $0 \%$ & $0 \%$ & $0 \%$ & $0 \%$ & $0 \%$ & $\mathbf{- 1 6 \%}$ & $0 \%$ & $0 \%$ & $0 \%$ & $0 \%$ \\
\hline Energy share, quads & 0.0 & 0.0 & 0.0 & 0.0 & $-\mathbf{6 . 7}$ & $-\mathbf{2 . 5}$ & 0.0 & 0.0 & 0.0 & 0.0 & $\mathbf{1 0 . 1}$ \\
\hline
\end{tabular}





\section{B.4 BUILDINGS}

Table B.4.1 provides the 2050 reference projections for the buildings sector that were used to assess the impacts of the 11 essential energy technologies on $\mathrm{CO}_{2}$ emissions from each fuel source for this sector, as documented in Table B.4.2.

Table B.4.3 documents the impacts of the 11 essential energy technologies on the U.S. petroleum supply/demand balance in the transportation sector in 2030.

Table B.4.1 Buildings sector: 2050 reference projections

\begin{tabular}{|c|c|c|c|c|}
\hline Energy source & $\begin{array}{c}\text { Energy, } \\
\text { quads }\end{array}$ & $\begin{array}{c}\text { Energy } \\
\text { share }\end{array}$ & $\begin{array}{c}\text { Carbon } \\
\text { intensity, } \\
\mathrm{Tg} \mathrm{CO}_{2} / \text { quad } \\
\end{array}$ & $\begin{array}{c}\text { Total } \mathrm{CO}_{2} \\
\text { emissions, } \\
\mathrm{Tg} \\
\end{array}$ \\
\hline Coal & 0.1 & $0.3 \%$ & 95.3 & 8.6 \\
\hline Natural gas & 10.5 & $32.9 \%$ & 53.1 & 554.7 \\
\hline Petroleum & 2.0 & $6.4 \%$ & 68.8 & 140.2 \\
\hline Biofuel/renewable & 0.5 & $1.6 \%$ & 0.0 & 0.0 \\
\hline Electricity/nuclear/electricity imports & 18.7 & $58.8 \%$ & 0.0 & 0.0 \\
\hline
\end{tabular}


Table B.4.2. Technology impacts on $\mathrm{CO}_{2}$ emissions in the buildings sector

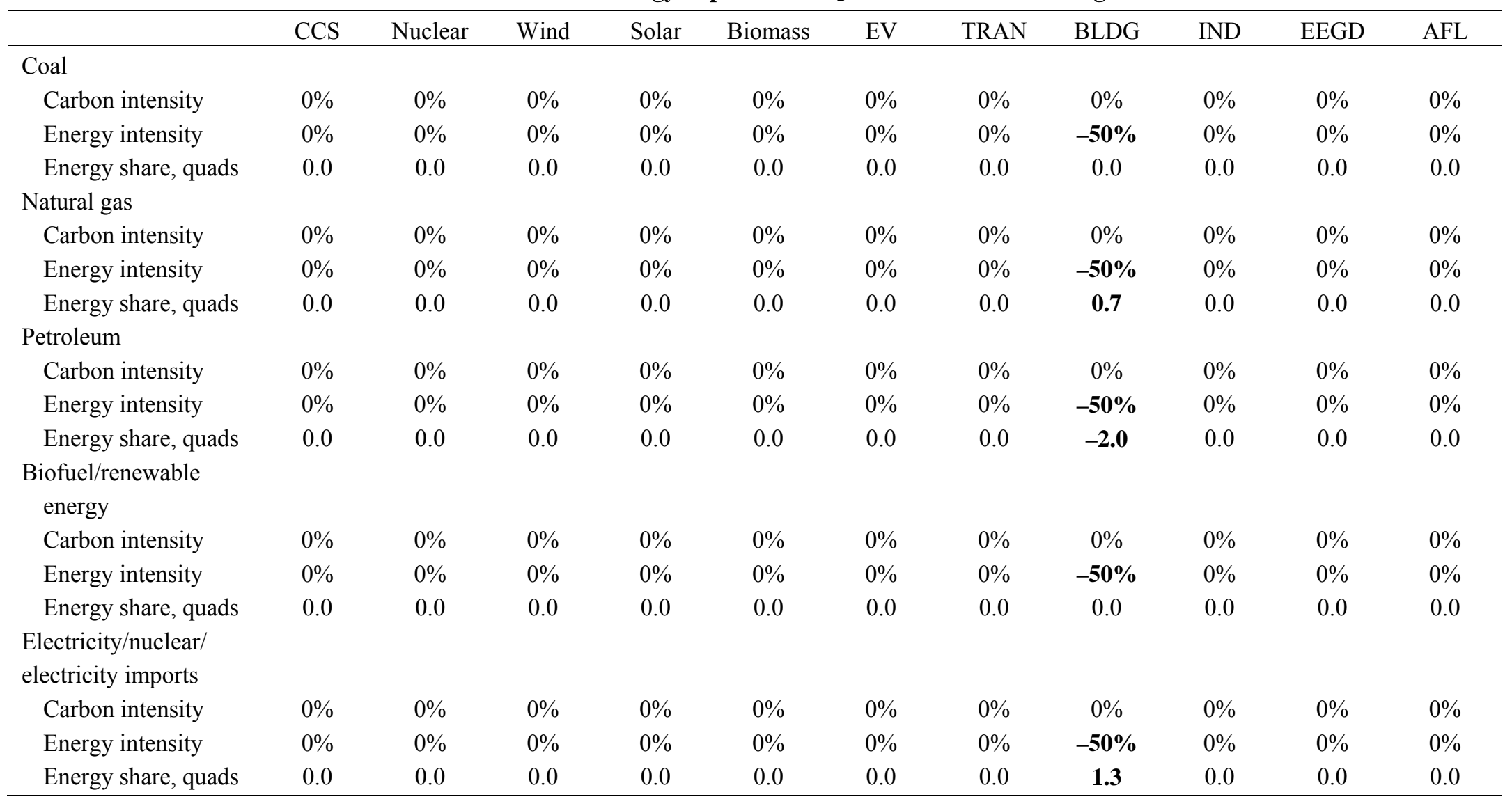


Table B.4.3. Technology impacts on petroleum in the buildings sector

2030 reference projection: Petroleum provides 2.03 quads of energy ( $8.0 \%$ of total for sector) with an impact factor of 68.8

\begin{tabular}{lccccccccccc}
\hline & CCS & Nuclear & Wind & Solar & Biomass & EV & TRAN & BLDG & IND & EEGD & AFL \\
\hline Petroleum intensity & $0 \%$ & $0 \%$ & $0 \%$ & $0 \%$ & $0 \%$ & $0 \%$ & $0 \%$ & $0 \%$ & $0 \%$ & $0 \%$ & $0 \%$ \\
Energy intensity & $0 \%$ & $0 \%$ & $0 \%$ & $0 \%$ & $0 \%$ & $0 \%$ & $0 \%$ & $\mathbf{- 2 5 \%}$ & $0 \%$ & $0 \%$ & $0 \%$ \\
Energy share, quads & 0.0 & 0.0 & 0.0 & 0.0 & 0.0 & 0.0 & 0.0 & $-\mathbf{2 . 0}$ & 0.0 & 0.0 & 0.0 \\
\hline
\end{tabular}

